\title{
Standards from Birth to Maturity for Height, Weight, Height Velocity, and Weight Velocity: British Children, I965
}

\author{
Part II* \\ J. M. TANNER, R. H. WHITEHOUSE, and M. TAKAISHI $\dagger$ \\ From the Department of Growth and Development, Institute of Child Health, University of London, \\ Guilford Street, London W.C.1
}

\section{(C) Whole-year Velocity Standards: Chronological Age-based and Individual Type}

We now consider how to construct velocity standards, to answer our second question 'Has this child's rate of growth been within normal limits ?' We are again confronted with the alternatives of plotting against chronological or developmental age at adolescence and we have adopted the same solution as before. First we give, in the conventional manner, centiles plotted against chronological age, over the whole age span. These are calculated simply from two measurements a year apart, without using further longitudinal data. They depend on a two-occasion longitudinal study, nothing further. At adolescence these standards are greatly scattered by the phase-difference effect. If we know nothing about a boy except that he is 12 years old and grew $3 \mathrm{~cm}$. during the last year, we must plot $3 \mathrm{~cm}$. at 11.5 years and interpret this according to the chronological age centiles. If, however, we know that he is midpubescent, or that his skeletal age is 14.0 years, then in theory we could make a more effective interpretation if we had the appropriate standards.

We have to remember, however, that in one important respect velocity standards differ from distance ones. In velocity standards a child does not have the same strong tendency to stay in the same centile position from one age to another; there is always a contrary tendency to a move from the outer centile positions towards a more central position in the subsequent year. Though a child can follow the 60 th or even 70 th centile of velocity from the pre-school years till maturity and end up a large but normal adult, a child who follows the 97th centile

\footnotetext{
Received February 21, 1966.

* Part I of this article appeared in this Journal, p. 454.

+ On study leave from the Institute of Public Health, Tokyo, Japan.
}

for very long would become pathologically enormous. Another way of saying the same thing is to note that while in general the correlations of height at age 5 , say, with height at the subsequent age, i.e. 6 , is of the order of 0.9 , the correlation of height gain from 5 to 6 with gain from 6 to 7 is only around $0 \cdot 3$. This is not to say that patterns of continuously increasing or decreasing velocities do not occur, particularly in pathological cases; but velocity plots must be regarded in a more episodic way than plots of distance.

Chronological age velocity standards of wholeyear velocity. To obtain the conventional centiles we began by plotting the yearly increments of height and weight of the Child Study Centre series and the sixmonthly increments of the Harpenden Growth Study on probability paper to see whether or not the increments were Normally distributed. Up to adolescence all the height increments were closely fitted by straight lines, but during adolescence considerable curvature occurred, indicating the presence of fairly complex deviations from Normality in the distributions, as indeed would be expected, particularly at ages when some children have actually stopped growing.

The standard deviations of the height increments of these two sets of data from birth to age 8 are plotted on the left hand side of Fig. 16. The lower line represents the smoothed curve of the whole-year SDs from the Child Study Centre, together with similar values from Heierli (1960), which are consistently a little lower, and from Deming and Washburn (1963). The sexes are averaged in all instances. The upper line gives the smoothed curve of six-monthly SDs from the Harpenden Growth Study, with earlier points from the Child Study Centre, Heierli, and Deming data. The six-monthly increments have a consistently higher variability than the yearly increments (when both are converted to $\mathrm{cm}$./yr.). This is so even in the same children. It occurs because the season of the year exerts a considerable effect on the growth of some, though not all, children; in the extreme case a child may grow in height during the spring at one and a half times its rate of growth during the autumn 


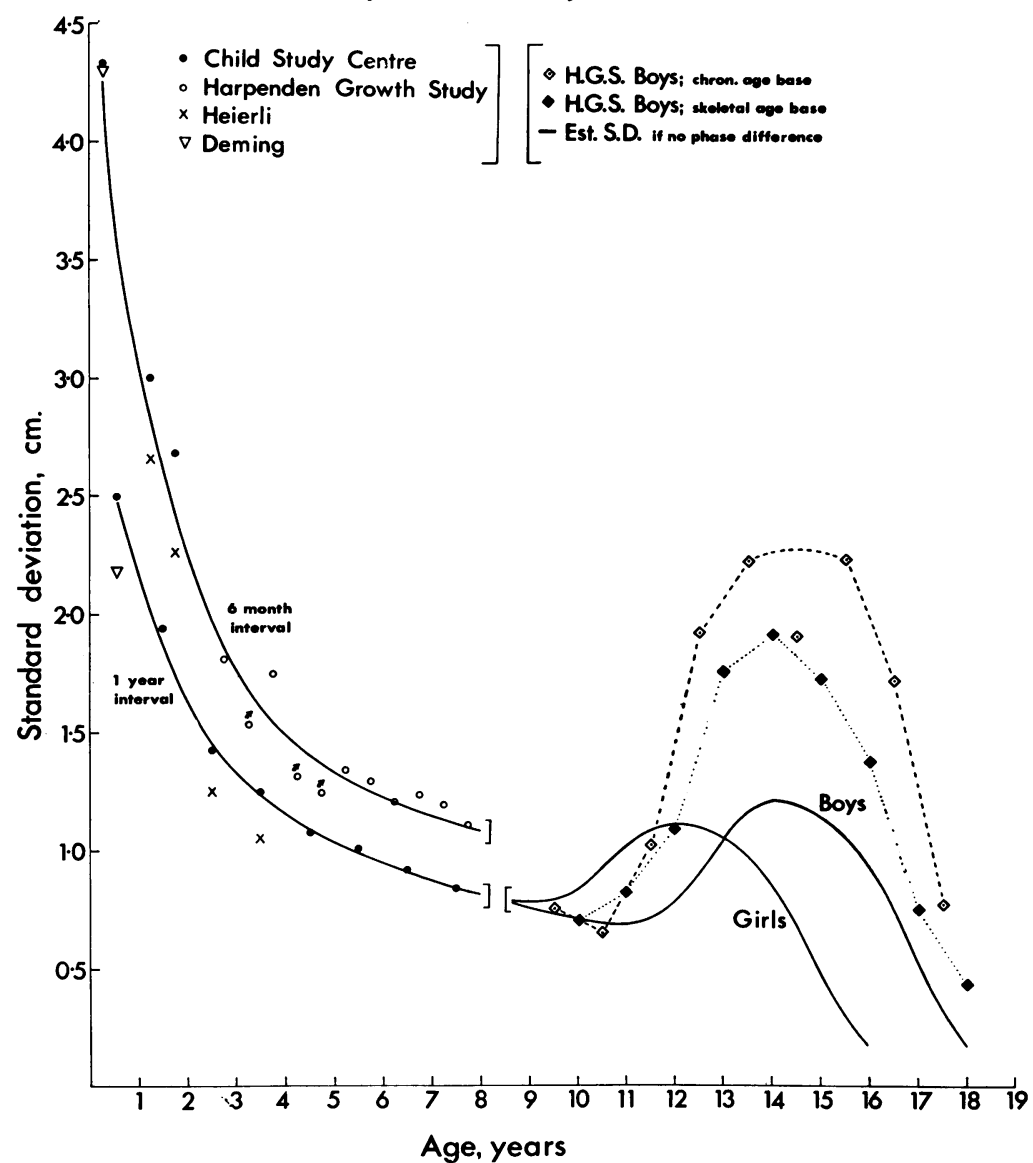

FIG. 16.-Left: Standard deviations of 6-monthly increments (upper line) and one-yearly increments (lower line) of height, both converted to cm./yr. Various data, smoothed, sexes averaged in pre-adolescent ages. Arrowed points refer to upper line.

(Tanner, 1962a). Any six-monthly age period therefore includes children growing rapidly and children growing slowly, except in the relatively rare type of cohort survey, where all children recruited are born in a particular week or month. Over a whole year these seasonal variations are ironed out.

After much deliberation we have decided to present our increment standards in terms of wholeyear increments, since this is the minimum period over which seasonal differences between children are eliminated. Any drug having a long-term effect on growth should be administered over a whole year before its final effects are assessed, since otherwise the seasonal influence may be confused with the result of treatment. We routinely see growthdisordered patients three-monthly and compute and
Right: Smoothed standard deviations of one-year increments computed in years-from-peak-height-velocity as age base, with $S D$ of boys plotted against chronological (note the one aberrant point) and skeletal age. (See text.)

plot their three-monthly velocities; but the total yearly velocity is also computed and plotted, and it is this that as a rule governs further therapeutic or scientific decisions (for an example of plotting, see below). The six-monthly SDs are about $30 \%$ higher than the whole-year SDs. Thus as a rough guide for interpreting six-monthly increments on the whole-year chart we can say that a six-month centile line is nearly coincident with the next furthest-out centile line on the whole-year chart. Thus a child at the 97th centile over a six-month period is only a little more unusual than a child at the 90th centile over the whole-year period, and his status should be interpreted correspondingly. Three-monthly periods have a still greater variability than six-monthly periods, but the data are too 


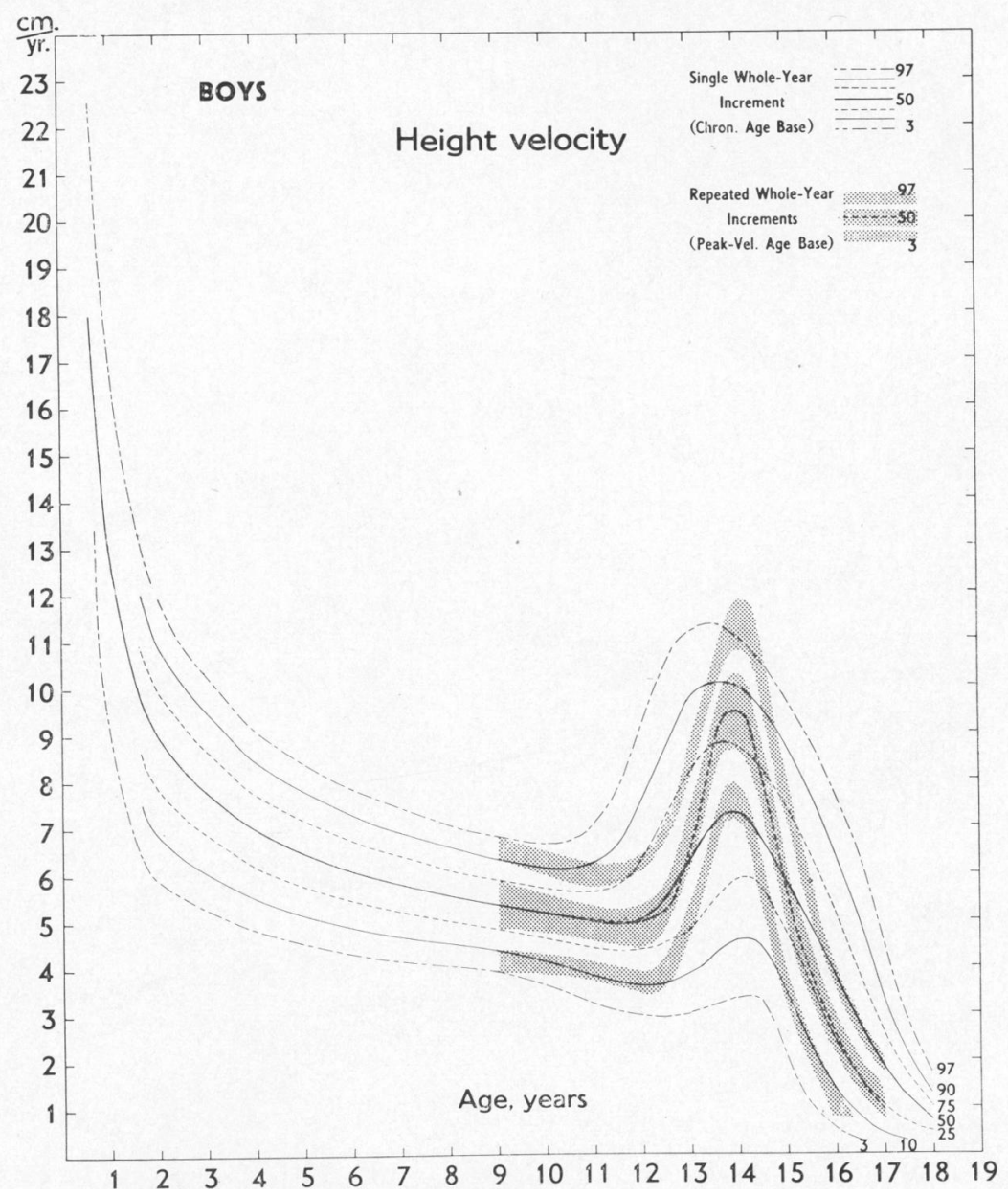

FIG. 17.-Whole-year velocity standards for height (boys). For construction see text.

scanty to allow an estimate of the magnitude of the difference.

The SDs of increments over a two- or three-year period are lower than the SD over 1 year. Presumably this is because children growing faster at the beginning of such a period decelerate harder than children growing more slowly. Thus the fast beginners end the period relatively slower while the slow beginners end relatively faster. The upshot is that our one-year SDs and centiles cannot be used quantitatively in respect of increments calculated over more than one year any more than they can for increments calculated over less than one year.

For the chronological-age type standards, then, the SDs of the yearly increments from birth till adolescence were calculated and smoothed, and the centiles computed from them. During adolescence the centiles were obtained by smoothing the actual centiles observed in the two sets of admittedly scanty data available to us (covering about 100 children of each sex up to peak velocity and progressively less thereafter).

These centiles are listed in Appendix Table VII and displayed in the conventional manner in Fig. 17 and 18 by means of the continuous and broken lines. These are the standards to use before adolescence, and during adolescence if no data on developmental age are available.

Peak height velocity-centred graphs. At adolescence, as we have seen, the situation is unsatisfactory because of the widely different chronological ages at which children experience their adolescent growth spurt. We had hoped that by the 


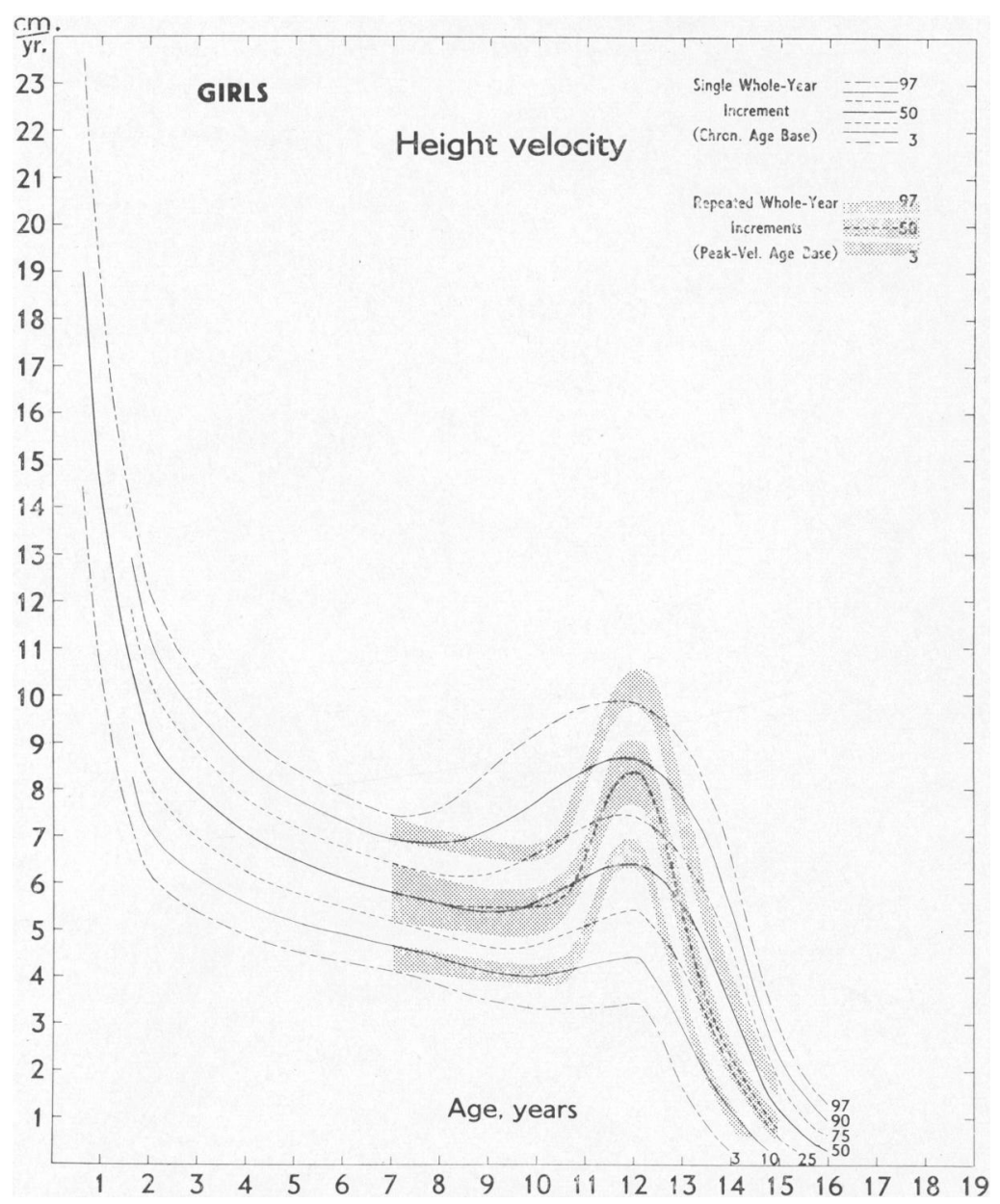

Fig. 18.-Whole-year velocity standards for height (girls). For construction see text.

use of skeletal age as the time base we would be able to eliminate most of this phase-difference effect, and thus provide more powerful standards. Surprisingly, however, it turned out that skeletal age was not linked closely enough to peak height velocity age to reduce the phase difference very greatly. Some reduction is certainly made; it is illustrated for boys in the right-hand section of Fig. 16. The broken line shows the increase in standard deviation of height velocity at adolescence (note the one aberrant point, through which the line has not been drawn); the next line below, dotted, shows the SD when plotted against skeletal age, and the continuous line far below represents the estimated SD on peak height velocity age, when phase differences have been eliminated. Looked at another way, we may note that the SD of chronological age at the moment of peak height velocity is $0 \cdot 86 \mathrm{yr}$. in boys and $0.87 \mathrm{yr}$. in girls, and the SD of skeletal age at the same point is $0.50 \mathrm{yr}$. and $0.62 \mathrm{yr}$. But we need a standard deviation of zero, and skeletal age leaves us far from that.

Accordingly, instead of plotting, as we had hoped, skeletal age centiles superimposed on the chronological age centiles in Fig. 17 and 18, we have put in the rather impractical, but theoretically very important, channels based on peak height velocity age. As in the case of distance, these are plotted as shaded bands, with a dashed 50th centile typicalindividual curve in the centre of the middle band. This typical-individual curve represents the velocity taken at each successive year by an individual who has his peak at the average age and an average velocity throughout adolescence. Such an individ- 
ual will not travel up the 50th centile of the conventional (single-increment) velocity standards, just as he did not travel up the 50th centile of the conventional distance standards. But here the resemblance to the two distance standards ends; for we have to remember that a child does not usually travel throughout adolescence along one of the outer centiles even of the individual velocity plots. Some children may do so; a boy who remained at the 90th shaded centile from age 12 to 17 would gain a total of $24 \mathrm{~cm}$. compared with the $20 \mathrm{~cm}$. gained by the 50th centile boy. This is not a big difference; but it probably represents a bias, as there is little evidence that a boy whose peak velocity is at the 90th centile actually has a velocity curve which is wider than the boy whose PHV is at the 50th centile, as the charts may seem to indicate. With this proviso, however, the shaded curves do represent the shape of the individual child's growth spurt at adolescence much better than the singleincrement line centiles.

Besides being able to judge whether the magnitude of a child's peak velocity is within normal limits we need to know whether the age at which it occurs is normal too. The standard deviation of the age of peak height velocity is about $0.9 \mathrm{yr}$. Thus we may take the individual 50th peak height velocity point, and imagine two age limits for its occurrence, one $1.8 \mathrm{yr}$. earlier nd the other $1.8 \mathrm{yr}$. later. Since, however, early maturers have on average a higher PHV than late maturers, this 'early50 th' point will be raised some $1.4 \mathrm{~cm}$./yr. above the 'middling-50th' point and the 'late-50th' point will be lower by the same amount. These two points represent the same probability of occurrence of a peak height velocity as the 97 th and 3rd magnitude points at average age. Other similar points could be found and an ellipse constructed, which would define the limits within which the normal PHV would lie. However, this would be unduly cumbersome and we can instead find a simpler, and approximately equivalent guide in the 97 th centile of the single-increment lines. This was constructed so that 97 out of 100 peaks fell below it, irrespective of whether they were occurring early or late.

Thus we can use the 97th single-increment line as the outer normal limit for peak height velocity points, whether they are early or late. Similarly we can use the 3rd single-increment line as the lower limit. In other words, nearly all normal individuals' velocity curves have the shape of the repeatedincrement shaded curves, and are wholly contained within the shell defined by the single-increment 3rd and 97 th percentile lines. The same principle applies to weight velocity.
The peak height velocity-centred curves, as we may call the shaded ones, were calculated from the smoothed standard deviations observed in the Harpenden Growth Study data when these were lined up on a peak height velocity age basis, so that the SDs for PHV-3 years, PHV-2 years, etc. were computed. The distribution of height velocity at these 'ages', i.e. when the phase difference was removed, became indistinguishable from Normal. The values are given in Appendix Table IX, and the smoothed SDs plotted in the right-hand panel of Fig. 16.

The 50th centile of this system of curves relates to increments taken over a whole year and so is slightly different from the individual-type 50th centiles given in Fig. 8 and 9 (p.466), which represented the instantaneous velocity. The instantaneous velocity median can only be used for a standard when a curve has been fitted to the height-attained values of a child and then differentiated to give an estimate of the true instantaneous velocity of the child. The difference between whole-year increments and instantaneous velocity is only quantitatively important when the curves show a sharp peak or trough, i.e. at peak adolescent velocity. We have calculated graphically for each boy and girl the average increment over the whole year containing, at its centre, the peak velocity. Naturally this 'peak' whole-year increment is less than the instantaneous peak velocity, the boys' average being $9.5 \mathrm{~cm}$./yr. (compared with 10.3 for instantaneous peak velocity) and the girls' $8 \cdot 4 \mathrm{~cm} . / \mathrm{yr}$. (compared with 9.0 instantaneous). The SDs are, respectively, $1 \cdot 1 \mathrm{~cm} . / \mathrm{yr}$. and $0.9 \mathrm{~cm}$. $/ \mathrm{yr}$. (compared with 1.5 and 1.0 for instantaneous). We have thus flattened out the very steeply rising curves.

A small further modification should perhaps also have been made. The curves we have now produced relate to children whose peak height velocity falls exactly at the mid-point of their interval between measurements. This follows from the way in which we modified the instantaneous curves to obtain whole-year ones. But a child's peak height velocity might actually occur the day after his measuring day and hence six months away from the central point. In practice we must deal with wholeyear velocities calculated on this basis, in which peaks occur any time within the year. This lowers again the average peak height velocity, though not very greatly. In the case of boys the peak height velocity calculated from the actually observed whole-year increments in the Harpenden Growth Study data comes to $9.0 \mathrm{~cm} . / \mathrm{yr}$. (compared to $9 \cdot 5$ for whole-year centred) and for girls 7.9 (compared to 8.4 for whole-year centred). This would bring our average peak velocities down to just about the level observed by others who have reported simply the maximum yearly increment without resorting to curve-fitting to find the instantaneous peak. Kiil (1941), for example, in 135 Norwegian boys, found an average peak of $9.5 \mathrm{~cm}$./yr. (at $14 \cdot 3$ years) and in 189 girls a peak of $7.6 \mathrm{~cm}$./yr. (at 12.2 years). The Bayer and Bayley (1959) standards, based presumably on similarly computed whole-year-increments give peaks of $9.0 \mathrm{~cm} . / \mathrm{yr}$. and $8.0 \mathrm{~cm}$. $/ \mathrm{yr}$. for boys and girls maturing at an average age. In our standards, however, we have let the whole-year centred velocities stand. 


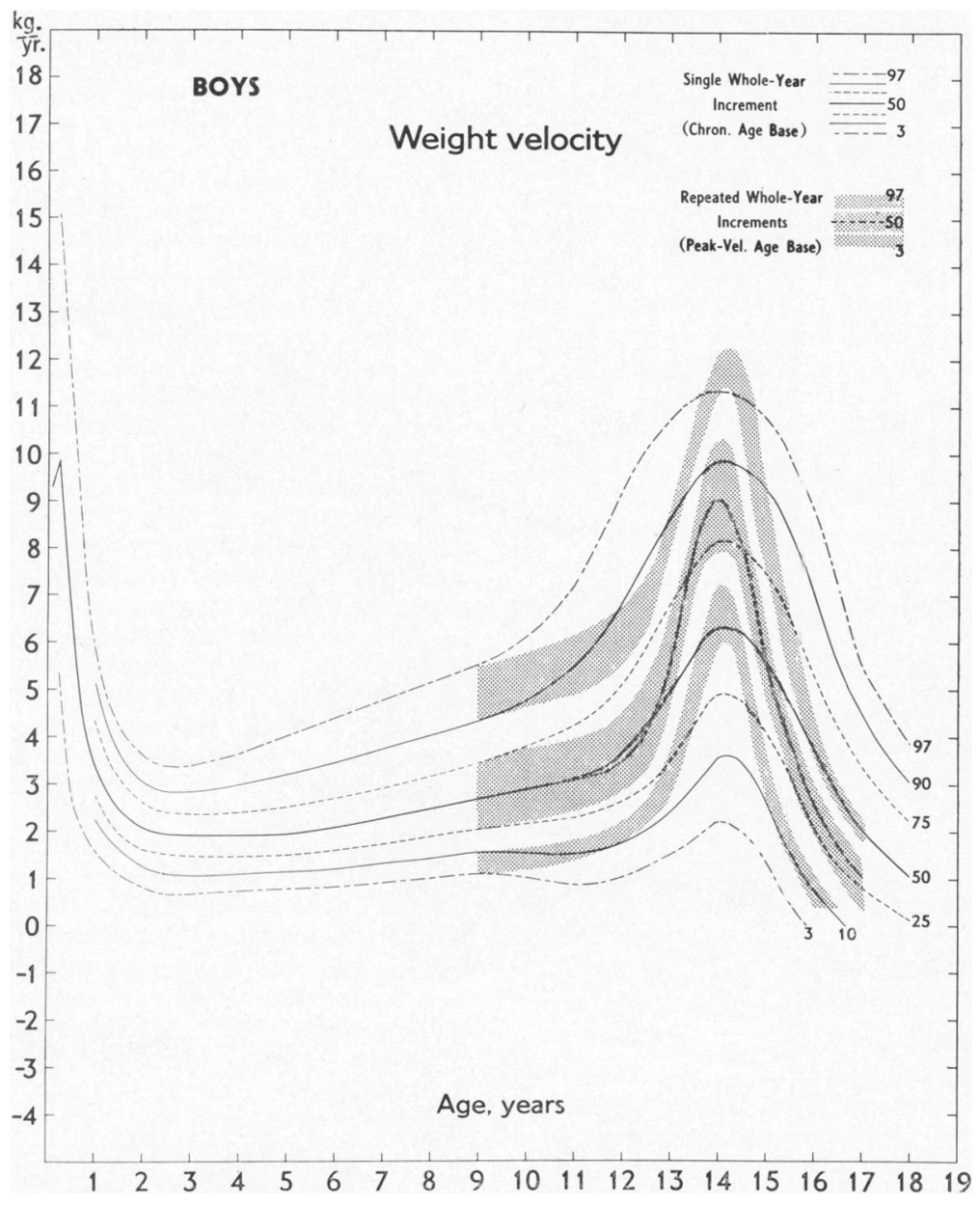

FIG. 19.-Whole-year velocity standards for weight (boys). For construction see text.

We have plotted out the centiles for our data against a time base of Tanner-Whitehouse skeletal age, and confirmed that they lie, as expected, between the two sets of curves given in the Figures. It seems, however, that the increased precision of the skeletal-age-based assessments is insufficient to be really important. The skeletal age curves are more peaked and lie approximately one degree further towards the centre than the chronologicalage curves, that is the 97th on the skeletal age base very roughly corresponds to the illustrated 90th on the chronological base, and the 3rd to the 10th. This, however, is when the bone-ageing is all done by one experienced rater; in less accustomed hands the relative lack of reliability of any technique of bone-ageing compared with counting chronological age would make the two sets of curves more nearly coincident.

When skeletal age is used as a time base, the child's increment from one occasion to another should be worked out in terms of the actual time elapsed between the two occasions, that is from the chronological age change. Skeletal ages are subject to too much unreliability to be usually suitable for calculating an increment in terms of $\mathrm{cm}$./yr. But the increment, when calculated, should be plotted at the mid-point of the two skeletal ages, one corresponding to the beginning of the increment period, the other to the end of it. In special circumstances menarcheal age could be used instead of skeletal age. If the average age of menarche is taken as $13 \cdot 0$, a girl whose menarche occurred at $12 \cdot 0$ has her $14 \cdot 0$ - 


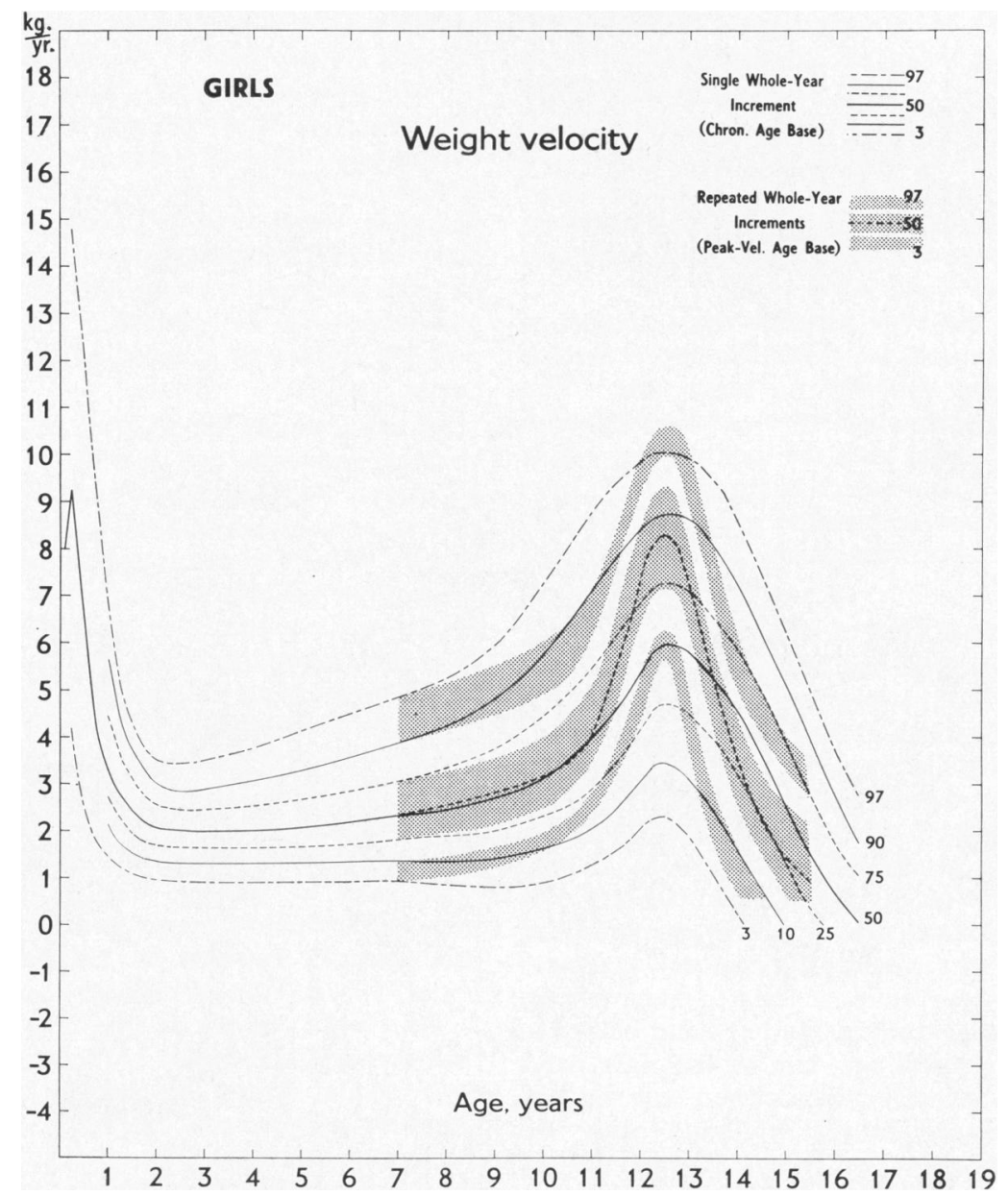

FIG. 20.-Whole-year velocity standards for weight (girls). For construction see text.

$15 \cdot 0$ increment plotted at $15 \cdot 5$, i.e. $14 \cdot 5$ plus 1 year. If her menarche was at $14 \cdot 0$, her 14 to 15 increment would be plotted at $13 \cdot 5$. The stages of development of secondary sex characters could be used in a similar way once their median ages of occurrence had been well established in a population. However, this would probably entail a considerably greater degree of inaccuracy than skeletal age.

Weight velocity standards. The weight increments did not fall in a straight line when plotted on probability paper. Weight increments, like weights themselves, are somewhat skewed. Curved lines were, therefore, fitted by eye to the distributions at each age, the curves making a regular progression in shape from one age to the next. From these the centile points at each age from birth to adolescence were read off, and these are the figures used in the standards, after final smoothing. Boys and girls had to be treated separately as significant differences were clearly present. The chronological age standards are given in Fig. 19 and 20 and Appendix Table VIII.

For the peak weight velocity-centred curves whole-year peak increments had again to be calculated, and these were $9 \cdot 1 \mathrm{~kg}$. $/ \mathrm{yr}$. for boys and $8.3 \mathrm{~kg}$. $/ \mathrm{yr}$. for girls, compared with instantaneous peak weight velocities of $9.8 \mathrm{~kg}$. $/ \mathrm{yr}$. and $8.8 \mathrm{~kg}$. $/ \mathrm{yr}$. These curves are shown shaded in Fig. 19 and 20 and are tabulated in Appendix Table X.

Standards for degree of advancement. The degree of advancement is an important statistic from the clinical point of view. No formal standards for it are needed, since it is adequately measured by the difference between chronological age and skeletal 
age (or, less well, menarcheal age). The standard deviation of this difference during adolescence is approximately 1.0 years. Thus a deviation of greater than 2 years either way may be regarded as beyond the usual normal limits. At ages before adolescence the standard deviation of the difference is less, but the degree of advancement then is better read directly from the centile charts for skeletal maturity (Tanner et al., 1962).

In the individual-type distance chart, degree of advancement can to some extent be appreciated if the child has been followed for some time. The curve of an early-maturing boy at adolescence rises approximately parallel with the median line, but at an earlier age. The distance apart of the two lines at their steepest points therefore gives an indication of the degree of advancement when peak velocity is reached.

(D) Clinical Use of the Standards

Two examples of the use of the standards follow: one concerns a healthy boy followed from age 3 to 16; the other illustrates a clinical case in which the effect of treatment is by no means obvious when looked for in the distance plots only.

The course of the healthy boy's growth in height is plotted in Fig. 21, the distance curve on the left, the velocity curve on the right. We routinely plot height against skeletal age as well as chronological age; in this way we can assess the degree of smallness and retardation separately, at least to some extent. Thus the stars represent in the left-hand chart the height at each skeletal age, and in the right-hand chart the height velocity over a period between two skeletal age points. In the left-hand chart the round dots represent the height plotted against chronological age every six months, and the stars represent the height plotted against skeletal age at yearly intervals. The horizontal distance between corresponding dots and stars therefore shows the amount in years by which chronological and skeletal age differ. For example, at chronological age 5.0 (and height approx. $105 \mathrm{~cm}$.) skeletal age is 5.5 years. At chronological age 3.05 , however (the first point), skeletal age is $2 \cdot 8$ years. Note that we use the decimal system of age throughout, and the charts ${ }^{\star}$ are printed with the vertical grid lines in tenths of a year. (The charts are printed in two colours so that the grid disappears on photographic reproduction, except in the shaded area.) We find decimal age far easier to handle than the traditional division into years and months, both for clinical and research purposes, and its use is virtually essential for calculating velocities. The table for converting the

\footnotetext{
$\star$ Obtainable from Creaseys of Hertford, Herts. See note at end
} of this article, on p. 624 . regular calendar into decimals (Jan. 1, $1966=$ $66 \cdot 000$, July $1,1966=66 \cdot 496$, Dec. $31,1966=$ $66 \cdot 997)$ and the methods for calculating the age of the child in decimals are given in Appendix II.

The height of the healthy boy (Fig. 21) lies mostly at about the 25 th centile, but his first three points are distinctly below this. On entry to the children's home at age 3 he had a history of neglect and undernourishment, and it is probable that at that time he was retarded in his growth. The first few points probably represent a catch-up towards his normal curve.

At adolescence he follows the individual-type curve as expected, but then as adolescence finishes he drops back to about the 10th centile. His skeletal age, though initially retarded, soon becomes about a year in advance, and maintains this pattern throughout the rest of his growth. Thus his final height, while seeming to be smaller than expected from his chronological age plot, is just what would be predicted from his skeletal age plot, where he is mostly at or a little below the 10th centile.

In the velocity graph (Fig. 21, right), the average yearly velocity is plotted, with the dot at the centre of the year concerned, i.e. the velocity from 3.0 to 4.0 is plotted at 3.5 years. The stars represent the same rates of growth, but plotted at the midinterval between the two skeletal ages, that is, in this example, between the skeletal age at chronological $3 \cdot 0$, and the skeletal age at chronological $4 \cdot 0$.

This boy's velocity of height growth during the first year after admission to the home was above the 97th centile; during the second year it dropped to the 90th centile, and thereafter remained mostly between the 40th and 80th centiles. At adolescence the curve follows the individual-type shaded curve but with a peak about half a year earlier than average. Correspondingly, the growth rate has fallen to the 5 th centile by age 15-16 and will clearly soon reach zero. When plotted in skeletal age terms (the stars and dotted line) the same centile positions hold before adolescence, but the peak comes later, about six months after the average time of peaking. Thus in chronological age terms this boy has an adolescent height spurt six months earlier than the average boy, but in relation to his skeletal development the peak is a little later than average.

The second example concerns a dwarfed child believed to be suffering from defective secretion of growth hormone. The distance plots, on the left-hand side of Fig. 22, are self-explanatory. Treatment is shown, the figures representing I.U. of human growth hormone per week. For convenience, horizontal dots are drawn between the corresponding chronological and skeletal age plots at the 


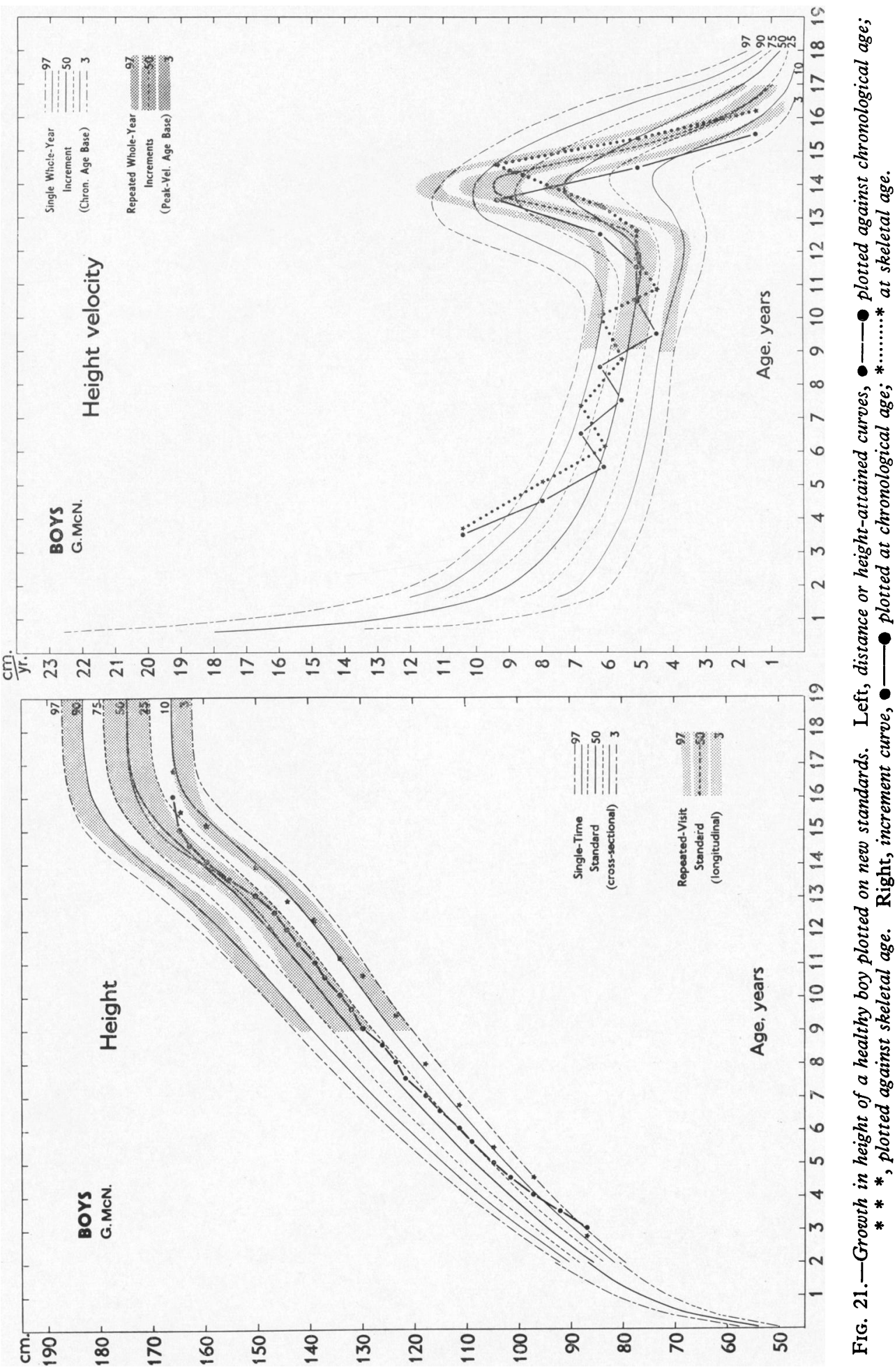



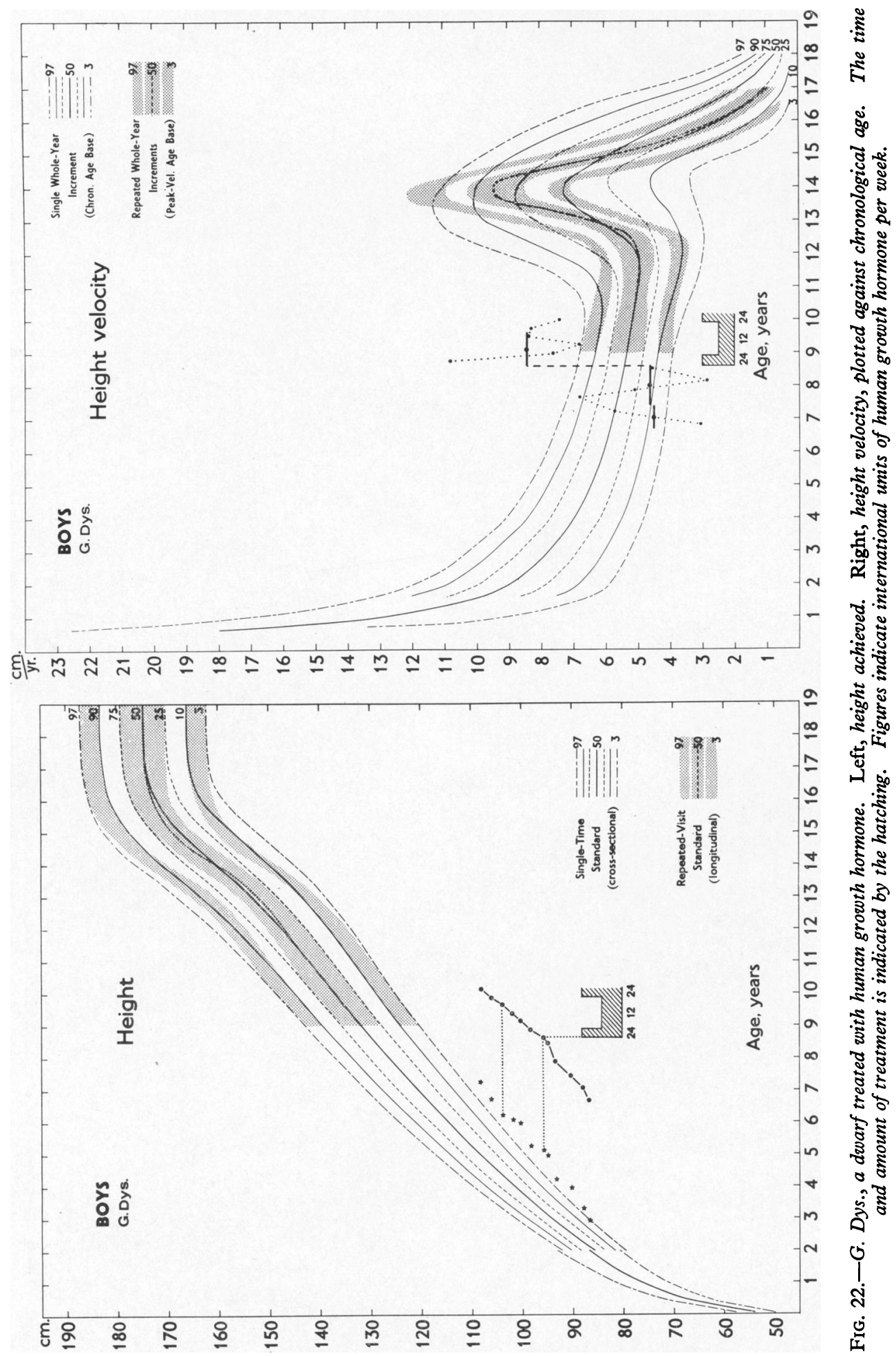
beginning of and after a year of treatment, so that the effect of treatment on skeletal development can be more easily appreciated. (In hypothyroid children treated with thyroxine, for example, the lag of skeletal age greatly diminishes and the lines of dots and stars approach each other.)

In this child, however, it is not at all clear from the distance chart alone whether administration of the hormone had any significant effect. In the velocity curve (Fig. 22, right) however, the effect is seen quite clearly.

A problem arises when plotting the velocity in cases where treatment has been given. Whereas each distance plot represents a measurement taken at a particular point in time, each velocity plot represents only the average velocity over the time elapsed between the measuring sessions. It must not be assumed, therefore, that each velocity point represents the instantaneous velocity at that point in time; on the contrary it would only do so if the velocity curve were rectilinear over the period concerned. We plot the velocity point at the centre of the period considered, since this accords with mathematical practice. But where necessary (not in this instance) we place a horizontal line in relation to each velocity point to indicate the period of time over which the velocity represented was measured. Further, since our standards are wholeyear increment standards, we put in with a heavy bar the average velocity over each yearly period as well as plotting 3-monthly velocities, according to the visits to the clinic. (The velocity is represented by the top level of the bar.) It is this yearly velocity which is accorded the chief importance and on which we normally make decisions as to treatment.

A purely illustrational difficulty arises when a treatment is started or stopped, or when other radical change in circumstances occurs. Prof. Andrea Prader has pointed out to us that if the yearly velocity mid-points are simply connected one with another (as in normal individuals' plots) it may look as though the response to treatment began in the middle of the period preceding treatment. In these circumstances, therefore, we do not join up the mid-points, but continue a line along the top of the pre-treatment average until we come to the treatment period. We then go up (or down) with a dashed line vertically to the top of the first treatment velocity, and then along horizontally till we get to the first treatment velocity mid-point (see Fig. 22, right). This system has the double advantage of accentuating visually the time of the beginning of treatment, and approaching more closely to the true velocity situation; for in Fig. 22 the velocity directly after treatment was probably greater than represent- ed, and not less, as would appear if we joined up the two velocity mid-points. We have thus changed our method of plotting from that of a previous paper (Prader et al., 1963).

The small dots, joined before and again during treatment by dotted lines, represent 3-monthly velocities. These vary considerably, perhaps partly due to a seasonal effect, since the maximum velocity for the year was reached at ages $7 \frac{3}{4}, 8 \frac{3}{4}$, and $9 \frac{3}{4}$ (though not at $6 \frac{3}{4}$ ), irrespective of whether treatment was given or not. But the solid lines representing the whole-year velocities show that the pre-treatment rates were at the 10th centile, whereas the rates during treatment were above the 97th. Almost certainly, then, the hormone has caused significant acceleration. (A case in which the result of treatment was clinically rather poor has been chosen to illustrate the point we desire to make; in suitable cases growth hormone causes a much greater increase in rate of growth than this.)

The effect of treatment on skeletal age can be seen in the distance plot. Skeletal age was 3.5 years retarded at the beginning of treatment, and remained so at the end. The velocity curves plotted against skeletal age therefore reproduce closely those plotted on chronological age, merely shifted to the left. They are, therefore, not reproduced here.

Finally, we would like to stress that the distance and velocity plots are not competitive; they are complementary. Distance plots give some information not present in velocity plots. One treats a hypopituitary patient with growth hormone, for example, and the velocity shows a great success; but only the distance plot shows when to stop.

\section{Summary}

Conventional centile standards of height and weight attained at each age from birth to maturity, appropriate for British children in 1965, are given. These differ from previous standards because children have become larger. They answer the question, 'Is this child's size within normal limits ?' in a circumstance in which the child has been examined once only.

In the same chart a new type of standard is also given, which is more appropriate for judging whether a whole segment of the child's growth curve has been normal. Conventional charts give an erroneous impression of the course of growth at adolescence if used to follow a single child longitudinally, as in clinical work. This is due to the 'phase-difference' effect which is discussed and illustrated. In conventional charts a late-maturing child, for example, departs at adolescence from the 
height centile he has previously been following, reaches a lower centile, and later regains his original centile. In the new 'individual-type' charts this effect is obviated.

Centile standards for the velocity of growth in height and weight from birth to maturity are presented. They relate to increments calculated over the period of a whole year, since over shorter periods the variability of growth rate is higher due to seasonal alterations. In addition to these standards, at adolescence the velocity equivalent of the new type of height-attained standard is given. This shows the curve of velocity where phase differences are eliminated. The use of skeletal age as an alternative time base to chronological age over this period is discussed.

To obtain the curves for the new 'individual-type' standards it is necessary to use longitudinal records extending over adolescence. The records of the Harpenden Growth Study were used for this purpose. In 49 boys and 41 girls measured every three months throughout adolescence, curves were fitted graphically to height and weight measurements and velocities thus derived. The average 'instanttaneous' peak height velocity was $10.3 \pm 0.22 \mathrm{~cm}$./ yr. in boys and $9 \cdot 0 \pm 0.16 \mathrm{~cm}$. $/ \mathrm{yr}$. in girls. There was a correlation of -0.47 and -0.40 in boys and girls between peak height velocity and the age at which it was reached. No such correlation existed for peak weight velocity. The peak weight velocity was $9.8 \pm 0.30 \mathrm{~kg}$./yr. for boys and $8 \cdot 8 \pm 0.25 \mathrm{~kg}$./ yr. for girls. The correlations between peak height velocity and peak weight velocity were only 0.29 and 0.18 in boys and girls, but the correlations between age at reaching peak height velocity and at reaching peak weight velocity were 0.93 and 0.80 .

Curves of distance and velocity for the typical or 50th centile boy and girl are contrasted. In both height and weight boys are growing faster than girls at birth, but are also decelerating more, so that by 7 or 8 months they are growing more slowly than girls.

Examples are given of the clinical use of the new standards, in a healthy child followed from 3 to 16 , and in a dwarf treated with human growth hormone. Height and weight are routinely plotted against both chronological and skeletal age. The way in which plots of 'distance' and velocity of growth complement each other is discussed, and the extreme methodological difficulty of providing a valid quantitative answer to the seemingly simple question 'Has this treatment significantly altered the child's rate of growth ?' It is shown how the new charts can at least be used to give an approximate answer to this question.
We are deeply grateful to M. J. R. Healy, whose criticism of our successive manuscripts led to much clarification of our ideas and resulted in very considerable improvements. We wish also to thank W. A. Marshall and $\mathrm{H}$. Goldstein for further helpful comments, and our numerous friendly critics in the seven longitudinal growth study teams co-ordinated by the International Children's Centre, Paris.

Parts of this work were supported by the Medical Research Council, the Ministry of Health, the Nuffield Foundation, and the Joint Research Board of the Institute of Child Health and The Hospital for Sick Children; we are most grateful for their help.

\section{Charts}

Two versions of the charts are commercially available (from Creasey's, Hertford, Herts). The larger is double foolscap size and is the two-colour version described in this paper. The smaller is made to fit inside the usual hospital notes; in this version the age-scale is in twotenths per year and the vertical scales correspondingly reduced. The hospital version has the table of decimal age instruction for use of the charts printed on it.

\section{REFERENCES}

Bayer, L. M., and Bayley, N. (1959). Growth Diagnosis. University Press, Chicago.

Bayley, N. (1956). Growth curves of height and weight by age for boys and girls, scaled according to physical maturity. F. Pediat., 48, 187.

Boas, F. (1932). Studies in growth. Hum. Biol, 4, 307.

Deming, J. (1957). Application of the Gompertz curve to the observed pattern of growth in length of 48 individual boys and girls during the adolescent cycle of growth. ibid., 29, 83.

- , and Washburn, A. H. (1963). Application of the Jenss curve to the observed pattern of growth during the first eight years of life in forty boys and forty girls. ibid., 35,484 .

Grant, M. W. (1964). Individual variations in the rate of growth of children between the ages of five and fifteen years. Med. Offr, $112,37$.

Healy, M. J. R. (1962). The effect of age-grouping on the distribution of a measurement affected by growth. Amer. F. phys. Anthrop., 20, 49.

Heierli, E. (1960). Longitudinale Wachstumsstudie. Resultate von Länge, Gewicht und Kopfumfang in den ersten vier Lebensjahren. Helv. paediat. Acta, 15, 311.

Joint Clothing Council (1957). Women's Measurements and Sizes. H.M.S.O., London.

Kiil, V. (1941). Fysisk Utvikling hos natidens Oslo gymnasiaster fra 7- til 19-arsalderen. Skr. norske Vidensk.-Akad., I. Mat.-naturv. Kl., No. 2.

Ministry of Health (1959). Standards of Normal Weight in Infancy. Min. Hlth. Rep. Publ. Hlth. No. 99. H.M.S.O., London.

Moore, T., Hindley, C. B., and Falkner, F. (1954). A longitudinal research in child development and some of its problems. Brit. med. F., 2, 1132.

Prader, A., Tanner, J. M., and von Harnack, G. A. (1963). Catchup growth following illness or starvation. F. Pediat., 62, 646.

Rosenbaum, S. (1954). Heights and weights of the Army intake 1951. F. roy. statist. Soc. A, 117, 331.

Scott, J. A. (1961). Report on the Heights and Weights (and Other Measurements) of School Pupils in the County of London in 1959. London County Council, London.

Sempé, M., Tutin, C., and Masse, N. P. (1964). La croissance de l'enfant de 0 à 7 ans. Arch. franc. Pédiat., 21, 111.

Shuttleworth, F. K. (1939). The physical and mental growth of girls and boys age six to nineteen in relation to age at maximum growth. Monogr. Soc. Res. Child Develop., 4, No. 3.

Simmons, K., and Greulich, W. W. (1943). Menarcheal age and the height, weight and skeletal age of girls aged 7 to 17 years. F. Pediat., 22, 518.

Tanner, J. M. (1952). The assessment of growth and development in children. Arch. Dis. Childh., 27, 10. 

In Modern Trends in Paediatrics (second series), ed. A. Holzel and J. P. M. Tizard, p. 325 . Butterworth, London.

- (1959). Boas' contributions to knowledge of human growth and form. In The Anthropology of Franz Boas: Essays on the Centennial of his Birth, ed. W. Goldschmidt. (Mem. Amer. Anthrop. Ass., No. 89.) Chandler Publ. Co., San Francisco.

- (1962a). Growth at Adolescence, 2nd ed. Blackwell, Oxford. (1962b). The evaluation of growth and maturity in children. In Protein Metabolism, ed. F. Gross. Springer, Berlin. , and Whitehouse, R. H. (1959). Standards for height and weight of British children from birth to maturity. Lancet, 2, 1086.
- (1958). The evaluation of physical growth and development.

- and - (1962). Standards for subcutaneous fat in British children. Percentiles for thickness of skinfolds over triceps and below scapula. Brit. med. F., 1, 446.

- ing Skeletal Maturity from the Hand and Wrist, with Standards Derived from a Study of 2,600 Healthv British Children. International Children's Centre, Paris.

Thomson, J. (1956a). Infant growth. Arch. Dis. Childh., 31, 382. (1956b). Growth from three to five years. Brit. F. prev. soc. Med., 10, 128.

Tuddenham, R. D., and Snyder, M. M. (1954). Physical growth of California boys and girls from birth to eighteen years. Univ. Calif. Publ. Child Develop., 1, 183.

\section{Appendix I}

TABLE I

'Instantaneous' 50th Centile Velocities for Height of Boys and Girls from Birth to Maturity

\begin{tabular}{|c|c|c|c|c|c|c|}
\hline \multirow{2}{*}{ Age (yr.) } & \multicolumn{2}{|c|}{ Velocity (cm./yr.) } & \multicolumn{2}{|c|}{ Boys } & \multicolumn{2}{|c|}{ Girls } \\
\hline & Boys & Girls & Age (yr.) & Velocity (cm./yr.) & Age (yr.) & Velocity (cm./yr.) \\
\hline $\begin{array}{l}0 \cdot 16 \\
0 \cdot 37 \\
0 \cdot 62 \\
0 \cdot 87 \\
1 \cdot 12 \\
1 \cdot 37 \\
1 \cdot 62 \\
1 \cdot 87 \\
2 \cdot 25 \\
2 \cdot 75 \\
3 \cdot 25 \\
3 \cdot 75 \\
4 \cdot 25 \\
4 \cdot 75 \\
5 \cdot 25 \\
5 \cdot 75 \\
6 \cdot 25 \\
6 \cdot 75 \\
7 \cdot 25 \\
7 \cdot 75 \\
8 \cdot 25 \\
8 \cdot 75 \\
9 \cdot 25 \\
9 \cdot 75\end{array}$ & $\begin{array}{r}40 \cdot 00 \\
30 \cdot 00 \\
18 \cdot 00 \\
14 \cdot 50 \\
12 \cdot 30 \\
11 \cdot 10 \\
9 \cdot 90 \\
9 \cdot 20 \\
8 \cdot 60 \\
8 \cdot 02 \\
7 \cdot 60 \\
7 \cdot 16 \\
6 \cdot 84 \\
6 \cdot 60 \\
6 \cdot 36 \\
6 \cdot 18 \\
6 \cdot 00 \\
5 \cdot 84 \\
5 \cdot 74 \\
5 \cdot 60 \\
5 \cdot 50 \\
5 \cdot 40 \\
5 \cdot 30 \\
5 \cdot 20\end{array}$ & $\begin{array}{r}36 \cdot 00 \\
26 \cdot 00 \\
19 \cdot 00 \\
15 \cdot 90 \\
13 \cdot 50 \\
11 \cdot 80 \\
10 \cdot 60 \\
9 \cdot 60 \\
8 \cdot 70 \\
8 \cdot 12 \\
7 \cdot 64 \\
7 \cdot 22 \\
6 \cdot 88 \\
6 \cdot 60 \\
6 \cdot 36 \\
6 \cdot 18 \\
6 \cdot 00 \\
5 \cdot 84 \\
5 \cdot 74 \\
5 \cdot 60 \\
5 \cdot 50 \\
5 \cdot 49 \\
5 \cdot 46 \\
5 \cdot 44\end{array}$ & $\begin{array}{l}10 \cdot 25 \\
10 \cdot 75 \\
11 \cdot 25 \\
11 \cdot 75 \\
12 \cdot 10 \\
12 \cdot 30 \\
12 \cdot 50 \\
12 \cdot 70 \\
12 \cdot 90 \\
13 \cdot 10 \\
13 \cdot 30 \\
13 \cdot 50 \\
13 \cdot 70 \\
13 \cdot 85 \\
13 \cdot 95 \\
14 \cdot 05 \\
14 \cdot 15 \\
14 \cdot 25 \\
14 \cdot 50 \\
14 \cdot 70 \\
14 \cdot 90 \\
15 \cdot 25 \\
15 \cdot 75 \\
16 \cdot 25 \\
16 \cdot 75 \\
17 \cdot 25\end{array}$ & $\begin{array}{r}5 \cdot 12 \\
5 \cdot 04 \\
4 \cdot 98 \\
4 \cdot 94 \\
4 \cdot 97 \\
5 \cdot 04 \\
5 \cdot 20 \\
5 \cdot 45 \\
5 \cdot 88 \\
6 \cdot 53 \\
7 \cdot 40 \\
8 \cdot 50 \\
9 \cdot 46 \\
10 \cdot 10 \\
10 \cdot 30 \\
10 \cdot 26 \\
9 \cdot 90 \\
9 \cdot 06 \\
8 \cdot 00 \\
7 \cdot 00 \\
6 \cdot 10 \\
4 \cdot 70 \\
3 \cdot 20 \\
2 \cdot 08 \\
1 \cdot 22 \\
0 \cdot 62\end{array}$ & $\begin{array}{l}10 \cdot 10 \\
10 \cdot 30 \\
10 \cdot 50 \\
10 \cdot 70 \\
10 \cdot 90 \\
11 \cdot 10 \\
11 \cdot 30 \\
11 \cdot 50 \\
11 \cdot 70 \\
11 \cdot 85 \\
11 \cdot 95 \\
12 \cdot 05 \\
12 \cdot 15 \\
12 \cdot 30 \\
12 \cdot 50 \\
12 \cdot 70 \\
12 \cdot 90 \\
13 \cdot 25 \\
13 \cdot 75 \\
14 \cdot 25 \\
14 \cdot 75 \\
15 \cdot 25\end{array}$ & $\begin{array}{l}5 \cdot 44 \\
5 \cdot 52 \\
5 \cdot 64 \\
5 \cdot 84 \\
6 \cdot 14 \\
6 \cdot 64 \\
7 \cdot 20 \\
7 \cdot 80 \\
8 \cdot 40 \\
8 \cdot 86 \\
8 \cdot 96 \\
8 \cdot 94 \\
8 \cdot 76 \\
8 \cdot 22 \\
7 \cdot 34 \\
6 \cdot 52 \\
5 \cdot 68 \\
4 \cdot 40 \\
2 \cdot 82 \\
1 \cdot 86 \\
1 \cdot 08 \\
0 \cdot 52\end{array}$ \\
\hline
\end{tabular}

For explanation, see text and Fig. 8.

TABLE II

'Instantaneous' 50th Centile Velocities for Weight of Boys and Girls from Birth to Maturity

\begin{tabular}{|c|c|c|c|c|c|c|}
\hline \multirow{2}{*}{ Age (yr.) } & \multicolumn{2}{|c|}{ Velocity (kg./yr.) } & \multicolumn{2}{|c|}{ Boys } & \multicolumn{2}{|c|}{ Girls } \\
\hline & Boys & Girls & Age (yr.) & Velocity (kg./yr.) & Age (yr.) & Velocity (kg./yr.) \\
\hline $\begin{array}{r}0 \cdot 10 \\
0 \cdot 20 \\
0 \cdot 30 \\
0 \cdot 50 \\
0 \cdot 70 \\
0 \cdot 90 \\
1 \cdot 10 \\
1 \cdot 30 \\
1 \cdot 50 \\
1 \cdot 70 \\
1 \cdot 90 \\
2 \cdot 25 \\
2 \cdot 75 \\
3 \cdot 25 \\
3 \cdot 75 \\
4 \cdot 25 \\
4 \cdot 75 \\
5 \cdot 25 \\
5 \cdot 75 \\
6 \cdot 25 \\
6 \cdot 75 \\
7 \cdot 25 \\
7 \cdot 75 \\
8 \cdot 25 \\
8 \cdot 75 \\
9 \cdot 25 \\
9 \cdot 75 \\
10 \cdot 25 \\
10 \cdot 75\end{array}$ & $\begin{array}{r}9 \cdot 30 \\
10 \cdot 60 \\
9 \cdot 10 \\
6 \cdot 80 \\
4 \cdot 60 \\
3 \cdot 60 \\
3 \cdot 10 \\
2 \cdot 74 \\
2 \cdot 44 \\
2 \cdot 29 \\
2 \cdot 11 \\
1 \cdot 98 \\
1 \cdot 92 \\
1 \cdot 90 \\
1 \cdot 90 \\
1 \cdot 90 \\
1 \cdot 90 \\
1 \cdot 94 \\
2 \cdot 02 \\
2 \cdot 11 \\
2 \cdot 21 \\
2 \cdot 31 \\
2 \cdot 42 \\
2 \cdot 52 \\
2 \cdot 62 \\
2 \cdot 72 \\
2 \cdot 82 \\
2 \cdot 92 \\
3 \cdot 02\end{array}$ & $\begin{array}{l}8 \cdot 00 \\
9 \cdot 80 \\
8 \cdot 70 \\
6 \cdot 60 \\
4 \cdot 60 \\
3 \cdot 60 \\
3 \cdot 10 \\
2 \cdot 74 \\
2 \cdot 44 \\
2 \cdot 28 \\
2 \cdot 11 \\
2 \cdot 03 \\
2 \cdot 00 \\
2 \cdot 00 \\
2 \cdot 00 \\
2 \cdot 00 \\
2 \cdot 03 \\
2 \cdot 08 \\
2 \cdot 14 \\
2 \cdot 21 \\
2 \cdot 28 \\
2 \cdot 38 \\
2 \cdot 48 \\
2 \cdot 60 \\
2 \cdot 73 \\
2 \cdot 88 \\
3 \cdot 05 \\
3 \cdot 26 \\
3 \cdot 68\end{array}$ & $\begin{array}{l}11 \cdot 25 \\
11 \cdot 75 \\
12 \cdot 25 \\
12 \cdot 75 \\
13 \cdot 10 \\
13 \cdot 30 \\
13 \cdot 50 \\
13 \cdot 70 \\
13 \cdot 90 \\
14 \cdot 10 \\
14 \cdot 30 \\
14 \cdot 50 \\
14 \cdot 70 \\
14 \cdot 90 \\
15 \cdot 25 \\
15 \cdot 75 \\
16 \cdot 25 \\
16 \cdot 75 \\
17 \cdot 25 \\
17 \cdot 75\end{array}$ & $\begin{array}{l}3 \cdot 14 \\
3 \cdot 30 \\
3 \cdot 70 \\
4 \cdot 68 \\
5 \cdot 70 \\
6 \cdot 68 \\
7 \cdot 74 \\
8 \cdot 84 \\
9 \cdot 74 \\
9 \cdot 74 \\
8 \cdot 92 \\
7 \cdot 90 \\
6 \cdot 90 \\
6 \cdot 00 \\
4 \cdot 60 \\
3 \cdot 16 \\
2 \cdot 24 \\
1 \cdot 50 \\
1 \cdot 06 \\
0 \cdot 80\end{array}$ & $\begin{array}{l}11 \cdot 25 \\
11 \cdot 75 \\
12 \cdot 10 \\
12 \cdot 30 \\
12 \cdot 50 \\
12 \cdot 70 \\
12 \cdot 90 \\
13 \cdot 25 \\
13 \cdot 75 \\
14 \cdot 25 \\
14 \cdot 75 \\
15 \cdot 25 \\
15 \cdot 75 \\
16 \cdot 25\end{array}$ & $\begin{array}{l}4 \cdot 64 \\
6 \cdot 20 \\
7 \cdot 70 \\
8 \cdot 50 \\
8 \cdot 80 \\
8 \cdot 40 \\
7 \cdot 50 \\
6 \cdot 10 \\
4 \cdot 30 \\
2 \cdot 82 \\
1 \cdot 68 \\
1 \cdot 00 \\
0 \cdot 66 \\
0 \cdot 44\end{array}$ \\
\hline
\end{tabular}

For explanation, see text and Fig. 9. 
TABLE IIIA

Cross-sectional-type Standards for Supine Length (up to 2) and Height Attained, Boys

\begin{tabular}{|c|c|c|c|c|c|c|c|c|c|}
\hline \multirow{2}{*}{ Age (yr.) } & \multicolumn{7}{|c|}{ Centiles (cm.) } & \multirow{2}{*}{ SD } & \multirow{2}{*}{$\begin{array}{c}\text { 50th Centile } \\
\text { as \% Adult } \\
\text { Height }\end{array}$} \\
\hline & 3 rd & 10th & 25 th & 50th & 75th & 90th & 97th & & \\
\hline $\begin{array}{l}0 \cdot 08 \\
0 \cdot 25 \\
0 \cdot 50 \\
0 \cdot 75 \\
1 \cdot 00 \\
1 \cdot 25 \\
1 \cdot 50 \\
1 \cdot 75 \\
2 \cdot 00\end{array}$ & $\begin{array}{l}50 \cdot 2 \\
56 \cdot 6 \\
63 \cdot 8 \\
67 \cdot 9 \\
71 \cdot 2 \\
74 \cdot 0 \\
76 \cdot 5 \\
78 \cdot 7 \\
80 \cdot 7\end{array}$ & $\begin{array}{l}51 \cdot 4 \\
57 \cdot 9 \\
65 \cdot 2 \\
69 \cdot 4 \\
72 \cdot 8 \\
75 \cdot 7 \\
78 \cdot 3 \\
80 \cdot 6 \\
82 \cdot 7\end{array}$ & $\begin{array}{l}52 \cdot 7 \\
59 \cdot 2 \\
66 \cdot 6 \\
71 \cdot 0 \\
74 \cdot 5 \\
77 \cdot 4 \\
80 \cdot 1 \\
82 \cdot 5 \\
84 \cdot 7\end{array}$ & $\begin{array}{l}54 \cdot 0 \\
60 \cdot 7 \\
68 \cdot 2 \\
72 \cdot 7 \\
76 \cdot 3 \\
79 \cdot 4 \\
82 \cdot 1 \\
84 \cdot 6 \\
86 \cdot 9\end{array}$ & $\begin{array}{l}55 \cdot 4 \\
62 \cdot 1 \\
69 \cdot 7 \\
74 \cdot 4 \\
78 \cdot 1 \\
81 \cdot 3 \\
84 \cdot 2 \\
86 \cdot 7 \\
89 \cdot 1\end{array}$ & $\begin{array}{l}56 \cdot 6 \\
63 \cdot 4 \\
71 \cdot 2 \\
75 \cdot 9 \\
79 \cdot 7 \\
83 \cdot 0 \\
86 \cdot 0 \\
88 \cdot 7 \\
91 \cdot 1\end{array}$ & $\begin{array}{l}57 \cdot 8 \\
64 \cdot 7 \\
72 \cdot 6 \\
77 \cdot 4 \\
81 \cdot 4 \\
84 \cdot 7 \\
87 \cdot 8 \\
90 \cdot 5 \\
93 \cdot 1\end{array}$ & $\begin{array}{l}2 \cdot 00 \\
2 \cdot 16 \\
2 \cdot 34 \\
2 \cdot 52 \\
2 \cdot 69 \\
2 \cdot 85 \\
3 \cdot 01 \\
3 \cdot 15 \\
3 \cdot 30\end{array}$ & $\begin{array}{l}30 \cdot 9 \\
34 \cdot 7 \\
39 \cdot 0 \\
41 \cdot 6 \\
43 \cdot 7 \\
45 \cdot 4 \\
47 \cdot 0 \\
48 \cdot 4 \\
49 \cdot 8\end{array}$ \\
\hline $\begin{array}{r}2 \cdot 0 \\
2 \cdot 5 \\
3 \cdot 0 \\
3 \cdot 5 \\
4 \cdot 0 \\
4 \cdot 5 \\
5 \cdot 0 \\
5 \cdot 5 \\
6 \cdot 0 \\
6 \cdot 5 \\
7 \cdot 0 \\
7 \cdot 5 \\
8 \cdot 0 \\
8 \cdot 5 \\
9 \cdot 0 \\
9 \cdot 5 \\
10 \cdot 0 \\
10 \cdot 5 \\
11 \cdot 0 \\
11 \cdot 5 \\
12 \cdot 0 \\
12.5 \\
13 \cdot 0 \\
13 \cdot 5 \\
14 \cdot 0 \\
14 \cdot 5 \\
15 \cdot 0 \\
15 \cdot 5 \\
16 \cdot 0 \\
16.5 \\
17 \cdot 0 \\
17.5 \\
18 \cdot 0\end{array}$ & $\begin{array}{r}79 \cdot 7 \\
83 \cdot 5 \\
87 \cdot 0 \\
90 \cdot 4 \\
93 \cdot 5 \\
96 \cdot 5 \\
99 \cdot 4 \\
102 \cdot 2 \\
104 \cdot 9 \\
107 \cdot 6 \\
110 \cdot 3 \\
112 \cdot 9 \\
115 \cdot 4 \\
117 \cdot 9 \\
120 \cdot 4 \\
122 \cdot 8 \\
125 \cdot 1 \\
127 \cdot 2 \\
129 \cdot 4 \\
131 \cdot 7 \\
133 \cdot 7 \\
136 \cdot 3 \\
138 \cdot 7 \\
141 \cdot 5 \\
145 \cdot 0 \\
148 \cdot 4 \\
152 \cdot 3 \\
155 \cdot 9 \\
158 \cdot 9 \\
160 \cdot 7 \\
161 \cdot 7 \\
162 \cdot 0 \\
162 \cdot 2\end{array}$ & $\begin{array}{r}81 \cdot 7 \\
85 \cdot 6 \\
89 \cdot 3 \\
92 \cdot 8 \\
96 \cdot 1 \\
99 \cdot 2 \\
102 \cdot 2 \\
105 \cdot 2 \\
108 \cdot 0 \\
110 \cdot 8 \\
113 \cdot 5 \\
116 \cdot 2 \\
118 \cdot 8 \\
121 \cdot 4 \\
124 \cdot 0 \\
126 \cdot 5 \\
128 \cdot 8 \\
131 \cdot 0 \\
133 \cdot 3 \\
135 \cdot 8 \\
138 \cdot 0 \\
140 \cdot 7 \\
143 \cdot 4 \\
146 \cdot 4 \\
150 \cdot 0 \\
153 \cdot 4 \\
157 \cdot 1 \\
160 \cdot 4 \\
163 \cdot 1 \\
164 \cdot 8 \\
165 \cdot 7 \\
166 \cdot 0 \\
166 \cdot 2\end{array}$ & $\begin{array}{r}83 \cdot 7 \\
87 \cdot 8 \\
91 \cdot 6 \\
95 \cdot 3 \\
98 \cdot 7 \\
102 \cdot 0 \\
105 \cdot 1 \\
108 \cdot 2 \\
111 \cdot 1 \\
114 \cdot 0 \\
116 \cdot 8 \\
119 \cdot 6 \\
122 \cdot 3 \\
125 \cdot 0 \\
127 \cdot 6 \\
130 \cdot 2 \\
132 \cdot 6 \\
135 \cdot 0 \\
137 \cdot 4 \\
140 \cdot 0 \\
142 \cdot 4 \\
145 \cdot 3 \\
148 \cdot 2 \\
151 \cdot 3 \\
155 \cdot 0 \\
158 \cdot 4 \\
161 \cdot 9 \\
165 \cdot 0 \\
167 \cdot 4 \\
168 \cdot 9 \\
169 \cdot 8 \\
170 \cdot 0 \\
170 \cdot 2\end{array}$ & $\begin{array}{r}85 \cdot 9 \\
90 \cdot 2 \\
94 \cdot 2 \\
98 \cdot 0 \\
101 \cdot 6 \\
105 \cdot 0 \\
108 \cdot 3 \\
111 \cdot 5 \\
114 \cdot 6 \\
117 \cdot 6 \\
120 \cdot 5 \\
123 \cdot 4 \\
126 \cdot 2 \\
128 \cdot 9 \\
131 \cdot 6 \\
134 \cdot 3 \\
136 \cdot 8 \\
139 \cdot 3 \\
141 \cdot 9 \\
144 \cdot 7 \\
147 \cdot 3 \\
150 \cdot 3 \\
153 \cdot 4 \\
156 \cdot 8 \\
160 \cdot 7 \\
164 \cdot 0 \\
167 \cdot 3 \\
170 \cdot 1 \\
172 \cdot 2 \\
173 \cdot 5 \\
174 \cdot 3 \\
174 \cdot 5 \\
174 \cdot 7\end{array}$ & $\begin{array}{r}88 \cdot 1 \\
92 \cdot 6 \\
96 \cdot 8 \\
100 \cdot 8 \\
104 \cdot 5 \\
108 \cdot 1 \\
111 \cdot 5 \\
114 \cdot 8 \\
118 \cdot 1 \\
121 \cdot 2 \\
124 \cdot 2 \\
127 \cdot 2 \\
130 \cdot 0 \\
132 \cdot 9 \\
135 \cdot 7 \\
138 \cdot 4 \\
141 \cdot 0 \\
143 \cdot 6 \\
146 \cdot 4 \\
149 \cdot 4 \\
152 \cdot 2 \\
155 \cdot 4 \\
158 \cdot 7 \\
162 \cdot 3 \\
166 \cdot 3 \\
169 \cdot 6 \\
172 \cdot 7 \\
175 \cdot 2 \\
177 \cdot 0 \\
178 \cdot 0 \\
178 \cdot 8 \\
179 \cdot 0 \\
179 \cdot 2\end{array}$ & $\begin{array}{r}90 \cdot 1 \\
94 \cdot 8 \\
99 \cdot 1 \\
103 \cdot 2 \\
107 \cdot 1 \\
110 \cdot 8 \\
114 \cdot 4 \\
117 \cdot 8 \\
121 \cdot 2 \\
124 \cdot 4 \\
127 \cdot 5 \\
130 \cdot 6 \\
133 \cdot 5 \\
136 \cdot 4 \\
139 \cdot 3 \\
142 \cdot 1 \\
144 \cdot 8 \\
147 \cdot 6 \\
150 \cdot 4 \\
153 \cdot 6 \\
156 \cdot 6 \\
159 \cdot 9 \\
163 \cdot 5 \\
167 \cdot 2 \\
171 \cdot 3 \\
174 \cdot 6 \\
177 \cdot 6 \\
179 \cdot 8 \\
181 \cdot 3 \\
182 \cdot 1 \\
182 \cdot 8 \\
183 \cdot 0 \\
183 \cdot 2\end{array}$ & $\begin{array}{r}92 \cdot 1 \\
96 \cdot 9 \\
101 \cdot 4 \\
105 \cdot 7 \\
109 \cdot 7 \\
113 \cdot 5 \\
117 \cdot 2 \\
120 \cdot 8 \\
124 \cdot 3 \\
127 \cdot 6 \\
130 \cdot 8 \\
133 \cdot 9 \\
137 \cdot 0 \\
139 \cdot 9 \\
142 \cdot 9 \\
145 \cdot 8 \\
148 \cdot 5 \\
151 \cdot 4 \\
154 \cdot 4 \\
157 \cdot 8 \\
160 \cdot 9 \\
164 \cdot 4 \\
168 \cdot 2 \\
172 \cdot 0 \\
176 \cdot 2 \\
179 \cdot 6 \\
182 \cdot 4 \\
184 \cdot 3 \\
185 \cdot 5 \\
186 \cdot 2 \\
186 \cdot 8 \\
187 \cdot 0 \\
187 \cdot 2\end{array}$ & $\begin{array}{l}3 \cdot 30 \\
3 \cdot 57 \\
3 \cdot 83 \\
4 \cdot 07 \\
4 \cdot 30 \\
4 \cdot 52 \\
4 \cdot 74 \\
4 \cdot 94 \\
5 \cdot 14 \\
5 \cdot 31 \\
5 \cdot 46 \\
5 \cdot 60 \\
5 \cdot 73 \\
5 \cdot 85 \\
5 \cdot 98 \\
6 \cdot 10 \\
6 \cdot 24 \\
6 \cdot 44 \\
6 \cdot 67 \\
6 \cdot 95 \\
7 \cdot 24 \\
7 \cdot 48 \\
7 \cdot 82 \\
8 \cdot 11 \\
8 \cdot 31 \\
8 \cdot 30 \\
8 \cdot 00 \\
7 \cdot 55 \\
7 \cdot 08 \\
6 \cdot 77 \\
6 \cdot 67 \\
6 \cdot 66 \\
6 \cdot 65\end{array}$ & $\begin{array}{c}49 \cdot 2 \\
51 \cdot 6 \\
53 \cdot 9 \\
56 \cdot 1 \\
58 \cdot 2 \\
60 \cdot 1 \\
62 \cdot 0 \\
63 \cdot 8 \\
65 \cdot 6 \\
67 \cdot 3 \\
69 \cdot 0 \\
70 \cdot 6 \\
72 \cdot 2 \\
73 \cdot 8 \\
75 \cdot 4 \\
76 \cdot 9 \\
78 \cdot 3 \\
\text { See Table VA }\end{array}$ \\
\hline
\end{tabular}

For source of data and method of construction, see text.

TABLE IIIB

Cross-sectional-type Standards for Supine Length (up to 2) and Height Attained, Girls

\begin{tabular}{|c|c|c|c|c|c|c|c|c|c|}
\hline \multirow{2}{*}{ Age (yr.) } & \multicolumn{7}{|c|}{ Centiles (cm.) } & \multirow{2}{*}{ SD } & \multirow{2}{*}{$\begin{array}{c}\text { 50th Centile } \\
\text { as \% Adult } \\
\text { Height }\end{array}$} \\
\hline & $3 r d$ & 10 th & 25 th & 50 th & 75 th & 90th & 97th & & \\
\hline $\begin{array}{l}0.08 \\
0.25 \\
0.50 \\
0.75 \\
1.00 \\
1.25 \\
1.50 \\
1.75 \\
2.00\end{array}$ & $\begin{array}{l}49 \cdot 2 \\
54 \cdot 9 \\
61 \cdot 1 \\
65 \cdot 5 \\
69 \cdot 1 \\
72 \cdot 2 \\
74 \cdot 9 \\
77 \cdot 2 \\
79 \cdot 4\end{array}$ & $\begin{array}{l}50 \cdot 4 \\
56 \cdot 2 \\
62 \cdot 5 \\
67 \cdot 0 \\
70 \cdot 8 \\
73 \cdot 9 \\
76 \cdot 7 \\
79 \cdot 1 \\
81 \cdot 3\end{array}$ & $\begin{array}{l}51 \cdot 6 \\
57 \cdot 5 \\
63 \cdot 9 \\
68 \cdot 6 \\
72 \cdot 4 \\
75 \cdot 7 \\
78 \cdot 5 \\
81 \cdot 1 \\
83 \cdot 4\end{array}$ & $\begin{array}{l}53 \cdot 0 \\
59 \cdot 0 \\
65 \cdot 5 \\
70 \cdot 2 \\
74 \cdot 2 \\
77 \cdot 6 \\
80 \cdot 5 \\
83 \cdot 2 \\
85 \cdot 6\end{array}$ & $\begin{array}{l}54 \cdot 4 \\
60 \cdot 5 \\
67 \cdot 1 \\
72 \cdot 0 \\
76 \cdot 0 \\
79 \cdot 5 \\
82 \cdot 6 \\
85 \cdot 3 \\
87 \cdot 8\end{array}$ & $\begin{array}{l}55 \cdot 6 \\
61 \cdot 8 \\
68 \cdot 5 \\
73 \cdot 5 \\
77 \cdot 7 \\
81 \cdot 2 \\
84 \cdot 4 \\
87 \cdot 2 \\
89 \cdot 8\end{array}$ & $\begin{array}{l}56 \cdot 8 \\
63 \cdot 1 \\
69 \cdot 9 \\
74 \cdot 9 \\
79 \cdot 3 \\
82 \cdot 9 \\
86 \cdot 2 \\
89 \cdot 1 \\
91 \cdot 8\end{array}$ & $\begin{array}{l}2 \cdot 00 \\
2 \cdot 16 \\
2 \cdot 34 \\
2 \cdot 52 \\
2 \cdot 69 \\
2 \cdot 85 \\
3 \cdot 01 \\
3 \cdot 15 \\
3 \cdot 30\end{array}$ & $\begin{array}{l}32 \cdot 7 \\
36 \cdot 4 \\
40 \cdot 4 \\
43 \cdot 3 \\
45 \cdot 7 \\
47 \cdot 8 \\
49 \cdot 7 \\
51 \cdot 3 \\
52 \cdot 8\end{array}$ \\
\hline $\begin{array}{l}2 \cdot 0 \\
2 \cdot 5 \\
3 \cdot 0 \\
3 \cdot 5 \\
4 \cdot 0 \\
4 \cdot 5 \\
5 \cdot 0 \\
5 \cdot 5 \\
6 \cdot 0 \\
6 \cdot 5 \\
7 \cdot 0 \\
7 \cdot 5 \\
8 \cdot 0 \\
8 \cdot 5\end{array}$ & $\begin{array}{r}78 \cdot 4 \\
82 \cdot 2 \\
85 \cdot 7 \\
89 \cdot 2 \\
92 \cdot 3 \\
95 \cdot 4 \\
98 \cdot 2 \\
101 \cdot 0 \\
103 \cdot 8 \\
106 \cdot 4 \\
109 \cdot 1 \\
111 \cdot 7 \\
114 \cdot 2 \\
116 \cdot 7\end{array}$ & $\begin{array}{r}80 \cdot 3 \\
84 \cdot 3 \\
88 \cdot 1 \\
91 \cdot 6 \\
94 \cdot 9 \\
98 \cdot 1 \\
101 \cdot 1 \\
104 \cdot 0 \\
106 \cdot 8 \\
109 \cdot 6 \\
112 \cdot 4 \\
115 \cdot 0 \\
117 \cdot 6 \\
120 \cdot 3\end{array}$ & $\begin{array}{r}82 \cdot 4 \\
86 \cdot 5 \\
90 \cdot 4 \\
94 \cdot 1 \\
97 \cdot 5 \\
100 \cdot 8 \\
104 \cdot 0 \\
107 \cdot 0 \\
110 \cdot 0 \\
112 \cdot 8 \\
115 \cdot 7 \\
118 \cdot 4 \\
121 \cdot 1 \\
123 \cdot 8\end{array}$ & $\begin{array}{r}84 \cdot 6 \\
88 \cdot 9 \\
93 \cdot 0 \\
96 \cdot 8 \\
100 \cdot 4 \\
103 \cdot 8 \\
107 \cdot 2 \\
110 \cdot 3 \\
113 \cdot 4 \\
116 \cdot 4 \\
119 \cdot 3 \\
122 \cdot 2 \\
125 \cdot 0 \\
127 \cdot 8\end{array}$ & $\begin{array}{r}86 \cdot 8 \\
91 \cdot 3 \\
95 \cdot 6 \\
99 \cdot 6 \\
103 \cdot 3 \\
106 \cdot 9 \\
110 \cdot 3 \\
113 \cdot 7 \\
116 \cdot 9 \\
120 \cdot 0 \\
123 \cdot 0 \\
126 \cdot 0 \\
128 \cdot 9 \\
131 \cdot 8\end{array}$ & $\begin{array}{r}88 \cdot 8 \\
93 \cdot 5 \\
97 \cdot 9 \\
102 \cdot 0 \\
105 \cdot 9 \\
109 \cdot 7 \\
113 \cdot 2 \\
116 \cdot 7 \\
120 \cdot 0 \\
123 \cdot 2 \\
126 \cdot 3 \\
129 \cdot 4 \\
132 \cdot 4 \\
135 \cdot 3\end{array}$ & $\begin{array}{r}90 \cdot 8 \\
95 \cdot 6 \\
100 \cdot 2 \\
104 \cdot 5 \\
108 \cdot 5 \\
112 \cdot 4 \\
116 \cdot 1 \\
119 \cdot 6 \\
123 \cdot 1 \\
126 \cdot 4 \\
129 \cdot 6 \\
132 \cdot 8 \\
135 \cdot 8 \\
138 \cdot 8\end{array}$ & $\begin{array}{l}3 \cdot 30 \\
3 \cdot 57 \\
3 \cdot 83 \\
4 \cdot 07 \\
4 \cdot 30 \\
4 \cdot 52 \\
4 \cdot 74 \\
4 \cdot 94 \\
5 \cdot 14 \\
5 \cdot 31 \\
5 \cdot 46 \\
5 \cdot 60 \\
5 \cdot 75 \\
5 \cdot 87\end{array}$ & $\begin{array}{c}52 \cdot 1 \\
54 \cdot 8 \\
57 \cdot 3 \\
59 \cdot 7 \\
61 \cdot 9 \\
64 \cdot 0 \\
66 \cdot 1 \\
68 \cdot 0 \\
69 \cdot 9 \\
71 \cdot 8 \\
73 \cdot 6 \\
75 \cdot 3 \\
77 \cdot 1 \\
\text { See Table VB }\end{array}$ \\
\hline
\end{tabular}

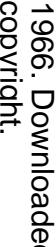


TABLE IIIB-continued

Cross-sectional-type Standards for Supine Length (up to 2) and Height Attained, Girls

\begin{tabular}{|c|c|c|c|c|c|c|c|c|c|}
\hline \multirow{2}{*}{ Age (yr.) } & \multicolumn{7}{|c|}{ Centiles (cm.) } & \multirow{2}{*}{$\mathrm{SD}$} & \multirow{2}{*}{$\begin{array}{c}\text { 50th Centile } \\
\text { as \% Adult } \\
\text { Height }\end{array}$} \\
\hline & $3 r d$ & 10 th & 25 th & 50 th & 75 th & 90th & 97th & & \\
\hline $\begin{array}{r}9 \cdot 0 \\
9.5 \\
10 \cdot 0 \\
10.5 \\
11 \cdot 0 \\
11 \cdot 5 \\
12.0 \\
12.5 \\
13.0 \\
13.5 \\
14 \cdot 0 \\
14.5 \\
15.0 \\
15.5 \\
16.0\end{array}$ & $\begin{array}{l}119 \cdot 3 \\
121 \cdot 9 \\
124 \cdot 5 \\
127 \cdot 1 \\
129 \cdot 5 \\
132 \cdot 0 \\
135 \cdot 0 \\
139 \cdot 0 \\
142 \cdot 6 \\
145 \cdot 4 \\
147 \cdot 6 \\
149 \cdot 4 \\
150 \cdot 3 \\
150 \cdot 6 \\
150 \cdot 9\end{array}$ & $\begin{array}{l}122 \cdot 9 \\
125 \cdot 6 \\
128 \cdot 3 \\
131 \cdot 1 \\
133 \cdot 7 \\
136 \cdot 5 \\
139 \cdot 6 \\
143 \cdot 3 \\
146 \cdot 7 \\
149 \cdot 4 \\
151 \cdot 4 \\
153 \cdot 1 \\
153 \cdot 9 \\
154 \cdot 2 \\
154 \cdot 5\end{array}$ & $\begin{array}{l}126 \cdot 6 \\
129 \cdot 3 \\
132 \cdot 1 \\
135 \cdot 0 \\
138 \cdot 0 \\
141 \cdot 0 \\
144 \cdot 2 \\
147 \cdot 7 \\
150 \cdot 9 \\
153 \cdot 4 \\
155 \cdot 3 \\
156 \cdot 9 \\
157 \cdot 6 \\
157 \cdot 9 \\
158 \cdot 2\end{array}$ & $\begin{array}{l}130 \cdot 6 \\
133 \cdot 5 \\
136 \cdot 4 \\
139 \cdot 5 \\
142 \cdot 7 \\
146 \cdot 1 \\
149 \cdot 3 \\
152 \cdot 5 \\
155 \cdot 5 \\
157 \cdot 9 \\
159 \cdot 6 \\
161 \cdot 1 \\
161 \cdot 7 \\
162 \cdot 0 \\
162 \cdot 2\end{array}$ & $\begin{array}{l}134 \cdot 6 \\
137 \cdot 6 \\
140 \cdot 6 \\
143 \cdot 9 \\
147 \cdot 4 \\
151 \cdot 1 \\
154 \cdot 4 \\
157 \cdot 4 \\
160 \cdot 2 \\
162 \cdot 3 \\
163 \cdot 9 \\
165 \cdot 3 \\
165 \cdot 8 \\
166 \cdot 1 \\
166 \cdot 2\end{array}$ & $\begin{array}{l}138 \cdot 3 \\
141 \cdot 3 \\
144 \cdot 5 \\
147 \cdot 9 \\
151 \cdot 6 \\
155 \cdot 6 \\
159 \cdot 1 \\
161 \cdot 8 \\
164 \cdot 4 \\
166 \cdot 3 \\
167 \cdot 8 \\
169 \cdot 0 \\
169 \cdot 5 \\
169 \cdot 7 \\
169 \cdot 9\end{array}$ & $\begin{array}{l}141 \cdot 9 \\
145 \cdot 0 \\
148 \cdot 3 \\
151 \cdot 8 \\
155 \cdot 8 \\
160 \cdot 1 \\
163 \cdot 6 \\
166 \cdot 1 \\
168 \cdot 5 \\
170 \cdot 3 \\
171 \cdot 6 \\
172 \cdot 7 \\
173 \cdot 2 \\
173 \cdot 4 \\
173 \cdot 5\end{array}$ & $\begin{array}{l}6 \cdot 00 \\
6 \cdot 14 \\
6 \cdot 31 \\
6 \cdot 56 \\
6 \cdot 97 \\
7 \cdot 47 \\
7 \cdot 61 \\
7 \cdot 21 \\
6 \cdot 90 \\
6 \cdot 61 \\
6 \cdot 38 \\
6 \cdot 20 \\
6 \cdot 09 \\
6 \cdot 04 \\
6 \cdot 00\end{array}$ & \\
\hline
\end{tabular}

For source of data and method of construction, see text.

TABLE IVA

Cross-sectional Type Standards for Weight Attained, Boys

\begin{tabular}{|c|c|c|c|c|c|c|c|c|}
\hline \multirow{2}{*}{ Age (yr.) } & \multicolumn{7}{|c|}{ Centiles (kg.) } & \multirow{2}{*}{$\begin{array}{c}\text { 50th Centile } \\
\text { as \% } 18 \mathrm{yr} \text {. } \\
\text { Weight }\end{array}$} \\
\hline & 3rd & 10th & 25 th & 50 th & 75th & 90th & 97th & \\
\hline 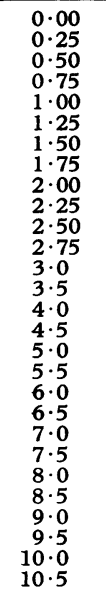 & $\begin{array}{c}2 \cdot 50 \\
4 \cdot 65 \\
6 \cdot 38 \\
7 \cdot 48 \\
8 \cdot 3 \\
8 \cdot 9 \\
9 \cdot 4 \\
9 \cdot 8 \\
10 \cdot 2 \\
10 \cdot 5 \\
10 \cdot 9 \\
11 \cdot 2 \\
11 \cdot 6 \\
12 \cdot 3 \\
13 \cdot 0 \\
13 \cdot 7 \\
14 \cdot 4 \\
15 \cdot 1 \\
15 \cdot 9 \\
16 \cdot 6 \\
17 \cdot 4 \\
18 \cdot 2 \\
19 \cdot 1 \\
20 \cdot 0 \\
21 \cdot 0 \\
21 \cdot 9 \\
23 \cdot 0 \\
24 \cdot 0\end{array}$ & $\begin{array}{l}2 \cdot 80 \\
5 \cdot 01 \\
6 \cdot 80 \\
7 \cdot 98 \\
8 \cdot 8 \\
9 \cdot 6 \\
10 \cdot 1 \\
10 \cdot 5 \\
11 \cdot 0 \\
11 \cdot 4 \\
11 \cdot 9 \\
12 \cdot 2 \\
12 \cdot 7 \\
13 \cdot 4 \\
14 \cdot 3 \\
15 \cdot 0 \\
15 \cdot 7 \\
16 \cdot 5 \\
17 \cdot 3 \\
18 \cdot 1 \\
19 \cdot 0 \\
19 \cdot 9 \\
20 \cdot 9 \\
21 \cdot 9 \\
22 \cdot 9 \\
24 \cdot 0 \\
25 \cdot 2 \\
26 \cdot 3\end{array}$ & $\begin{array}{r}3 \cdot 10 \\
5 \cdot 43 \\
7 \cdot 32 \\
8 \cdot 55 \\
9 \cdot 5 \\
10 \cdot 2 \\
10 \cdot 7 \\
11 \cdot 2 \\
11 \cdot 8 \\
12 \cdot 2 \\
12 \cdot 7 \\
13 \cdot 1 \\
13 \cdot 6 \\
14 \cdot 5 \\
15 \cdot 3 \\
16 \cdot 1 \\
16 \cdot 9 \\
17 \cdot 7 \\
18 \cdot 6 \\
19 \cdot 5 \\
20 \cdot 6 \\
21 \cdot 6 \\
22 \cdot 7 \\
23 \cdot 9 \\
25 \cdot 0 \\
26 \cdot 2 \\
27 \cdot 5 \\
28 \cdot 7\end{array}$ & $\begin{array}{c}3 \cdot 50 \\
5 \cdot 93 \\
7 \cdot 90 \\
9 \cdot 20 \\
10 \cdot 2 \\
11 \cdot 0 \\
11 \cdot 6 \\
12 \cdot 2 \\
12 \cdot 7 \\
13 \cdot 2 \\
13 \cdot 7 \\
14 \cdot 2 \\
14 \cdot 7 \\
15 \cdot 6 \\
16 \cdot 6 \\
17 \cdot 5 \\
18 \cdot 5 \\
19 \cdot 5 \\
20 \cdot 5 \\
21 \cdot 5 \\
22 \cdot 6 \\
23 \cdot 7 \\
25 \cdot 0 \\
26 \cdot 2 \\
27 \cdot 5 \\
28 \cdot 9 \\
30 \cdot 3 \\
31 \cdot 9\end{array}$ & $\begin{array}{c}3 \cdot 80 \\
6 \cdot 45 \\
8 \cdot 58 \\
9 \cdot 95 \\
11 \cdot 0 \\
11 \cdot 8 \\
12 \cdot 5 \\
13 \cdot 1 \\
13 \cdot 7 \\
14 \cdot 2 \\
14 \cdot 8 \\
15 \cdot 3 \\
15 \cdot 8 \\
16 \cdot 8 \\
17 \cdot 9 \\
19 \cdot 0 \\
20 \cdot 0 \\
21 \cdot 2 \\
22 \cdot 4 \\
23 \cdot 6 \\
24 \cdot 9 \\
26 \cdot 1 \\
27 \cdot 5 \\
28 \cdot 9 \\
30 \cdot 3 \\
31 \cdot 9 \\
33 \cdot 6 \\
35 \cdot 6\end{array}$ & $\begin{array}{c}4 \cdot 10 \\
6 \cdot 99 \\
9 \cdot 20 \\
10 \cdot 63 \\
11 \cdot 7 \\
12 \cdot 6 \\
13 \cdot 3 \\
13 \cdot 9 \\
14 \cdot 6 \\
15 \cdot 1 \\
15 \cdot 8 \\
16 \cdot 3 \\
16 \cdot 9 \\
18 \cdot 0 \\
19 \cdot 1 \\
20 \cdot 2 \\
21 \cdot 5 \\
22 \cdot 8 \\
24 \cdot 0 \\
25 \cdot 4 \\
26 \cdot 9 \\
28 \cdot 4 \\
30 \cdot 0 \\
31 \cdot 6 \\
33 \cdot 4 \\
35 \cdot 3 \\
37 \cdot 3 \\
39 \cdot 7\end{array}$ & $\begin{array}{r}4 \cdot 40 \\
7 \cdot 43 \\
9 \cdot 90 \\
11 \cdot 45 \\
12 \cdot 6 \\
13 \cdot 5 \\
14 \cdot 3 \\
14 \cdot 9 \\
15 \cdot 6 \\
16 \cdot 2 \\
16 \cdot 9 \\
17 \cdot 4 \\
18 \cdot 0 \\
19 \cdot 2 \\
20 \cdot 4 \\
21 \cdot 8 \\
23 \cdot 2 \\
24 \cdot 8 \\
26 \cdot 5 \\
28 \cdot 3 \\
30 \cdot 3 \\
32 \cdot 3 \\
34 \cdot 4 \\
36 \cdot 5 \\
38 \cdot 8 \\
41 \cdot 0 \\
43 \cdot 3 \\
46 \cdot 3\end{array}$ & $\begin{array}{c}5 \cdot 6 \\
9 \cdot 4 \\
12 \cdot 5 \\
14 \cdot 6 \\
16 \cdot 2 \\
17 \cdot 5 \\
18 \cdot 4 \\
19 \cdot 4 \\
20 \cdot 2 \\
21 \cdot 0 \\
21 \cdot 7 \\
22 \cdot 5 \\
23 \cdot 3 \\
24 \cdot 8 \\
26 \cdot 3 \\
27 \cdot 8 \\
29 \cdot 4 \\
31 \cdot 0 \\
32 \cdot 5 \\
34 \cdot 1 \\
35 \cdot 9 \\
37 \cdot 6 \\
39 \cdot 7 \\
41 \cdot 6 \\
43 \cdot 7 \\
45 \cdot 9 \\
48 \cdot 1 \\
\text { See Table }\end{array}$ \\
\hline $\begin{array}{l}11 \cdot 0 \\
11 \cdot 5 \\
12 \cdot 0 \\
12 \cdot 5 \\
13 \cdot 0 \\
13 \cdot 5 \\
14 \cdot 0 \\
14 \cdot 5 \\
15 \cdot 0 \\
15 \cdot 5 \\
16 \cdot 0 \\
16 \cdot 5 \\
17 \cdot 0 \\
18 \cdot 0 \\
19 \cdot 0\end{array}$ & $\begin{array}{l}24 \cdot 9 \\
26 \cdot 0 \\
27 \cdot 1 \\
28 \cdot 1 \\
29 \cdot 6 \\
31 \cdot 2 \\
33 \cdot 3 \\
36 \cdot 0 \\
39 \cdot 0 \\
42 \cdot 7 \\
45 \cdot 7 \\
47 \cdot 5 \\
48 \cdot 6 \\
50 \cdot 0 \\
50 \cdot 4\end{array}$ & $\begin{array}{l}27 \cdot 4 \\
28 \cdot 6 \\
29 \cdot 9 \\
31 \cdot 3 \\
33 \cdot 0 \\
35 \cdot 1 \\
37 \cdot 7 \\
40 \cdot 6 \\
43 \cdot 7 \\
47 \cdot 0 \\
49 \cdot 6 \\
51 \cdot 3 \\
52 \cdot 3 \\
53 \cdot 5 \\
53 \cdot 7\end{array}$ & $\begin{array}{l}30 \cdot 1 \\
31 \cdot 6 \\
33 \cdot 2 \\
35 \cdot 0 \\
37 \cdot 1 \\
39 \cdot 7 \\
42 \cdot 6 \\
45 \cdot 7 \\
48 \cdot 7 \\
51 \cdot 7 \\
54 \cdot 1 \\
55 \cdot 6 \\
56 \cdot 6 \\
57 \cdot 8 \\
58 \cdot 1\end{array}$ & $\begin{array}{l}33 \cdot 6 \\
35 \cdot 5 \\
37 \cdot 7 \\
40 \cdot 0 \\
42 \cdot 6 \\
45 \cdot 5 \\
48 \cdot 8 \\
51 \cdot 9 \\
54 \cdot 7 \\
57 \cdot 4 \\
59 \cdot 6 \\
61 \cdot 0 \\
61 \cdot 9 \\
63 \cdot 0 \\
63 \cdot 3\end{array}$ & $\begin{array}{l}37 \cdot 7 \\
40 \cdot 2 \\
42 \cdot 7 \\
45 \cdot 7 \\
49 \cdot 0 \\
52 \cdot 2 \\
55 \cdot 4 \\
58 \cdot 4 \\
60 \cdot 9 \\
63 \cdot 0 \\
65 \cdot 0 \\
66 \cdot 2 \\
67 \cdot 1 \\
68 \cdot 0 \\
68 \cdot 3\end{array}$ & $\begin{array}{l}42 \cdot 6 \\
45 \cdot 4 \\
49 \cdot 0 \\
52 \cdot 5 \\
56 \cdot 0 \\
59 \cdot 4 \\
62 \cdot 5 \\
65 \cdot 4 \\
68 \cdot 0 \\
70 \cdot 1 \\
71 \cdot 7 \\
72 \cdot 8 \\
73 \cdot 6 \\
74 \cdot 5 \\
75 \cdot 0\end{array}$ & $\begin{array}{l}49 \cdot 5 \\
53 \cdot 3 \\
57 \cdot 2 \\
61 \cdot 0 \\
64 \cdot 4 \\
67 \cdot 8 \\
70 \cdot 9 \\
73 \cdot 7 \\
75 \cdot 9 \\
77 \cdot 5 \\
78 \cdot 6 \\
79 \cdot 5 \\
80 \cdot 2 \\
81 \cdot 0 \\
81 \cdot 6\end{array}$ & \\
\hline
\end{tabular}

For source of data and method of construction, see text. 
TABLE IVB

Cross-sectional Type Standards for Weight Attained, Girls

\begin{tabular}{|c|c|c|c|c|c|c|c|c|}
\hline \multirow{2}{*}{ Age (yr.) } & \multicolumn{7}{|c|}{ Centiles (kg.) } & \multirow{2}{*}{$\begin{array}{c}\text { 50th Centile } \\
\text { as \% } 18 \mathrm{yr} \text {. } \\
\text { Weight }\end{array}$} \\
\hline & $3 r d$ & 10th & 25 th & 50 th & 75th & 90th & 97 th & \\
\hline $\begin{array}{l}0 \cdot 00 \\
0 \cdot 25 \\
0 \cdot 50 \\
0 \cdot 75 \\
1 \cdot 00 \\
1 \cdot 25 \\
1 \cdot 50 \\
1 \cdot 75 \\
2 \cdot 00 \\
2 \cdot 25 \\
2 \cdot 50 \\
2 \cdot 75 \\
3 \cdot 0 \\
3 \cdot 5 \\
4 \cdot 0 \\
4 \cdot 5 \\
5 \cdot 0 \\
5 \cdot 5 \\
6 \cdot 0 \\
6 \cdot 5 \\
7 \cdot 0 \\
7 \cdot 5 \\
8 \cdot 0\end{array}$ & $\begin{array}{c}2 \cdot 55 \\
4 \cdot 36 \\
5 \cdot 89 \\
6 \cdot 99 \\
7 \cdot 8 \\
8 \cdot 3 \\
8 \cdot 9 \\
9 \cdot 3 \\
9 \cdot 7 \\
10 \cdot 0 \\
10 \cdot 5 \\
10 \cdot 9 \\
11 \cdot 4 \\
12 \cdot 2 \\
13 \cdot 1 \\
13 \cdot 8 \\
14 \cdot 6 \\
15 \cdot 4 \\
16 \cdot 2 \\
17 \cdot 0 \\
17 \cdot 8 \\
18 \cdot 6 \\
19 \cdot 4\end{array}$ & $\begin{array}{l}2 \cdot 85 \\
4 \cdot 81 \\
6 \cdot 44 \\
7 \cdot 58 \\
8 \cdot 4 \\
9 \cdot 0 \\
9 \cdot 5 \\
10 \cdot 0 \\
10 \cdot 4 \\
10 \cdot 8 \\
11 \cdot 3 \\
11 \cdot 8 \\
12 \cdot 3 \\
13 \cdot 2 \\
14 \cdot 1 \\
15 \cdot 0 \\
15 \cdot 9 \\
16 \cdot 7 \\
17 \cdot 6 \\
18 \cdot 4 \\
19 \cdot 2 \\
20 \cdot 1 \\
21 \cdot 0\end{array}$ & $\begin{array}{c}3 \cdot 15 \\
5 \cdot 18 \\
6 \cdot 90 \\
8 \cdot 13 \\
9 \cdot 0 \\
9 \cdot 6 \\
10 \cdot 2 \\
10 \cdot 8 \\
11 \cdot 3 \\
11 \cdot 7 \\
12 \cdot 2 \\
12 \cdot 7 \\
13 \cdot 2 \\
14 \cdot 2 \\
15 \cdot 2 \\
16 \cdot 1 \\
17 \cdot 0 \\
18 \cdot 0 \\
18 \cdot 9 \\
19 \cdot 8 \\
20 \cdot 8 \\
21 \cdot 9 \\
22 \cdot 9\end{array}$ & $\begin{array}{c}3 \cdot 40 \\
5 \cdot 56 \\
7 \cdot 39 \\
8 \cdot 72 \\
9 \cdot 7 \\
10 \cdot 4 \\
11 \cdot 1 \\
11 \cdot 7 \\
12 \cdot 2 \\
12 \cdot 7 \\
13 \cdot 3 \\
13 \cdot 7 \\
14 \cdot 3 \\
15 \cdot 2 \\
16 \cdot 3 \\
17 \cdot 2 \\
18 \cdot 3 \\
19 \cdot 3 \\
20 \cdot 4 \\
21 \cdot 5 \\
22 \cdot 6 \\
23 \cdot 8 \\
25 \cdot 1\end{array}$ & $\begin{array}{c}3 \cdot 65 \\
6 \cdot 02 \\
7 \cdot 99 \\
9 \cdot 42 \\
10 \cdot 5 \\
11 \cdot 3 \\
12 \cdot 0 \\
12 \cdot 6 \\
13 \cdot 2 \\
13 \cdot 7 \\
14 \cdot 3 \\
14 \cdot 8 \\
15 \cdot 3 \\
16 \cdot 3 \\
17 \cdot 5 \\
18 \cdot 6 \\
19 \cdot 8 \\
20 \cdot 9 \\
22 \cdot 2 \\
23 \cdot 5 \\
25 \cdot 0 \\
26 \cdot 4 \\
28 \cdot 0\end{array}$ & $\begin{array}{c}3 \cdot 95 \\
6 \cdot 41 \\
8 \cdot 49 \\
10 \cdot 02 \\
11 \cdot 2 \\
12 \cdot 0 \\
12 \cdot 8 \\
13 \cdot 5 \\
14 \cdot 1 \\
14 \cdot 6 \\
15 \cdot 3 \\
15 \cdot 8 \\
16 \cdot 4 \\
17 \cdot 6 \\
18 \cdot 8 \\
20 \cdot 1 \\
21 \cdot 4 \\
22 \cdot 9 \\
24 \cdot 4 \\
26 \cdot 0 \\
27 \cdot 7 \\
29 \cdot 3 \\
31 \cdot 2\end{array}$ & $\begin{array}{c}4 \cdot 35 \\
6 \cdot 90 \\
9 \cdot 08 \\
10 \cdot 64 \\
11 \cdot 8 \\
12 \cdot 7 \\
13 \cdot 5 \\
14 \cdot 3 \\
14 \cdot 9 \\
15 \cdot 5 \\
16 \cdot 3 \\
16 \cdot 9 \\
17 \cdot 6 \\
18 \cdot 9 \\
20 \cdot 3 \\
21 \cdot 8 \\
23 \cdot 3 \\
25 \cdot 0 \\
26 \cdot 8 \\
28 \cdot 5 \\
30 \cdot 6 \\
32 \cdot 6 \\
35 \cdot 0\end{array}$ & \multirow[t]{2}{*}{$\begin{array}{c}6 \cdot 0 \\
9 \cdot 8 \\
13 \cdot 1 \\
15 \cdot 4 \\
17 \cdot 1 \\
18 \cdot 4 \\
19 \cdot 6 \\
20 \cdot 7 \\
21 \cdot 6 \\
22 \cdot 4 \\
23 \cdot 5 \\
24 \cdot 2 \\
25 \cdot 3 \\
26 \cdot 9 \\
28 \cdot 8 \\
30 \cdot 4 \\
32 \cdot 3 \\
34 \cdot 1 \\
36 \cdot 0 \\
38 \cdot 0 \\
39 \cdot 9 \\
42 \cdot 0 \\
\text { See Table } \\
\text { VIB }\end{array}$} \\
\hline 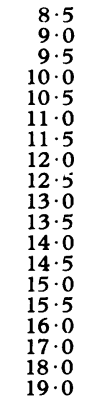 & $\begin{array}{l}20 \cdot 2 \\
21 \cdot 0 \\
21 \cdot 8 \\
22 \cdot 7 \\
23 \cdot 6 \\
24 \cdot 7 \\
26 \cdot 2 \\
27 \cdot 8 \\
29 \cdot 7 \\
32 \cdot 0 \\
34 \cdot 5 \\
37 \cdot 0 \\
39 \cdot 5 \\
41 \cdot 7 \\
43 \cdot 5 \\
44 \cdot 6 \\
45 \cdot 7 \\
46 \cdot 0 \\
46 \cdot 1\end{array}$ & $\begin{array}{l}21 \cdot 9 \\
23 \cdot 0 \\
24 \cdot 0 \\
25 \cdot 1 \\
26 \cdot 4 \\
27 \cdot 8 \\
29 \cdot 6 \\
31 \cdot 6 \\
33 \cdot 9 \\
36 \cdot 3 \\
38 \cdot 7 \\
41 \cdot 2 \\
43 \cdot 3 \\
45 \cdot 1 \\
46 \cdot 6 \\
47 \cdot 6 \\
48 \cdot 6 \\
48 \cdot 8 \\
4 \cdot 89\end{array}$ & $\begin{array}{l}24 \cdot 0 \\
25 \cdot 2 \\
26 \cdot 4 \\
27 \cdot 7 \\
29 \cdot 2 \\
31 \cdot 0 \\
33 \cdot 2 \\
35 \cdot 5 \\
38 \cdot 0 \\
40 \cdot 7 \\
43 \cdot 3 \\
45 \cdot 5 \\
47 \cdot 4 \\
49 \cdot 0 \\
50 \cdot 2 \\
51 \cdot 0 \\
51 \cdot 9 \\
52 \cdot 1 \\
52 \cdot 2\end{array}$ & $\begin{array}{l}26 \cdot 4 \\
27 \cdot 7 \\
29 \cdot 3 \\
31 \cdot 1 \\
33 \cdot 0 \\
35 \cdot 2 \\
37 \cdot 7 \\
40 \cdot 5 \\
43 \cdot 1 \\
45 \cdot 8 \\
48 \cdot 6 \\
51 \cdot 0 \\
52 \cdot 9 \\
54 \cdot 4 \\
55 \cdot 2 \\
55 \cdot 8 \\
56 \cdot 4 \\
56 \cdot 6 \\
56 \cdot 7\end{array}$ & $\begin{array}{l}29 \cdot 5 \\
31 \cdot 4 \\
33 \cdot 4 \\
35 \cdot 7 \\
38 \cdot 3 \\
41 \cdot 0 \\
43 \cdot 7 \\
46 \cdot 7 \\
49 \cdot 5 \\
52 \cdot 3 \\
54 \cdot 8 \\
57 \cdot 0 \\
58 \cdot 6 \\
59 \cdot 8 \\
60 \cdot 6 \\
61 \cdot 1 \\
61 \cdot 6 \\
61 \cdot 8 \\
61 \cdot 9\end{array}$ & $\begin{array}{l}33 \cdot 2 \\
35 \cdot 4 \\
38 \cdot 0 \\
41 \cdot 0 \\
44 \cdot 1 \\
47 \cdot 7 \\
51 \cdot 2 \\
54 \cdot 7 \\
57 \cdot 6 \\
60 \cdot 0 \\
62 \cdot 3 \\
63 \cdot 9 \\
65 \cdot 3 \\
66 \cdot 3 \\
67 \cdot 1 \\
67 \cdot 5 \\
67 \cdot 9 \\
68 \cdot 0 \\
68 \cdot 1\end{array}$ & $\begin{array}{l}37 \cdot 7 \\
40 \cdot 6 \\
43 \cdot 8 \\
47 \cdot 7 \\
51 \cdot 7 \\
55 \cdot 7 \\
59 \cdot 6 \\
63 \cdot 3 \\
66 \cdot 5 \\
69 \cdot 3 \\
71 \cdot 1 \\
72 \cdot 3 \\
73 \cdot 2 \\
73 \cdot 7 \\
74 \cdot 1 \\
74 \cdot 5 \\
74 \cdot 9 \\
75 \cdot 0 \\
75 \cdot 1\end{array}$ & \\
\hline
\end{tabular}

For source of data and method of construction, see text.

TABLE VA

Individual-type (Longitudinal) Standards for Height Attained, Boys

\begin{tabular}{|c|c|c|c|c|c|c|c|c|c|}
\hline \multirow{2}{*}{ Age (yr.) } & \multicolumn{7}{|c|}{ Centiles (cm.) } & \multirow{2}{*}{$\underset{\text { (estimate) }}{\mathrm{SD}}$} & \multirow{2}{*}{$\begin{array}{c}\text { 50th Centile } \\
\text { as \% Adult } \\
\text { Height }\end{array}$} \\
\hline & $3 r d$ & 10 th & 25th & 50th & 75 th & 90th & 97th & & \\
\hline $\begin{array}{l}10 \cdot 0 \\
10.5 \\
11 \cdot 0 \\
11.5 \\
12 \cdot 0 \\
12 \cdot 5 \\
13.0 \\
13.5 \\
14 \cdot 0 \\
14 \cdot 5 \\
15 \cdot 0 \\
15 \cdot 5 \\
16 \cdot 0 \\
16 \cdot 5 \\
17 \cdot 0 \\
17.5 \\
18 \cdot 0\end{array}$ & $\begin{array}{l}125 \cdot 2 \\
127 \cdot 6 \\
130 \cdot 0 \\
132 \cdot 3 \\
134 \cdot 7 \\
137 \cdot 2 \\
139 \cdot 9 \\
143 \cdot 3 \\
148 \cdot 3 \\
152 \cdot 9 \\
156 \cdot 3 \\
158 \cdot 6 \\
160 \cdot 2 \\
161 \cdot 2 \\
161 \cdot 8 \\
162 \cdot 1 \\
162 \cdot 2\end{array}$ & $\begin{array}{l}128 \cdot 9 \\
131 \cdot 4 \\
133 \cdot 8 \\
136 \cdot 2 \\
138 \cdot 6 \\
141 \cdot 1 \\
143 \cdot 8 \\
147 \cdot 3 \\
152 \cdot 2 \\
156 \cdot 8 \\
160 \cdot 2 \\
162 \cdot 6 \\
164 \cdot 2 \\
165 \cdot 2 \\
165 \cdot 8 \\
166 \cdot 1 \\
166 \cdot 2\end{array}$ & $\begin{array}{l}132 \cdot 7 \\
135 \cdot 2 \\
137 \cdot 7 \\
140 \cdot 1 \\
142 \cdot 5 \\
145 \cdot 1 \\
147 \cdot 8 \\
151 \cdot 2 \\
156 \cdot 2 \\
160 \cdot 8 \\
164 \cdot 2 \\
166 \cdot 6 \\
168 \cdot 2 \\
169 \cdot 2 \\
169 \cdot 8 \\
170 \cdot 1 \\
170 \cdot 2\end{array}$ & $\begin{array}{l}136 \cdot 9 \\
139 \cdot 4 \\
142 \cdot 0 \\
144 \cdot 5 \\
146 \cdot 9 \\
149 \cdot 4 \\
152 \cdot 2 \\
155 \cdot 7 \\
160 \cdot 6 \\
165 \cdot 3 \\
168 \cdot 7 \\
171 \cdot 1 \\
172 \cdot 7 \\
173 \cdot 7 \\
174 \cdot 3 \\
174 \cdot 6 \\
174 \cdot 7\end{array}$ & $\begin{array}{l}141 \cdot 1 \\
143 \cdot 7 \\
146 \cdot 3 \\
148 \cdot 8 \\
151 \cdot 3 \\
153 \cdot 9 \\
156 \cdot 7 \\
160 \cdot 1 \\
165 \cdot 1 \\
169 \cdot 7 \\
173 \cdot 2 \\
175 \cdot 5 \\
177 \cdot 1 \\
178 \cdot 2 \\
178 \cdot 8 \\
179 \cdot 1 \\
179 \cdot 2\end{array}$ & $\begin{array}{l}144 \cdot 8 \\
147 \cdot 5 \\
150 \cdot 1 \\
152 \cdot 7 \\
155 \cdot 2 \\
157 \cdot 8 \\
160 \cdot 6 \\
164 \cdot 1 \\
169 \cdot 1 \\
173 \cdot 7 \\
177 \cdot 2 \\
179 \cdot 5 \\
181 \cdot 1 \\
182 \cdot 2 \\
182 \cdot 8 \\
183 \cdot 1 \\
183 \cdot 2\end{array}$ & $\begin{array}{l}148 \cdot 5 \\
151 \cdot 3 \\
154 \cdot 0 \\
156 \cdot 6 \\
159 \cdot 1 \\
161 \cdot 7 \\
164 \cdot 6 \\
168 \cdot 0 \\
173 \cdot 1 \\
177 \cdot 7 \\
181 \cdot 1 \\
183 \cdot 5 \\
185 \cdot 1 \\
186 \cdot 2 \\
186 \cdot 8 \\
187 \cdot 1 \\
187 \cdot 2\end{array}$ & $\begin{array}{l}6 \cdot 20 \\
6 \cdot 29 \\
6 \cdot 37 \\
6 \cdot 44 \\
6 \cdot 48 \\
6 \cdot 52 \\
6 \cdot 55 \\
6 \cdot 57 \\
6 \cdot 59 \\
6 \cdot 60 \\
6 \cdot 61 \\
6 \cdot 62 \\
6 \cdot 63 \\
6 \cdot 64 \\
6 \cdot 65 \\
6 \cdot 65 \\
6 \cdot 65\end{array}$ & $\begin{array}{r}78 \cdot 4 \\
79 \cdot 8 \\
81 \cdot 3 \\
82 \cdot 7 \\
84 \cdot 1 \\
85 \cdot 5 \\
87 \cdot 1 \\
89 \cdot 1 \\
92 \cdot 0 \\
94 \cdot 6 \\
96 \cdot 6 \\
97 \cdot 9 \\
98 \cdot 8 \\
99 \cdot 4 \\
99 \cdot 8 \\
99 \cdot 9 \\
100 \cdot 0\end{array}$ \\
\hline
\end{tabular}

For source of data and method of construction, see text. Before age 10 the figures are identical with those of Table IIIA. 
Height, Weight, Height Velocity, Weight Velocity: British Children, 1965

TABLE VB

Individual-type (Longitudinal) Standards for Height Attained, Girls

\begin{tabular}{|c|c|c|c|c|c|c|c|c|c|}
\hline \multirow{2}{*}{ Age (yr.) } & \multicolumn{7}{|c|}{ Centiles (cm.) } & \multirow{2}{*}{$\underset{\text { (estimate) }}{\mathrm{SD}}$} & \multirow{2}{*}{$\begin{array}{c}\text { 50th Centile } \\
\text { as \% Adult } \\
\text { Height }\end{array}$} \\
\hline & $3 \mathrm{rd}$ & 10 th & 25 th & 50th & 75th & 90th & 97th & & \\
\hline $\begin{array}{r}8 \cdot 0 \\
8.5 \\
9.0 \\
9.5 \\
10.0 \\
10.5 \\
11.0 \\
11.5 \\
12.0 \\
12.5 \\
13.0 \\
13.5 \\
14.0 \\
14.5 \\
15.0 \\
15.5 \\
16.0\end{array}$ & $\begin{array}{l}114 \cdot 2 \\
116 \cdot 9 \\
119 \cdot 5 \\
122 \cdot 1 \\
124 \cdot 8 \\
127 \cdot 5 \\
130 \cdot 5 \\
134 \cdot 0 \\
138 \cdot 2 \\
142 \cdot 3 \\
145 \cdot 5 \\
147 \cdot 7 \\
149 \cdot 1 \\
150 \cdot 0 \\
150 \cdot 6 \\
150 \cdot 8 \\
150 \cdot 9\end{array}$ & $\begin{array}{l}117 \cdot 7 \\
120 \cdot 3 \\
123 \cdot 0 \\
125 \cdot 7 \\
128 \cdot 3 \\
131 \cdot 1 \\
134 \cdot 0 \\
137 \cdot 6 \\
141 \cdot 8 \\
145 \cdot 9 \\
149 \cdot 1 \\
151 \cdot 3 \\
152 \cdot 7 \\
153 \cdot 6 \\
154 \cdot 2 \\
154 \cdot 4 \\
154 \cdot 5\end{array}$ & $\begin{array}{l}121 \cdot 2 \\
123 \cdot 9 \\
126 \cdot 5 \\
129 \cdot 3 \\
131 \cdot 9 \\
134 \cdot 7 \\
137 \cdot 7 \\
141 \cdot 2 \\
145 \cdot 4 \\
149 \cdot 6 \\
152 \cdot 7 \\
154 \cdot 9 \\
156 \cdot 4 \\
157 \cdot 3 \\
157 \cdot 8 \\
158 \cdot 1 \\
158 \cdot 2\end{array}$ & $\begin{array}{l}125 \cdot 0 \\
127 \cdot 8 \\
130 \cdot 5 \\
133 \cdot 2 \\
136 \cdot 0 \\
138 \cdot 7 \\
141 \cdot 7 \\
145 \cdot 2 \\
149 \cdot 5 \\
153 \cdot 6 \\
156 \cdot 8 \\
159 \cdot 0 \\
160 \cdot 4 \\
161 \cdot 3 \\
161 \cdot 9 \\
162 \cdot 1 \\
162 \cdot 2\end{array}$ & $\begin{array}{l}128 \cdot 9 \\
131 \cdot 7 \\
134 \cdot 5 \\
137 \cdot 2 \\
140 \cdot 0 \\
142 \cdot 7 \\
145 \cdot 7 \\
149 \cdot 2 \\
153 \cdot 5 \\
157 \cdot 7 \\
160 \cdot 8 \\
163 \cdot 0 \\
164 \cdot 4 \\
165 \cdot 4 \\
165 \cdot 9 \\
166 \cdot 2 \\
166 \cdot 2\end{array}$ & $\begin{array}{l}132 \cdot 4 \\
135 \cdot 2 \\
138 \cdot 0 \\
140 \cdot 8 \\
143 \cdot 6 \\
146 \cdot 3 \\
149 \cdot 3 \\
152 \cdot 9 \\
157 \cdot 1 \\
161 \cdot 3 \\
164 \cdot 5 \\
166 \cdot 7 \\
168 \cdot 1 \\
169 \cdot 0 \\
169 \cdot 6 \\
169 \cdot 8 \\
169 \cdot 9\end{array}$ & $\begin{array}{l}135 \cdot 8 \\
138 \cdot 7 \\
141 \cdot 5 \\
144 \cdot 3 \\
147 \cdot 1 \\
149 \cdot 9 \\
152 \cdot 9 \\
156 \cdot 5 \\
160 \cdot 7 \\
164 \cdot 9 \\
168 \cdot 1 \\
170 \cdot 3 \\
171 \cdot 7 \\
172 \cdot 6 \\
173 \cdot 1 \\
173 \cdot 4 \\
173 \cdot 5\end{array}$ & $\begin{array}{l}5 \cdot 73 \\
5 \cdot 80 \\
5 \cdot 86 \\
5 \cdot 90 \\
5 \cdot 94 \\
5 \cdot 95 \\
5 \cdot 96 \\
5 \cdot 97 \\
5 \cdot 98 \\
5 \cdot 99 \\
6 \cdot 00 \\
6 \cdot 00 \\
6 \cdot 00 \\
6 \cdot 00 \\
6 \cdot 00 \\
6 \cdot 00 \\
6 \cdot 00\end{array}$ & $\begin{array}{r}77 \cdot 1 \\
78 \cdot 8 \\
80 \cdot 5 \\
82 \cdot 2 \\
83 \cdot 8 \\
85 \cdot 5 \\
87 \cdot 3 \\
89 \cdot 5 \\
92 \cdot 2 \\
94 \cdot 7 \\
96 \cdot 7 \\
98 \cdot 0 \\
98 \cdot 9 \\
99 \cdot 5 \\
99 \cdot 8 \\
99 \cdot 9 \\
100 \cdot 0\end{array}$ \\
\hline
\end{tabular}

For source of data and method of construction, see text. Before age 8 the figures are identical with those of Table IIIB.

TABLE VIA

Individual-type (Longitudinal) Standards for Weight Attained, Boys

\begin{tabular}{|c|c|c|c|c|c|c|c|c|}
\hline \multirow{2}{*}{ Age (yr.) } & \multicolumn{7}{|c|}{ Centiles (kg.) } & \multirow{2}{*}{$\begin{array}{c}\text { 50th Centile } \\
\text { as \% } 18 \text { yr. } \\
\text { Weight }\end{array}$} \\
\hline & $3 r d$ & 10 th & 25 th & 50 th & 75th & 90th & 97th & \\
\hline $\begin{array}{l}10.0 \\
10.5 \\
11.0 \\
11.5 \\
12.0 \\
12.5 \\
13.0 \\
13.5 \\
14.0 \\
14.5 \\
15.0 \\
15.5 \\
16.0 \\
16.5 \\
17.0 \\
18.0\end{array}$ & $\begin{array}{l}23 \cdot 0 \\
24 \cdot 0 \\
25 \cdot 1 \\
26 \cdot 1 \\
27 \cdot 2 \\
28 \cdot 4 \\
29 \cdot 7 \\
32 \cdot 3 \\
36 \cdot 1 \\
40 \cdot 1 \\
43 \cdot 4 \\
45 \cdot 5 \\
47 \cdot 2 \\
48 \cdot 2 \\
49 \cdot 1 \\
50 \cdot 0\end{array}$ & $\begin{array}{l}25 \cdot 2 \\
26 \cdot 4 \\
27 \cdot 5 \\
28 \cdot 6 \\
29 \cdot 8 \\
31 \cdot 0 \\
32 \cdot 6 \\
35 \cdot 3 \\
39 \cdot 4 \\
43 \cdot 6 \\
46 \cdot 9 \\
49 \cdot 1 \\
50 \cdot 7 \\
51 \cdot 8 \\
52 \cdot 6 \\
53 \cdot 5\end{array}$ & $\begin{array}{l}27 \cdot 5 \\
28 \cdot 6 \\
30 \cdot 0 \\
31 \cdot 2 \\
32 \cdot 6 \\
34 \cdot 0 \\
36 \cdot 0 \\
39 \cdot 2 \\
43 \cdot 4 \\
47 \cdot 7 \\
51 \cdot 1 \\
53 \cdot 3 \\
55 \cdot 0 \\
56 \cdot 1 \\
56 \cdot 8 \\
57 \cdot 8\end{array}$ & $\begin{array}{l}30 \cdot 3 \\
31 \cdot 6 \\
33 \cdot 3 \\
34 \cdot 8 \\
36 \cdot 5 \\
38 \cdot 3 \\
40 \cdot 7 \\
44 \cdot 0 \\
48 \cdot 4 \\
52 \cdot 9 \\
56 \cdot 3 \\
58 \cdot 5 \\
60 \cdot 2 \\
61 \cdot 2 \\
62 \cdot 1 \\
63 \cdot 0\end{array}$ & $\begin{array}{l}33 \cdot 6 \\
35 \cdot 3 \\
37 \cdot 2 \\
39 \cdot 0 \\
41 \cdot 0 \\
43 \cdot 0 \\
45 \cdot 5 \\
49 \cdot 2 \\
53 \cdot 4 \\
57 \cdot 8 \\
61 \cdot 3 \\
63 \cdot 6 \\
65 \cdot 2 \\
66 \cdot 3 \\
67 \cdot 1 \\
68 \cdot 0\end{array}$ & $\begin{array}{l}37 \cdot 3 \\
39 \cdot 3 \\
41 \cdot 5 \\
43 \cdot 7 \\
46 \cdot 0 \\
48 \cdot 4 \\
51 \cdot 2 \\
54 \cdot 9 \\
59 \cdot 5 \\
64 \cdot 3 \\
67 \cdot 8 \\
70 \cdot 1 \\
71 \cdot 7 \\
72 \cdot 7 \\
73 \cdot 6 \\
74 \cdot 5\end{array}$ & $\begin{array}{l}43 \cdot 3 \\
45 \cdot 7 \\
48 \cdot 0 \\
50 \cdot 5 \\
52 \cdot 9 \\
55 \cdot 5 \\
58 \cdot 5 \\
62 \cdot 2 \\
66 \cdot 3 \\
70 \cdot 8 \\
74 \cdot 3 \\
76 \cdot 5 \\
78 \cdot 2 \\
79 \cdot 3 \\
80 \cdot 1 \\
81 \cdot 0\end{array}$ & $\begin{array}{r}48 \cdot 1 \\
50 \cdot 2 \\
52 \cdot 9 \\
55 \cdot 2 \\
57 \cdot 9 \\
60 \cdot 8 \\
64 \cdot 6 \\
69 \cdot 4 \\
76 \cdot 8 \\
84 \cdot 0 \\
89 \cdot 4 \\
92 \cdot 9 \\
95 \cdot 6 \\
97 \cdot 1 \\
98 \cdot 6 \\
100 \cdot 0\end{array}$ \\
\hline
\end{tabular}

For source of data and method of construction, see text. Before age 10 the figures are identical with those of Table IVA.

TABLE VIB

Individual-type (Longitudinal) Standards for Weight Attained, Girls

\begin{tabular}{|c|c|c|c|c|c|c|c|c|}
\hline \multirow{2}{*}{ Age (yr.) } & \multicolumn{7}{|c|}{ Centiles (kg.) } & \multirow{2}{*}{$\begin{array}{c}50 \text { th Centile } \\
\text { as \% } 18 \mathrm{yr} . \\
\text { Weight }\end{array}$} \\
\hline & 3rd & 10th & 25 th & 50th & 75th & 90th & 97th & \\
\hline $\begin{array}{r}8 \cdot 0 \\
8.5 \\
9 \cdot 0 \\
9.5 \\
10 \cdot 0 \\
10.5 \\
11 \cdot 0 \\
11 \cdot 5 \\
12 \cdot 0 \\
12.5 \\
13 \cdot 0 \\
13.5 \\
14 \cdot 0 \\
14.5 \\
15 \cdot 0 \\
16 \cdot 0 \\
17.0 \\
18 \cdot 0\end{array}$ & $\begin{array}{l}19 \cdot 4 \\
20 \cdot 2 \\
21 \cdot 0 \\
21 \cdot 8 \\
22 \cdot 7 \\
23 \cdot 7 \\
24 \cdot 9 \\
26 \cdot 7 \\
29 \cdot 4 \\
33 \cdot 0 \\
37 \cdot 3 \\
40 \cdot 2 \\
42 \cdot 5 \\
43 \cdot 8 \\
44 \cdot 7 \\
45 \cdot 5 \\
45 \cdot 9 \\
46 \cdot 1\end{array}$ & $\begin{array}{l}21 \cdot 1 \\
21 \cdot 9 \\
23 \cdot 0 \\
24 \cdot 0 \\
25 \cdot 2 \\
26 \cdot 3 \\
27 \cdot 7 \\
29 \cdot 7 \\
32 \cdot 3 \\
35 \cdot 8 \\
40 \cdot 0 \\
43 \cdot 1 \\
45 \cdot 2 \\
46 \cdot 5 \\
47 \cdot 5 \\
48 \cdot 3 \\
48 \cdot 6 \\
48 \cdot 8\end{array}$ & $\begin{array}{l}22 \cdot 9 \\
24 \cdot 0 \\
25 \cdot 2 \\
26 \cdot 4 \\
27 \cdot 7 \\
29 \cdot 0 \\
30 \cdot 7 \\
32 \cdot 8 \\
35 \cdot 5 \\
39 \cdot 0 \\
43 \cdot 3 \\
46 \cdot 2 \\
48 \cdot 5 \\
49 \cdot 8 \\
50 \cdot 7 \\
51 \cdot 5 \\
51 \cdot 9 \\
52 \cdot 1\end{array}$ & $\begin{array}{l}25 \cdot 1 \\
26 \cdot 4 \\
27 \cdot 7 \\
29 \cdot 2 \\
30 \cdot 7 \\
32 \cdot 3 \\
34 \cdot 2 \\
36 \cdot 4 \\
39 \cdot 6 \\
43 \cdot 6 \\
47 \cdot 8 \\
50 \cdot 7 \\
53 \cdot 0 \\
54 \cdot 3 \\
55 \cdot 2 \\
56 \cdot 0 \\
56 \cdot 4 \\
56 \cdot 6\end{array}$ & $\begin{array}{l}28 \cdot 0 \\
29 \cdot 5 \\
31 \cdot 3 \\
33 \cdot 0 \\
35 \cdot 0 \\
36 \cdot 9 \\
39 \cdot 0 \\
41 \cdot 5 \\
44 \cdot 8 \\
48 \cdot 8 \\
53 \cdot 0 \\
55 \cdot 9 \\
58 \cdot 2 \\
59 \cdot 6 \\
60 \cdot 5 \\
61 \cdot 3 \\
61 \cdot 6 \\
61 \cdot 8\end{array}$ & $\begin{array}{l}31 \cdot 2 \\
33 \cdot 1 \\
35 \cdot 1 \\
37 \cdot 4 \\
39 \cdot 9 \\
42 \cdot 1 \\
44 \cdot 7 \\
47 \cdot 5 \\
50 \cdot 8 \\
55 \cdot 1 \\
59 \cdot 3 \\
62 \cdot 3 \\
64 \cdot 5 \\
65 \cdot 8 \\
66 \cdot 7 \\
67 \cdot 5 \\
67 \cdot 9 \\
68 \cdot 1\end{array}$ & $\begin{array}{l}35 \cdot 0 \\
37 \cdot 3 \\
39 \cdot 7 \\
42 \cdot 3 \\
45 \cdot 1 \\
47 \cdot 7 \\
50 \cdot 6 \\
53 \cdot 8 \\
57 \cdot 6 \\
61 \cdot 9 \\
66 \cdot 3 \\
69 \cdot 3 \\
71 \cdot 5 \\
72 \cdot 9 \\
73 \cdot 7 \\
74 \cdot 5 \\
74 \cdot 9 \\
75 \cdot 1\end{array}$ & $\begin{array}{r}44 \cdot 3 \\
46 \cdot 6 \\
48 \cdot 9 \\
51 \cdot 6 \\
54 \cdot 2 \\
57 \cdot 1 \\
60 \cdot 4 \\
64 \cdot 3 \\
70 \cdot 0 \\
77 \cdot 0 \\
84 \cdot 4 \\
89 \cdot 6 \\
93 \cdot 6 \\
95 \cdot 9 \\
97 \cdot 5 \\
98 \cdot 9 \\
99 \cdot 6 \\
100 \cdot 0\end{array}$ \\
\hline
\end{tabular}

For source of data and method of construction, see text. Before age 8 the figures are identical with those of Table IVB. 
TABLE VIIA

Whole-year Velocity Standards for Height of Boys (chronological age based)

\begin{tabular}{|c|c|c|c|c|c|c|c|c|}
\hline \multirow{2}{*}{ Age (yr.) } & \multicolumn{7}{|c|}{ Centiles (cm./yr.) } & \multirow{2}{*}{ SD } \\
\hline & 3rd & 10th & 25 th & 50 th & 75th & 90th & 97th & \\
\hline 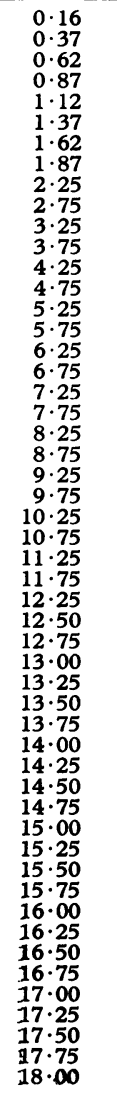 & $\begin{array}{r}13 \cdot 42 \\
10 \cdot 25 \\
8 \cdot 51 \\
7 \cdot 45 \\
6 \cdot 50 \\
6 \cdot 02 \\
5 \cdot 72 \\
5 \cdot 41 \\
5 \cdot 20 \\
4 \cdot 92 \\
4 \cdot 73 \\
4 \cdot 62 \\
4 \cdot 46 \\
4 \cdot 37 \\
4 \cdot 26 \\
4 \cdot 17 \\
4 \cdot 14 \\
4 \cdot 06 \\
4 \cdot 01 \\
3 \cdot 97 \\
3 \cdot 87 \\
3 \cdot 71 \\
3 \cdot 53 \\
3 \cdot 34 \\
3 \cdot 16 \\
3 \cdot 03 \\
2 \cdot 95 \\
2 \cdot 92 \\
2 \cdot 95 \\
3 \cdot 00 \\
3 \cdot 08 \\
3 \cdot 18 \\
3 \cdot 27 \\
3 \cdot 33 \\
3 \cdot 36 \\
3 \cdot 28 \\
2 \cdot 80 \\
2 \cdot 09 \\
1 \cdot 47 \\
1 \cdot 06 \\
0 \cdot 77 \\
0 \cdot 54 \\
0 \cdot 39 \\
0 \cdot 26\end{array}$ & $\begin{array}{r}14 \cdot 88 \\
11 \cdot 60 \\
9 \cdot 72 \\
8 \cdot 61 \\
7 \cdot 58 \\
7 \cdot 03 \\
6 \cdot 64 \\
6 \cdot 24 \\
5 \cdot 96 \\
5 \cdot 63 \\
5 \cdot 40 \\
5 \cdot 25 \\
5 \cdot 07 \\
4 \cdot 94 \\
4 \cdot 81 \\
4 \cdot 70 \\
4 \cdot 65 \\
4 \cdot 55 \\
4 \cdot 49 \\
4 \cdot 43 \\
4 \cdot 32 \\
4 \cdot 20 \\
4 \cdot 05 \\
3 \cdot 90 \\
3 \cdot 75 \\
3 \cdot 64 \\
3 \cdot 62 \\
3 \cdot 66 \\
3 \cdot 75 \\
3 \cdot 87 \\
4 \cdot 02 \\
4 \cdot 21 \\
4 \cdot 43 \\
4 \cdot 57 \\
4 \cdot 58 \\
4 \cdot 41 \\
4 \cdot 01 \\
3 \cdot 49 \\
2 \cdot 87 \\
2 \cdot 32 \\
1 \cdot 82 \\
1 \cdot 40 \\
1 \cdot 07 \\
0 \cdot 80 \\
0 \cdot 60 \\
0 \cdot 44 \\
0 \cdot 34 \\
0 \cdot 26 \\
0 \cdot 20\end{array}$ & $\begin{array}{r}16 \cdot 36 \\
12 \cdot 97 \\
10 \cdot 94 \\
9 \cdot 79 \\
8 \cdot 68 \\
8 \cdot 06 \\
7 \cdot 57 \\
7 \cdot 08 \\
6 \cdot 74 \\
6 \cdot 36 \\
6 \cdot 08 \\
5 \cdot 89 \\
5 \cdot 68 \\
5 \cdot 53 \\
5 \cdot 38 \\
5 \cdot 24 \\
5 \cdot 16 \\
5 \cdot 05 \\
4 \cdot 97 \\
4 \cdot 89 \\
4 \cdot 78 \\
4 \cdot 67 \\
4 \cdot 56 \\
4 \cdot 47 \\
4 \cdot 38 \\
4 \cdot 36 \\
4 \cdot 42 \\
4 \cdot 52 \\
4 \cdot 64 \\
4 \cdot 80 \\
5 \cdot 10 \\
5 \cdot 40 \\
5 \cdot 68 \\
5 \cdot .89 \\
5 \cdot 90 \\
5 \cdot 65 \\
5 \cdot 26 \\
4 \cdot .76 \\
4 \cdot 22 \\
3 \cdot 60 \\
3 \cdot .02 \\
2 \cdot 48 \\
2 \cdot 02 \\
1 \cdot 60 \\
1 \cdot 30 \\
1 \cdot 03 \\
0 \cdot 83 \\
0 \cdot 69 \\
0 \cdot 57 \\
0 \cdot 47\end{array}$ & $\begin{array}{r}40 \cdot 00 \\
30 \cdot 00 \\
18 \cdot 00 \\
14 \cdot 50 \\
12 \cdot 30 \\
11 \cdot 10 \\
9 \cdot 90 \\
9 \cdot 20 \\
8 \cdot 60 \\
8 \cdot 02 \\
7 \cdot 60 \\
7 \cdot 16 \\
6 \cdot \cdot 44 \\
6 \cdot 60 \\
6 \cdot 36 \\
6 \cdot 18 \\
6 \cdot 00 \\
5 \cdot 84 \\
5 \cdot 74 \\
5 \cdot 60 \\
5 \cdot 50 \\
5 \cdot 40 \\
5 \cdot 30 \\
5 \cdot 20 \\
5 \cdot 12 \\
5 \cdot 02 \\
4 \cdot 93 \\
4 \cdot 93 \\
5 \cdot 23 \\
5 \cdot 54 \\
5 \cdot 90 \\
6 \cdot 30 \\
6 \cdot 70 \\
7 \cdot 03 \\
7 \cdot 27 \\
7 \cdot 30 \\
7 \cdot 10 \\
6 \cdot 77 \\
6 \cdot 22 \\
5 \cdot 84 \\
5 \cdot 34 \\
4 \cdot 84 \\
4 \cdot 36 \\
3 \cdot 86 \\
3 \cdot 32 \\
2 \cdot 80 \\
2 \cdot 31 \\
1 \cdot 88 \\
1 \cdot 50 \\
1 \cdot 20 \\
0 \cdot 95 \\
0 \cdot 74\end{array}$ & $\begin{array}{r}19 \cdot 64 \\
16 \cdot 03 \\
13 \cdot 66 \\
12 \cdot 41 \\
10 \cdot 94 \\
10 \cdot 34 \\
9 \cdot 63 \\
8 \cdot 96 \\
8 \cdot 46 \\
7 \cdot 96 \\
7 \cdot 60 \\
7 \cdot 31 \\
7 \cdot 04 \\
6 \cdot 83 \\
6 \cdot 62 \\
6 \cdot 44 \\
6 \cdot 32 \\
6 \cdot 15 \\
6 \cdot 03 \\
5 \cdot 91 \\
5 \cdot 82 \\
5 \cdot 72 \\
5 \cdot 66 \\
5 \cdot 62 \\
5 \cdot 68 \\
5 \cdot 93 \\
6 \cdot 70 \\
7 \cdot 20 \\
7 \cdot 68 \\
8 \cdot 13 \\
8 \cdot 46 \\
8 \cdot 72 \\
8 \cdot 80 \\
8 \cdot 72 \\
8 \cdot 53 \\
8 \cdot 25 \\
7 \cdot 90 \\
7 \cdot 46 \\
6 \cdot 97 \\
6 \cdot 42 \\
5 \cdot 81 \\
5 \cdot 20 \\
4 \cdot 55 \\
3 \cdot 90 \\
3 \cdot 28 \\
2 \cdot 60 \\
2 \cdot 09 \\
1 \cdot 69 \\
1 \cdot 33 \\
1 \cdot 03\end{array}$ & $\begin{array}{r}21 \cdot 12 \\
17 \cdot 40 \\
14 \cdot 88 \\
13 \cdot 59 \\
12 \cdot 04 \\
11 \cdot 37 \\
10 \cdot 56 \\
9 \cdot 80 \\
9 \cdot 24 \\
8 \cdot 69 \\
8 \cdot 28 \\
7 \cdot 95 \\
7 \cdot 65 \\
7 \cdot 42 \\
7 \cdot 19 \\
6 \cdot 98 \\
6 \cdot 83 \\
6 \cdot 65 \\
6 \cdot 51 \\
6 \cdot 37 \\
6 \cdot 27 \\
6 \cdot 18 \\
6 \cdot 10 \\
6 \cdot 14 \\
6 \cdot 37 \\
6 \cdot 99 \\
8 \cdot 07 \\
8 \cdot 64 \\
9 \cdot 20 \\
9 \cdot 70 \\
9 \cdot 95 \\
10 \cdot 06 \\
10 \cdot 09 \\
10 \cdot 02 \\
9 \cdot 82 \\
9 \cdot 56 \\
9 \cdot 20 \\
8 \cdot 78 \\
8 \cdot 26 \\
7 \cdot 70 \\
7 \cdot 10 \\
6 \cdot 45 \\
5 \cdot 72 \\
5 \cdot 02 \\
4 \cdot 22 \\
3 \cdot 40 \\
2 \cdot 70 \\
2 \cdot 17 \\
1 \cdot 68 \\
1 \cdot 30\end{array}$ & 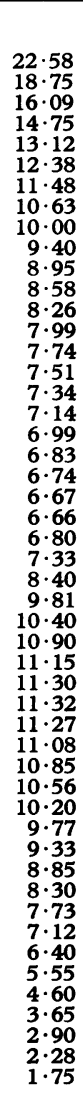 & $\begin{array}{l}2.43 \\
2.26 \\
2.02 \\
1.94 \\
1.81 \\
1.69 \\
1.53 \\
1.39 \\
1.28 \\
1.19 \\
1 \cdot 12 \\
1.06 \\
1.01 \\
0.96 \\
0.93 \\
0.89 \\
0.85 \\
0.82 \\
0.79 \\
0.76\end{array}$ \\
\hline
\end{tabular}

For source of data and method of construction, see text.

TABLE VIIB

Whole-year Velocity Standards for Height of Girls (chronological age based)

\begin{tabular}{|c|c|c|c|c|c|c|c|c|}
\hline \multirow{2}{*}{ Age (yr.) } & \multicolumn{7}{|c|}{ Centiles (cm./yr.) } & \multirow{2}{*}{ SD } \\
\hline & 3rd & 10th & 25th & 50th & 75th & 90th & 97th & \\
\hline $\begin{array}{l}0.16 \\
0.37 \\
0.62 \\
10.87 \\
1.12 \\
1.37 \\
1.62 \\
1.87 \\
2.25 \\
2.75 \\
3.25 \\
3.75 \\
.4 .25 \\
.4 .75 \\
5.25 \\
5.75 \\
.6 .25\end{array}$ & $\begin{array}{r}14.42 \\
11.65 \\
9.71 \\
8.15 \\
7.20 \\
6.42 \\
5.82 \\
5.51 \\
5.28 \\
4.98 \\
4.73 \\
4.62 \\
4.46 \\
4.37 \\
4.26\end{array}$ & $\begin{array}{r}15 \cdot 88 \\
13 \cdot 00 \\
10 \cdot 92 \\
9 \cdot 31 \\
8 \cdot 28 \\
7 \cdot 43 \\
6 \cdot 73 \\
6 \cdot 34 \\
6 \cdot 04 \\
5 \cdot 69 \\
5 \cdot 40 \\
5 \cdot 25 \\
5 \cdot 07 \\
4 \cdot 94 \\
4 \cdot 81\end{array}$ & $\begin{array}{r}17 \cdot 36 \\
14.37 \\
12.14 \\
10.49 \\
9 \cdot 38 \\
8.46 \\
7.67 \\
7 \cdot 18 \\
6 \cdot .82 \\
6 \cdot 42 \\
6 \cdot 08 \\
5 \cdot 89 \\
5 \cdot 68 \\
5 \cdot 53 \\
5 \cdot 38\end{array}$ & $\begin{array}{r}36.00 \\
26.00 \\
19.00 \\
15.90 \\
13.50 \\
11.80 \\
10.60 \\
9 \cdot 60 \\
8.70 \\
8.12 \\
7.68 \\
7.22 \\
6 \cdot 84 \\
6 \cdot 60 \\
6.36 \\
6 \cdot 18 \\
6.00\end{array}$ & $\begin{array}{c}20 \cdot 64 \\
17.43 \\
14 \cdot 86 \\
13 \cdot 11 \\
11 \cdot 82 \\
10 \cdot 74 \\
9 \cdot 73 \\
9 \cdot 06 \\
8 \cdot 54 \\
8 \cdot 02 \\
7 \cdot 60 \\
7 \cdot 31 \\
7 \cdot 04 \\
6 \cdot 83 \\
6 \cdot 62\end{array}$ & $\begin{array}{r}22 \cdot 12 \\
18 \cdot 80 \\
16 \cdot 08 \\
14 \cdot 29 \\
12 \cdot 92 \\
11 \cdot 77 \\
10 \cdot 66 \\
9 \cdot 90 \\
9 \cdot 32 \\
8 \cdot 75 \\
8 \cdot 28 \\
7 \cdot 95 \\
7 \cdot 65 \\
7 \cdot 42 \\
7 \cdot 19\end{array}$ & $\begin{array}{r}23 \cdot 58 \\
20 \cdot 15 \\
17 \cdot 29 \\
15 \cdot 45 \\
14 \cdot 00 \\
11 \cdot 78 \\
11 \cdot 58 \\
10 \cdot 73 \\
10 \cdot 08 \\
9 \cdot 46 \\
8 \cdot 95 \\
8 \cdot 58 \\
8 \cdot 26 \\
7 \cdot 99 \\
7 \cdot 74\end{array}$ & $\begin{array}{l}2.43 \\
2.26 \\
2.02 \\
1.94 \\
1.81 \\
1.69 \\
1.53 \\
1.39 \\
1.28 \\
1.19 \\
1.12 \\
1.06 \\
1.01 \\
0.96 \\
0.93\end{array}$ \\
\hline
\end{tabular}


Height, Weight, Height Velocity, Weight Velocity: British Children, 1965

TABLE VIIB-continued

Whole-year Velocity Standards for Height of Girls (chronological age based)

\begin{tabular}{|c|c|c|c|c|c|c|c|c|}
\hline \multirow{2}{*}{ Age (yr.) } & \multicolumn{7}{|c|}{ Centiles (cm./yr.) } & \multirow{2}{*}{ SD } \\
\hline & 3rd & 10th & 25 th & 50th & 75th & 90th & 97th & \\
\hline $\begin{array}{r}6 \cdot 75 \\
7 \cdot 25 \\
7 \cdot 75 \\
8 \cdot 25 \\
8 \cdot 75 \\
9 \cdot 25 \\
9 \cdot 75 \\
10 \cdot 25 \\
10 \cdot 75 \\
11 \cdot 00 \\
11 \cdot 25 \\
11 \cdot 50 \\
11 \cdot 75 \\
12 \cdot 00 \\
12 \cdot 25 \\
12 \cdot 50 \\
12 \cdot 75 \\
13 \cdot 00 \\
13 \cdot 25 \\
13 \cdot 50 \\
13 \cdot 75 \\
14 \cdot 00 \\
14 \cdot 25 \\
14 \cdot 50 \\
14 \cdot 75 \\
15 \cdot 00 \\
15 \cdot 25 \\
15 \cdot 50 \\
15 \cdot 75 \\
16 \cdot 00\end{array}$ & $\begin{array}{l}4 \cdot 17 \\
4 \cdot 07 \\
3 \cdot 90 \\
3 \cdot 71 \\
3 \cdot 56 \\
3 \cdot 43 \\
3 \cdot 35 \\
3 \cdot 30 \\
3 \cdot 30 \\
3 \cdot 32 \\
3 \cdot 35 \\
3 \cdot 36 \\
3 \cdot 39 \\
3 \cdot 41 \\
3 \cdot 30 \\
2 \cdot 84 \\
2 \cdot 30 \\
1 \cdot 68 \\
1 \cdot 20 \\
0.82 \\
0.52 \\
0.30\end{array}$ & $\begin{array}{l}4 \cdot 70 \\
4 \cdot 61 \\
4 \cdot 45 \\
4 \cdot 30 \\
4 \cdot 17 \\
4 \cdot 06 \\
4 \cdot 00 \\
4 \cdot 02 \\
4 \cdot 13 \\
4 \cdot 20 \\
4 \cdot 27 \\
4 \cdot 33 \\
4 \cdot 38 \\
4 \cdot 40 \\
4 \cdot 23 \\
3 \cdot 84 \\
3 \cdot 41 \\
2 \cdot 95 \\
2 \cdot 45 \\
1 \cdot 95 \\
1 \cdot 53 \\
1 \cdot 20 \\
0 \cdot 85 \\
0 \cdot 58 \\
0 \cdot 35\end{array}$ & $\begin{array}{l}5 \cdot 24 \\
5 \cdot 11 \\
4 \cdot 94 \\
4 \cdot 80 \\
4 \cdot 67 \\
4 \cdot 59 \\
4 \cdot 60 \\
4 \cdot 74 \\
4 \cdot 95 \\
5 \cdot 06 \\
5 \cdot 19 \\
5 \cdot 29 \\
5 \cdot 36 \\
5 \cdot 40 \\
5 \cdot 25 \\
4 \cdot 96 \\
4 \cdot 63 \\
4 \cdot 21 \\
3 \cdot 76 \\
3 \cdot 20 \\
2 \cdot 63 \\
2 \cdot 11 \\
1 \cdot 65 \\
1 \cdot 24 \\
0 \cdot 88 \\
0 \cdot 58 \\
0 \cdot 40 \\
0 \cdot 24\end{array}$ & $\begin{array}{l}5 \cdot 84 \\
5 \cdot 72 \\
5 \cdot 59 \\
5 \cdot 45 \\
5 \cdot 37 \\
5 \cdot 37 \\
5 \cdot 48 \\
5 \cdot 73 \\
6 \cdot 00 \\
6 \cdot 13 \\
6 \cdot 24 \\
6 \cdot 31 \\
6 \cdot 37 \\
6 \cdot 38 \\
6 \cdot 30 \\
6 \cdot 13 \\
5 \cdot 89 \\
5 \cdot 55 \\
5 \cdot 11 \\
4 \cdot 60 \\
4 \cdot 06 \\
3 \cdot 46 \\
2 \cdot 82 \\
2 \cdot 15 \\
1 \cdot 53 \\
1 \cdot 12 \\
0 \cdot 82 \\
0 \cdot 58 \\
0 \cdot 44 \\
0 \cdot 30\end{array}$ & $\begin{array}{l}6 \cdot 44 \\
6 \cdot 31 \\
6 \cdot 19 \\
6 \cdot 12 \\
6 \cdot 13 \\
6 \cdot 25 \\
6 \cdot 48 \\
6 \cdot 78 \\
7 \cdot 09 \\
7 \cdot 20 \\
7 \cdot 30 \\
7 \cdot 39 \\
7 \cdot 43 \\
7 \cdot 42 \\
7 \cdot 28 \\
7 \cdot 10 \\
6 \cdot 85 \\
6 \cdot 55 \\
6 \cdot 20 \\
5 \cdot 75 \\
5 \cdot 23 \\
4 \cdot 63 \\
3 \cdot 85 \\
3 \cdot 08 \\
2 \cdot 37 \\
1 \cdot 80 \\
1 \cdot 37 \\
1 \cdot 03 \\
0 \cdot 78 \\
0 \cdot 65\end{array}$ & $\begin{array}{l}6 \cdot 98 \\
6 \cdot 86 \\
6 \cdot 81 \\
6 \cdot 85 \\
7 \cdot 00 \\
7 \cdot 24 \\
7 \cdot 55 \\
7 \cdot 90 \\
8 \cdot 24 \\
8 \cdot 40 \\
8 \cdot 50 \\
8 \cdot 60 \\
8 \cdot 68 \\
8 \cdot 67 \\
8 \cdot 55 \\
8 \cdot 36 \\
8 \cdot 12 \\
7 \cdot 82 \\
7 \cdot 41 \\
6 \cdot 93 \\
6 \cdot 26 \\
5 \cdot 50 \\
4 \cdot 60 \\
3 \cdot 73 \\
2 \cdot 95 \\
2 \cdot 35 \\
1 \cdot 90 \\
1 \cdot 50 \\
1 \cdot 20 \\
0 \cdot 95\end{array}$ & $\begin{array}{l}7 \cdot 51 \\
7 \cdot 38 \\
7 \cdot 46 \\
7 \cdot 71 \\
8 \cdot 12 \\
8 \cdot 60 \\
9 \cdot 00 \\
9 \cdot 36 \\
9 \cdot 63 \\
9 \cdot 72 \\
9 \cdot 80 \\
9 \cdot 86 \\
9 \cdot 88 \\
9 \cdot 82 \\
9 \cdot 70 \\
9 \cdot 55 \\
9 \cdot 33 \\
9 \cdot 02 \\
8 \cdot 63 \\
8 \cdot 05 \\
7 \cdot 50 \\
6 \cdot 65 \\
5 \cdot 52 \\
4 \cdot 55 \\
3 \cdot 65 \\
3 \cdot 00 \\
2 \cdot 38 \\
1 \cdot 93 \\
1 \cdot 58 \\
1 \cdot 30\end{array}$ & 0.89 \\
\hline
\end{tabular}

For source of data and method of construction, see text.

TABLE VIIIA

Whole-year Velocity Standards for Weight of Boys (chronological age based)

\begin{tabular}{|c|c|c|c|c|c|c|c|}
\hline \multirow{2}{*}{ Age (yr.) } & \multicolumn{7}{|c|}{ Centiles (kg./yr.) } \\
\hline & 3rd & 10 th & 25th & 50th & 75th & 90th & 97th \\
\hline $\begin{array}{r}0 \cdot 10 \\
0.25 \\
0.50 \\
0.75 \\
1 \cdot 00 \\
1 \cdot 25 \\
1 \cdot 50 \\
1 \cdot 75 \\
2 \cdot 25 \\
2 \cdot 75 \\
3 \cdot 25 \\
3 \cdot 75 \\
4 \cdot 25 \\
4 \cdot 75 \\
5 \cdot 25 \\
5 \cdot 75 \\
6 \cdot 25 \\
6 \cdot 75 \\
7 \cdot 25 \\
7 \cdot 75 \\
8 \cdot 25 \\
8 \cdot 75 \\
9 \cdot 25 \\
9 \cdot 75 \\
10.25 \\
10 \cdot 75 \\
11 \cdot 25 \\
11 \cdot 75 \\
12 \cdot 00 \\
12 \cdot 25 \\
12 \cdot 50 \\
12 \cdot 75 \\
13 \cdot 00 \\
13 \cdot 25 \\
13 \cdot 50 \\
13 \cdot 75\end{array}$ & 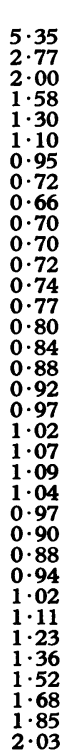 & $\begin{array}{l}6 \cdot 70 \\
3 \cdot 85 \\
2 \cdot 75 \\
2 \cdot 22 \\
1 \cdot 85 \\
1 \cdot 58 \\
1 \cdot 40 \\
1 \cdot 17 \\
1 \cdot 08 \\
1 \cdot 07 \\
1 \cdot 09 \\
1 \cdot 10 \\
1 \cdot 11 \\
1 \cdot 13 \\
1 \cdot 17 \\
1 \cdot 22 \\
1 \cdot 27 \\
1 \cdot 32 \\
1 \cdot 38 \\
1 \cdot 44 \\
1 \cdot 52 \\
1.54 \\
1 \cdot 52 \\
1.50 \\
1.50 \\
1.54 \\
1 \cdot 66 \\
1 \cdot 76 \\
1.88 \\
2.02 \\
2 \cdot 18 \\
2 \cdot 40 \\
2 \cdot 66 \\
2 \cdot 96 \\
3 \cdot 29\end{array}$ & $\begin{array}{l}7 \cdot 85 \\
5 \cdot 10 \\
3 \cdot 56 \\
2 \cdot 78 \\
2 \cdot 30 \\
1 \cdot 98 \\
1 \cdot 75 \\
1 \cdot 57 \\
1 \cdot 48 \\
1 \cdot 48 \\
1 \cdot 47 \\
1 \cdot 47 \\
1 \cdot 48 \\
1 \cdot 50 \\
1 \cdot 54 \\
1 \cdot 61 \\
1 \cdot 68 \\
1 \cdot 75 \\
1 \cdot 82 \\
1 \cdot 91 \\
2 \cdot 00 \\
2 \cdot 06 \\
2 \cdot 11 \\
2 \cdot 15 \\
2 \cdot 23 \\
2 \cdot 35 \\
2 \cdot 53 \\
2 \cdot 64 \\
2 \cdot 79 \\
2 \cdot 96 \\
3 \cdot 16 \\
3 \cdot 47 \\
3 \cdot 83 \\
4 \cdot 24 \\
4 \cdot 69\end{array}$ & $\begin{array}{l}9 \cdot 30 \\
9 \cdot 85 \\
6 \cdot 80 \\
4 \cdot 30 \\
3 \cdot 33 \\
2 \cdot 81 \\
2 \cdot 44 \\
2 \cdot 23 \\
1 \cdot 98 \\
1 \cdot 92 \\
1 \cdot 90 \\
1 \cdot 90 \\
1 \cdot 90 \\
1 \cdot 90 \\
1 \cdot 94 \\
2 \cdot 02 \\
2 \cdot 11 \\
2 \cdot 21 \\
2 \cdot 31 \\
2 \cdot 42 \\
2 \cdot 52 \\
2 \cdot 62 \\
2 \cdot 72 \\
2 \cdot 83 \\
2 \cdot 93 \\
3 \cdot 03 \\
3 \cdot 20 \\
3 \cdot 46 \\
3 \cdot 67 \\
3 \cdot 92 \\
4 \cdot 22 \\
4 \cdot 55 \\
4 \cdot 96 \\
5 \cdot 36 \\
5 \cdot 75 \\
6 \cdot 12\end{array}$ & $\begin{array}{r}11 \cdot 15 \\
8 \cdot 15 \\
5 \cdot 73 \\
4 \cdot 30 \\
3 \cdot 58 \\
3 \cdot 14 \\
2 \cdot 85 \\
2 \cdot 49 \\
2 \cdot 36 \\
2 \cdot 36 \\
2 \cdot 38 \\
2 \cdot 41 \\
2 \cdot 47 \\
2 \cdot 53 \\
2 \cdot 63 \\
2 \cdot 74 \\
2 \cdot 85 \\
2 \cdot 97 \\
3 \cdot 10 \\
3 \cdot 24 \\
3 \cdot 39 \\
3 \cdot 54 \\
3 \cdot 71 \\
3 \cdot 89 \\
4 \cdot 10 \\
4 \cdot 40 \\
4 \cdot 85 \\
5 \cdot 14 \\
5 \cdot 50 \\
5 \cdot 93 \\
6 \cdot 40 \\
6 \cdot 81 \\
7 \cdot 26 \\
7 \cdot 64 \\
7 \cdot 96\end{array}$ & $\begin{array}{r}13 \cdot 30 \\
9 \cdot 85 \\
6 \cdot 80 \\
5 \cdot 13 \\
4 \cdot 20 \\
3 \cdot 66 \\
3 \cdot 30 \\
2 \cdot 90 \\
2 \cdot 83 \\
2 \cdot 88 \\
2 \cdot 93 \\
3 \cdot 02 \\
3 \cdot 13 \\
3 \cdot 26 \\
3 \cdot 40 \\
3 \cdot 54 \\
3 \cdot 68 \\
3 \cdot 82 \\
3 \cdot 96 \\
4 \cdot 10 \\
4 \cdot 25 \\
4 \cdot 43 \\
4 \cdot 65 \\
4 \cdot 94 \\
5 \cdot 30 \\
5 \cdot 78 \\
6 \cdot 47 \\
6 \cdot 87 \\
7 \cdot 33 \\
7 \cdot 79 \\
8 \cdot 21 \\
8 \cdot 67 \\
9 \cdot 09 \\
9 \cdot 43 \\
9 \cdot 71\end{array}$ & $\begin{array}{r}15 \cdot 10 \\
11 \cdot 50 \\
8 \cdot 20 \\
5 \cdot 86 \\
4 \cdot 80 \\
4 \cdot 22 \\
3 \cdot 85 \\
3 \cdot 45 \\
3 \cdot 38 \\
3 \cdot 46 \\
3 \cdot 58 \\
3 \cdot 74 \\
3 \cdot 92 \\
4 \cdot 10 \\
4 \cdot 30 \\
4 \cdot 50 \\
4 \cdot 70 \\
4 \cdot 88 \\
5 \cdot 06 \\
5 \cdot 24 \\
5 \cdot 42 \\
5 \cdot 63 \\
5 \cdot 93 \\
6 \cdot 33 \\
6 \cdot 90 \\
7 \cdot 69 \\
8 \cdot 71 \\
9 \cdot 24 \\
9 \cdot 72 \\
10 \cdot 13 \\
10 \cdot 46 \\
10 \cdot 78 \\
11 \cdot 02 \\
11 \cdot 19 \\
11 \cdot 31\end{array}$ \\
\hline
\end{tabular}


TABLE VIIIA-continued Whole-year Velocity Standards for Weight of Boys (chronological age based)

\begin{tabular}{|c|c|c|c|c|c|c|c|}
\hline \multirow{2}{*}{ Age (yr.) } & \multicolumn{7}{|c|}{ Centiles (kg./yr.) } \\
\hline & 3rd & 10 th & 25 th & 50th & 75th & 90th & 97th \\
\hline $\begin{array}{l}14 \cdot 00 \\
14 \cdot 25 \\
14 \cdot 50 \\
14 \cdot 75 \\
15 \cdot 00 \\
15 \cdot 25 \\
15 \cdot 50 \\
15 \cdot 75 \\
16 \cdot 00 \\
16 \cdot 25 \\
16 \cdot 75 \\
17 \cdot 25 \\
17 \cdot 75 \\
18 \cdot 00\end{array}$ & $\begin{array}{l}2 \cdot 20 \\
2 \cdot 18 \\
2 \cdot 00 \\
1 \cdot 73 \\
1 \cdot 38 \\
0 \cdot 94 \\
0 \cdot 48 \\
0 \cdot 12\end{array}$ & $\begin{array}{l}3.58 \\
3.60 \\
3.46 \\
3.12 \\
2.65 \\
2.10 \\
1.57 \\
1.15 \\
0.75 \\
0.45\end{array}$ & $\begin{array}{l}4 \cdot 90 \\
4 \cdot 90 \\
4 \cdot 76 \\
4.49 \\
4 \cdot 11 \\
3 \cdot 67 \\
3 \cdot 16 \\
2.61 \\
2.09 \\
1.69 \\
1.06 \\
0 \cdot 62 \\
0 \cdot 27 \\
0.12\end{array}$ & $\begin{array}{l}6 \cdot 30 \\
6 \cdot 30 \\
6 \cdot 20 \\
5 \cdot 98 \\
5 \cdot 61 \\
5 \cdot 19 \\
4 \cdot 75 \\
4 \cdot 25 \\
3 \cdot 71 \\
3 \cdot 22 \\
2 \cdot 38 \\
1 \cdot 77 \\
1 \cdot 30 \\
1 \cdot 08\end{array}$ & $\begin{array}{l}8 \cdot 14 \\
8 \cdot 14 \\
8 \cdot 00 \\
7 \cdot 78 \\
7 \cdot 48 \\
7 \cdot 06 \\
6 \cdot 54 \\
5 \cdot 91 \\
5 \cdot 31 \\
4 \cdot 75 \\
3 \cdot 79 \\
3 \cdot 06 \\
2 \cdot 46 \\
2 \cdot 20\end{array}$ & $\begin{array}{l}9 \cdot 85 \\
9 \cdot 85 \\
9 \cdot 74 \\
9 \cdot 57 \\
9 \cdot 30 \\
8 \cdot 90 \\
8 \cdot 39 \\
7 \cdot 72 \\
7 \cdot 03 \\
6 \cdot 30 \\
4 \cdot 96 \\
4 \cdot 03 \\
3 \cdot 33 \\
3 \cdot 05\end{array}$ & $\begin{array}{r}11 \cdot 35 \\
11.31 \\
11.18 \\
11.01 \\
10.78 \\
10.43 \\
9.95 \\
9.40 \\
8.75 \\
8.02 \\
6.29 \\
5.03 \\
4.21 \\
3.85\end{array}$ \\
\hline
\end{tabular}

For source of data and method of construction, see text.

TABLE VIIIB

Whole-year Velocity Standards for Weight of Girls (chronological age based)

\begin{tabular}{|c|c|c|c|c|c|c|c|}
\hline \multirow{2}{*}{ Age (yr.) } & \multicolumn{7}{|c|}{ Centiles (kg./yr.) } \\
\hline & 3 rd & 10th & 25 th & 50 th & 75th & 90th & 97th \\
\hline $\begin{array}{r}0.10 \\
0.25 \\
0.50 \\
0.75 \\
1.00 \\
1.25 \\
1.50 \\
1.75 \\
2.25 \\
2.75 \\
3.25 \\
3.75 \\
4.25 \\
4.75 \\
5.25 \\
5.75 \\
6.25 \\
6.75 \\
7.25 \\
7.75 \\
8.25 \\
8.75 \\
9.25 \\
9.75 \\
10.25 \\
10.50 \\
10.75 \\
11.00 \\
11.25 \\
11.50 \\
11.75 \\
12.00 \\
12.25 \\
12.50 \\
12.75 \\
13.00 \\
13.25 \\
13.50 \\
13.75 \\
14.00 \\
14.25 \\
14.50 \\
14.75 \\
15.25 \\
15.75 \\
16.25 \\
16.50\end{array}$ & $\begin{array}{l}4 \cdot 20 \\
2 \cdot 50 \\
1 \cdot 80 \\
1 \cdot 45 \\
1 \cdot 23 \\
1 \cdot 08 \\
1 \cdot 00 \\
0 \cdot 91 \\
0 \cdot 90 \\
0 \cdot 90 \\
0 \cdot 90 \\
0 \cdot 90 \\
0 \cdot 90 \\
0 \cdot 90 \\
0 \cdot 90 \\
0 \cdot 91 \\
0 \cdot 94 \\
0 \cdot 90 \\
0 \cdot 86 \\
0 \cdot 82 \\
0 \cdot 80 \\
0 \cdot 79 \\
0 \cdot 83 \\
0 \cdot 95 \\
1 \cdot 03 \\
1 \cdot 13 \\
1 \cdot 26 \\
1 \cdot 40 \\
1 \cdot 58 \\
1 \cdot 79 \\
2 \cdot 02 \\
2 \cdot 23 \\
2 \cdot 30 \\
2 \cdot 16 \\
1 \cdot 90 \\
1 \cdot 51 \\
1 \cdot 09 \\
0 \cdot 67 \\
0 \cdot 25\end{array}$ & 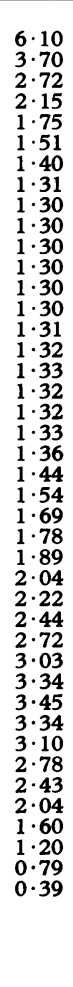 & $\begin{array}{r}7 \cdot 65 \\
5.20 \\
3.53 \\
2.75 \\
2.28 \\
1.96 \\
4.78 \\
1.66 \\
1.64 \\
1.64 \\
1.64 \\
1.64 \\
1.64 \\
1.68 \\
1.70 \\
1.74 \\
1.78 \\
1.82 \\
1.86 \\
1.90 \\
1.96 \\
2.06 \\
2.22 \\
2.40 \\
2.52 \\
2.67 \\
2.87 \\
3.14 \\
3.45 \\
3.81 \\
4.17 \\
4.51 \\
4.70 \\
4.67 \\
4.50 \\
4.27 \\
3.99 \\
3.66 \\
3.23 \\
2.79 \\
2.30 \\
1.81 \\
0.81\end{array}$ & $\begin{array}{l}8 \cdot 00 \\
9 \cdot 25 \\
6 \cdot 60 \\
4 \cdot 29 \\
3 \cdot 32 \\
2 \cdot 81 \\
2 \cdot 44 \\
2 \cdot 20 \\
2 \cdot 03 \\
2 \cdot 00 \\
2 \cdot 00 \\
2 \cdot 00 \\
2 \cdot 00 \\
2 \cdot 03 \\
2 \cdot 08 \\
2 \cdot 14 \\
2 \cdot 21 \\
2 \cdot 28 \\
2 \cdot 33 \\
2 \cdot 40 \\
2 \cdot 50 \\
2 \cdot 61 \\
2 \cdot 76 \\
2 \cdot 98 \\
3 \cdot 30 \\
3 \cdot 50 \\
3 \cdot 73 \\
3 \cdot 99 \\
4 \cdot 27 \\
4 \cdot 58 \\
4 \cdot 95 \\
5 \cdot 38 \\
5 \cdot 80 \\
5 \cdot 99 \\
5 \cdot 97 \\
5 \cdot 81 \\
5 \cdot 56 \\
5 \cdot 27 \\
4 \cdot 95 \\
4 \cdot 56 \\
4 \cdot 11 \\
3 \cdot 62 \\
3 \cdot 11 \\
2 \cdot 00 \\
1 \cdot 10 \\
0 \cdot 38 \\
0 \cdot 08\end{array}$ & $\begin{array}{r}11.20 \\
8.60 \\
6.05 \\
4.48 \\
3.63 \\
3.12 \\
2.79 \\
2.50 \\
2.45 \\
2.48 \\
2.50 \\
2.56 \\
2.63 \\
2.71 \\
2.80 \\
2.89 \\
3.00 \\
3.11 \\
3.26 \\
3.41 \\
3.61 \\
3.88 \\
4.23 \\
4.66 \\
4.92 \\
5.19 \\
5.48 \\
5.81 \\
6.17 \\
6.51 \\
6.88 \\
7.18 \\
7.29 \\
7.27 \\
7.11 \\
6.86 \\
6.56 \\
6.23 \\
5.85 \\
5.44 \\
4.99 \\
4.47 \\
3.36 \\
2.23 \\
1.35 \\
1.04\end{array}$ & 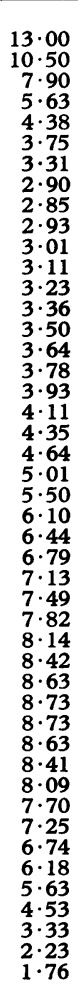 & 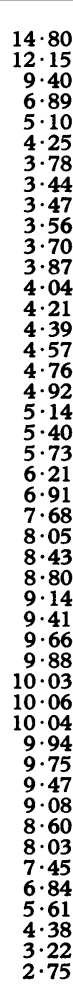 \\
\hline
\end{tabular}

For source of data and method of construction, see text. 
Height, Weight, Height Velocity, Weight Velocity: British Children, 1965

TABLE IXA

Whole-year Velocity Standards for Height of Boys (peak height velocity-centred)

\begin{tabular}{|c|c|c|c|c|c|c|c|c|}
\hline \multirow{2}{*}{ Age (yr.) } & \multicolumn{7}{|c|}{ Centiles (cm./yr.) } & \multirow{2}{*}{$\begin{array}{c}\text { SD } \\
\text { (estimated) }\end{array}$} \\
\hline & $3 \mathrm{rd}$ & 10 th & 25 th & 50 th & 75 th & 90th & 97th & \\
\hline $\begin{array}{r}9 \cdot 25 \\
9 \cdot 75 \\
10 \cdot 25 \\
10 \cdot 75 \\
11 \cdot 25 \\
11 \cdot 75 \\
12 \cdot 25 \\
12 \cdot 75 \\
13 \cdot 25 \\
13 \cdot 50 \\
13 \cdot 75 \\
14 \cdot 00 \\
14 \cdot 25 \\
14 \cdot 50 \\
14 \cdot 75 \\
15 \cdot 25 \\
15 \cdot 75 \\
16 \cdot 25 \\
16 \cdot 75\end{array}$ & $\begin{array}{l}3.91 \\
3.86 \\
3.81 \\
3.76 \\
3.68 \\
3.55 \\
3.45 \\
3.84 \\
5.37 \\
6.51 \\
7 \cdot 12 \\
7 \cdot 20 \\
6.98 \\
5.98 \\
4.85 \\
2.65 \\
1.34 \\
0.50\end{array}$ & $\begin{array}{l}4 \cdot 35 \\
4 \cdot 29 \\
4 \cdot 23 \\
4 \cdot 17 \\
4 \cdot 10 \\
3 \cdot 99 \\
3 \cdot 96 \\
4 \cdot 42 \\
6 \cdot 03 \\
7 \cdot 20 \\
7 \cdot 83 \\
7 \cdot 92 \\
7 \cdot 69 \\
6 \cdot 69 \\
5 \cdot 54 \\
3 \cdot 30 \\
1 \cdot 93 \\
1 \cdot 00\end{array}$ & $\begin{array}{l}4 \cdot 80 \\
4 \cdot 72 \\
4 \cdot 65 \\
4 \cdot 58 \\
4 \cdot 51 \\
4 \cdot 44 \\
4 \cdot 46 \\
5 \cdot 00 \\
6 \cdot 70 \\
7 \cdot 89 \\
8 \cdot 55 \\
8 \cdot 65 \\
8 \cdot 42 \\
7 \cdot 40 \\
6 \cdot 25 \\
3 \cdot 96 \\
2 \cdot 53 \\
1 \cdot 51 \\
0 \cdot 80\end{array}$ & $\begin{array}{l}5 \cdot 30 \\
5 \cdot 20 \\
5 \cdot 12 \\
5 \cdot 04 \\
4 \cdot 98 \\
4 \cdot 94 \\
5 \cdot 02 \\
5 \cdot 65 \\
7 \cdot 45 \\
8 \cdot 67 \\
9 \cdot 35 \\
9 \cdot 46 \\
9 \cdot 22 \\
8 \cdot 20 \\
7 \cdot 03 \\
4 \cdot 70 \\
3 \cdot 20 \\
2 \cdot 08 \\
1 \cdot 22\end{array}$ & $\begin{array}{r}5 \cdot 80 \\
5 \cdot 68 \\
5 \cdot 59 \\
5 \cdot 50 \\
5 \cdot 45 \\
5 \cdot 44 \\
5 \cdot 58 \\
6 \cdot 30 \\
8 \cdot 20 \\
9 \cdot 45 \\
10 \cdot 15 \\
10 \cdot 27 \\
10 \cdot 02 \\
9 \cdot 00 \\
7 \cdot 81 \\
5 \cdot 44 \\
3 \cdot 87 \\
2 \cdot 65 \\
1 \cdot 64\end{array}$ & $\begin{array}{r}6 \cdot 24 \\
6 \cdot 11 \\
6 \cdot 00 \\
5 \cdot 91 \\
5 \cdot 86 \\
5 \cdot 88 \\
6 \cdot 08 \\
6 \cdot 87 \\
8 \cdot 86 \\
10 \cdot 14 \\
10 \cdot 86 \\
10 \cdot 99 \\
10 \cdot 74 \\
9 \cdot 70 \\
8 \cdot 51 \\
6 \cdot 09 \\
4 \cdot 46 \\
3 \cdot 15 \\
2 \cdot 01\end{array}$ & $\begin{array}{r}6 \cdot 69 \\
6 \cdot 54 \\
6 \cdot 43 \\
6 \cdot 32 \\
6 \cdot 28 \\
6 \cdot 33 \\
6 \cdot 58 \\
7 \cdot 46 \\
9 \cdot 53 \\
10 \cdot 83 \\
11 \cdot 58 \\
11 \cdot 72 \\
11 \cdot 46 \\
10 \cdot 42 \\
9 \cdot 21 \\
6 \cdot 75 \\
5 \cdot 06 \\
3 \cdot 66 \\
2 \cdot 39\end{array}$ & $\begin{array}{l}0 \cdot 74 \\
0 \cdot 71 \\
0.69 \\
0.68 \\
0.69 \\
0 \cdot 74 \\
0.83 \\
0.96 \\
1 \cdot 11 \\
1 \cdot 15 \\
1 \cdot 19 \\
1 \cdot 20 \\
1 \cdot 19 \\
1 \cdot 18 \\
1 \cdot 16 \\
1 \cdot 09 \\
0.99 \\
0 \cdot 84 \\
0.62\end{array}$ \\
\hline
\end{tabular}

For source of data and method of construction, see text.

TABLE IXB

Whole-year Velocity Standards for Height of Girls (peak height velocity-centred)

\begin{tabular}{|c|c|c|c|c|c|c|c|c|}
\hline \multirow{2}{*}{ Age (yr.) } & \multicolumn{7}{|c|}{ Centiles (cm./yr.) } & \multirow{2}{*}{$\underset{\text { (estimated) }}{\text { SD }}$} \\
\hline & $3 r d$ & 10th & 25 th & 50th & 75th & 90th & 97th & \\
\hline $\begin{array}{r}7 \cdot 25 \\
7 \cdot 75 \\
8 \cdot 25 \\
8 \cdot 75 \\
9 \cdot 25 \\
9 \cdot 75 \\
10 \cdot 25 \\
10 \cdot 50 \\
10 \cdot 75 \\
11 \cdot 00 \\
11 \cdot 25 \\
11 \cdot 50 \\
11 \cdot 75 \\
12 \cdot 00 \\
12 \cdot 25 \\
12 \cdot 50 \\
12 \cdot 75 \\
13 \cdot 00 \\
13 \cdot 25 \\
13 \cdot 75 \\
14 \cdot 25 \\
14 \cdot 75\end{array}$ & $\begin{array}{l}4 \cdot 14 \\
4 \cdot 06 \\
4 \cdot 01 \\
4 \cdot 02 \\
3 \cdot 99 \\
3 \cdot 94 \\
3 \cdot 86 \\
3 \cdot 91 \\
4 \cdot 10 \\
4 \cdot 60 \\
5 \cdot 23 \\
5 \cdot 87 \\
6 \cdot 21 \\
6 \cdot 26 \\
6 \cdot 10 \\
5 \cdot 51 \\
4 \cdot 56 \\
3 \cdot 52 \\
2 \cdot 58 \\
1 \cdot 15\end{array}$ & $\begin{array}{l}4 \cdot 65 \\
4 \cdot 55 \\
4 \cdot 49 \\
4 \cdot 49 \\
4 \cdot 46 \\
4 \cdot 41 \\
4 \cdot 38 \\
4 \cdot 46 \\
4 \cdot 68 \\
5 \cdot 21 \\
5 \cdot 86 \\
6 \cdot 52 \\
6 \cdot 86 \\
6 \cdot 92 \\
6 \cdot 76 \\
6 \cdot 16 \\
5 \cdot 20 \\
4 \cdot 15 \\
3 \cdot 19 \\
1 \cdot 69 \\
0 \cdot 87\end{array}$ & $\begin{array}{l}5 \cdot 16 \\
5 \cdot 05 \\
4 \cdot 97 \\
4 \cdot 96 \\
4 \cdot 93 \\
4 \cdot 90 \\
4 \cdot 91 \\
5 \cdot 02 \\
5 \cdot 27 \\
5 \cdot 81 \\
6 \cdot 50 \\
7 \cdot 17 \\
7 \cdot 53 \\
7 \cdot 59 \\
7 \cdot 43 \\
6 \cdot 82 \\
5 \cdot 85 \\
4 \cdot 79 \\
3 \cdot 80 \\
2 \cdot 25 \\
1 \cdot 34 \\
0 \cdot 70\end{array}$ & $\begin{array}{l}5 \cdot 74 \\
5 \cdot 60 \\
5 \cdot 50 \\
5 \cdot 49 \\
5 \cdot 46 \\
5 \cdot 44 \\
5 \cdot 50 \\
5 \cdot 64 \\
5 \cdot 92 \\
6 \cdot 50 \\
7 \cdot 21 \\
7 \cdot 90 \\
8 \cdot 27 \\
8 \cdot 33 \\
8 \cdot 17 \\
7 \cdot 56 \\
6 \cdot 57 \\
5 \cdot 50 \\
4 \cdot 48 \\
2 \cdot 86 \\
1 \cdot 86 \\
1 \cdot 08\end{array}$ & $\begin{array}{l}6 \cdot 32 \\
6 \cdot 15 \\
6 \cdot 03 \\
6 \cdot 02 \\
5 \cdot 99 \\
5 \cdot 98 \\
6 \cdot 09 \\
6 \cdot 26 \\
6 \cdot 57 \\
7 \cdot 18 \\
7 \cdot 92 \\
8 \cdot 63 \\
9 \cdot 01 \\
9 \cdot 07 \\
8 \cdot 91 \\
8 \cdot 30 \\
7 \cdot 29 \\
6 \cdot 21 \\
5 \cdot 16 \\
3 \cdot 47 \\
2 \cdot 38 \\
1 \cdot 46\end{array}$ & $\begin{array}{l}6 \cdot 83 \\
6 \cdot 65 \\
6 \cdot 51 \\
6 \cdot 48 \\
6 \cdot 45 \\
6 \cdot 46 \\
6 \cdot 61 \\
6 \cdot 81 \\
7 \cdot 16 \\
7 \cdot 79 \\
8 \cdot 55 \\
9 \cdot 28 \\
9 \cdot 67 \\
9 \cdot 73 \\
9 \cdot 57 \\
8 \cdot 95 \\
7 \cdot 93 \\
6 \cdot 84 \\
5 \cdot 77 \\
4 \cdot 02 \\
2 \cdot 84 \\
1 \cdot 81\end{array}$ & $\begin{array}{r}7 \cdot 34 \\
7 \cdot 14 \\
6 \cdot 99 \\
6 \cdot 96 \\
6 \cdot 93 \\
6 \cdot 94 \\
7 \cdot 14 \\
7 \cdot 37 \\
7 \cdot 74 \\
8 \cdot 40 \\
9 \cdot 19 \\
9 \cdot 93 \\
10 \cdot 33 \\
10 \cdot 40 \\
10 \cdot 24 \\
9 \cdot 61 \\
8 \cdot 58 \\
7 \cdot 48 \\
6 \cdot 40 \\
4 \cdot 57 \\
3 \cdot 31 \\
2 \cdot 15\end{array}$ & $\begin{array}{l}0.85 \\
0.82 \\
0.79 \\
0 \cdot 78 \\
0.78 \\
0.80 \\
0.87 \\
0.92 \\
0.97 \\
1.01 \\
1 \cdot 05 \\
1.08 \\
1 \cdot 10 \\
1.10 \\
1.10 \\
1.09 \\
1.07 \\
1.05 \\
1.01 \\
0.91 \\
0.77 \\
0.57\end{array}$ \\
\hline
\end{tabular}

For source of data and method of construction, see text.

TABLE XA

Whole-year Velocity Standard for Weight of Boys (peak weight velocity-centred)

\begin{tabular}{|c|c|c|c|c|c|c|c|}
\hline \multirow{2}{*}{ Age (yr.) } & \multicolumn{7}{|c|}{ Centiles (kg./yr.) } \\
\hline & $3 r d$ & 10th & 25 th & 50th & 75 th & 90th & 97th \\
\hline $\begin{array}{r}9 \cdot 25 \\
9 \cdot 75 \\
10 \cdot 25 \\
10 \cdot 75 \\
11 \cdot 25 \\
11 \cdot 75 \\
12 \cdot 25 \\
12 \cdot 50 \\
12 \cdot 75 \\
13 \cdot 00 \\
13 \cdot 25\end{array}$ & $\begin{array}{l}1 \cdot 12 \\
1 \cdot 18 \\
1 \cdot 24 \\
1 \cdot 31 \\
1 \cdot 43 \\
1 \cdot 62 \\
1 \cdot 98 \\
2 \cdot 18 \\
2 \cdot 45 \\
2 \cdot 90 \\
3 \cdot 45\end{array}$ & $\begin{array}{l}1 \cdot 60 \\
1 \cdot 68 \\
1 \cdot 76 \\
1 \cdot 84 \\
1 \cdot 97 \\
2 \cdot 14 \\
2 \cdot 46 \\
2 \cdot 75 \\
3 \cdot 10 \\
3 \cdot 70 \\
4 \cdot 60\end{array}$ & $\begin{array}{l}2 \cdot 09 \\
2 \cdot 18 \\
2 \cdot 28 \\
2 \cdot 38 \\
2 \cdot 51 \\
2 \cdot 70 \\
3 \cdot 00 \\
3 \cdot 26 \\
3 \cdot 70 \\
4 \cdot 40 \\
5 \cdot 50\end{array}$ & $\begin{array}{l}2 \cdot 72 \\
2 \cdot 82 \\
2 \cdot 92 \\
3 \cdot 02 \\
3 \cdot 14 \\
3 \cdot 30 \\
3 \cdot 70 \\
4 \cdot 09 \\
4 \cdot 75 \\
5 \cdot 50 \\
6 \cdot 55\end{array}$ & $\begin{array}{l}3 \cdot 54 \\
3 \cdot 68 \\
3 \cdot 78 \\
3 \cdot 93 \\
4 \cdot 10 \\
4 \cdot 35 \\
4 \cdot 75 \\
5 \cdot 05 \\
5 \cdot 60 \\
6 \cdot 45 \\
7 \cdot 57\end{array}$ & $\begin{array}{l}4 \cdot 40 \\
4 \cdot 54 \\
4 \cdot 69 \\
4 \cdot 84 \\
5 \cdot 00 \\
5 \cdot 28 \\
5 \cdot 80 \\
6 \cdot 22 \\
6 \cdot 85 \\
7 \cdot 75 \\
8 \cdot 85\end{array}$ & $\begin{array}{l}5 \cdot 60 \\
5 \cdot 80 \\
6 \cdot 00 \\
6 \cdot 20 \\
6 \cdot 40 \\
6 \cdot 66 \\
7 \cdot 07 \\
7 \cdot 50 \\
8 \cdot 10 \\
8 \cdot 90 \\
9 \cdot 90\end{array}$ \\
\hline
\end{tabular}


TABLE XA-continued

Whole-year Velocity Standard for Weight of Boys (peak weight velocity-centred)

\begin{tabular}{|c|c|c|c|c|c|c|c|}
\hline \multirow{2}{*}{ Age (yr.) } & \multicolumn{7}{|c|}{ Centiles (kg./yr.) } \\
\hline & $3 r d$ & 10th & 25 th & 50th & 75th & 90th & 97th \\
\hline $\begin{array}{l}13 \cdot 50 \\
13 \cdot 75 \\
13 \cdot 90 \\
14 \cdot 00 \\
14 \cdot 10 \\
14 \cdot 25 \\
14 \cdot 50 \\
14 \cdot 75 \\
15 \cdot 00 \\
15 \cdot 25 \\
15 \cdot 50 \\
15 \cdot 75 \\
16 \cdot 00 \\
16 \cdot 25 \\
16 \cdot 50 \\
16 \cdot 75\end{array}$ & $\begin{array}{l}4 \cdot 28 \\
5 \cdot 50 \\
6 \cdot 17 \\
6 \cdot 20 \\
6 \cdot 17 \\
5 \cdot 83 \\
4 \cdot 95 \\
4 \cdot 07 \\
3 \cdot 22 \\
2 \cdot 40 \\
1 \cdot 66 \\
0 \cdot 96\end{array}$ & $\begin{array}{l}5 \cdot 71 \\
6 \cdot 95 \\
7 \cdot 17 \\
7 \cdot 20 \\
7 \cdot 17 \\
6 \cdot 95 \\
6 \cdot 13 \\
4 \cdot 97 \\
4 \cdot 00 \\
3 \cdot 17 \\
2 \cdot 50 \\
1 \cdot 84 \\
1 \cdot 27 \\
0 \cdot 82\end{array}$ & $\begin{array}{l}6 \cdot 88 \\
7 \cdot 85 \\
8 \cdot 05 \\
8 \cdot 08 \\
8 \cdot 05 \\
7 \cdot 85 \\
7 \cdot 12 \\
5 \cdot 90 \\
4 \cdot 80 \\
3 \cdot 97 \\
3 \cdot 18 \\
2 \cdot 50 \\
1 \cdot 98 \\
1 \cdot 45 \\
1 \cdot 05 \\
0 \cdot 75\end{array}$ & $\begin{array}{l}8 \cdot 00 \\
8 \cdot 80 \\
9 \cdot 02 \\
9 \cdot 06 \\
9 \cdot 02 \\
8 \cdot 75 \\
8 \cdot 06 \\
6 \cdot 82 \\
5 \cdot 68 \\
4 \cdot 72 \\
3 \cdot 89 \\
3 \cdot 15 \\
2 \cdot 60 \\
2 \cdot 15 \\
1 \cdot 70 \\
1 \cdot 35\end{array}$ & $\begin{array}{r}8 \cdot 95 \\
10 \cdot 05 \\
10.37 \\
10 \cdot 40 \\
10.37 \\
10 \cdot 18 \\
9 \cdot 25 \\
7.97 \\
6 \cdot 74 \\
5 \cdot 63 \\
4.63 \\
3 \cdot 88 \\
3.24 \\
2.75 \\
2.30 \\
1.90\end{array}$ & $\begin{array}{r}10 \cdot 18 \\
11 \cdot 15 \\
11 \cdot 48 \\
11 \cdot 50 \\
11 \cdot 48 \\
11 \cdot 30 \\
10 \cdot 22 \\
9 \cdot 00 \\
7 \cdot 82 \\
6 \cdot 73 \\
5 \cdot 55 \\
4 \cdot 60 \\
3 \cdot 78 \\
3 \cdot 11 \\
2 \cdot 65 \\
2 \cdot 25\end{array}$ & $\begin{array}{r}11 \cdot 35 \\
12 \cdot 55 \\
12 \cdot 72 \\
12 \cdot 74 \\
12 \cdot 72 \\
12 \cdot 58 \\
11 \cdot 90 \\
10 \cdot 68 \\
9 \cdot 25 \\
7 \cdot 87 \\
6 \cdot 52 \\
5 \cdot 45 \\
4 \cdot 50 \\
3 \cdot 70 \\
3 \cdot 12 \\
2 \cdot 65\end{array}$ \\
\hline
\end{tabular}

For source of data and method of construction, see text.

TABLE XB

Whole-year Velocity Standard for Weight of Girls (peak weight velocity-centred)

\begin{tabular}{|c|c|c|c|c|c|c|c|}
\hline \multirow{2}{*}{ Age (yr.) } & \multicolumn{7}{|c|}{ Centiles (kg./yr.) } \\
\hline & $3 \mathrm{rd}$ & 10th & 25 th & 50th & 75th & 90th & 97th \\
\hline $\begin{array}{r}7 \cdot 25 \\
7 \cdot 75 \\
8 \cdot 25 \\
8 \cdot 75 \\
9 \cdot 25 \\
9 \cdot 75 \\
10 \cdot 25 \\
10 \cdot 50 \\
10 \cdot 75 \\
11 \cdot 00 \\
11 \cdot 25 \\
11 \cdot 50 \\
11 \cdot 75 \\
12 \cdot 00 \\
12 \cdot 25 \\
12 \cdot 40 \\
12 \cdot 50 \\
12 \cdot 60 \\
12 \cdot 75 \\
13 \cdot 00 \\
13 \cdot 25 \\
13 \cdot 50 \\
13 \cdot 75 \\
14 \cdot 00 \\
14 \cdot 25 \\
14 \cdot 50 \\
14 \cdot 75 \\
15 \cdot 00 \\
15 \cdot 25 \\
15 \cdot 50\end{array}$ & $\begin{array}{l}0 \cdot 98 \\
1 \cdot 02 \\
1 \cdot 08 \\
1 \cdot 15 \\
1 \cdot 25 \\
1 \cdot 40 \\
1 \cdot 67 \\
1 \cdot 83 \\
2 \cdot 07 \\
2 \cdot 32 \\
2 \cdot 63 \\
2 \cdot 98 \\
3 \cdot 50 \\
4 \cdot 25 \\
5 \cdot 10 \\
5 \cdot 48 \\
5 \cdot 55 \\
5 \cdot 52 \\
5 \cdot 35 \\
4 \cdot 25 \\
2.80 \\
1 \cdot 80 \\
1 \cdot 15 \\
0.65\end{array}$ & $\begin{array}{l}1 \cdot 35 \\
1 \cdot 39 \\
1 \cdot 45 \\
1 \cdot 55 \\
1 \cdot 70 \\
1 \cdot 87 \\
2 \cdot 15 \\
2 \cdot 32 \\
2 \cdot 55 \\
2 \cdot 80 \\
3 \cdot 15 \\
3 \cdot 65 \\
4 \cdot 30 \\
5 \cdot 20 \\
5 \cdot 95 \\
6 \cdot 26 \\
6 \cdot 30 \\
6 \cdot 28 \\
6 \cdot 06 \\
5 \cdot 13 \\
4 \cdot 05 \\
3 \cdot 00 \\
2 \cdot 23 \\
1 \cdot 57 \\
1 \cdot 07 \\
0 \cdot 70\end{array}$ & $\begin{array}{l}1 \cdot 84 \\
1 \cdot 91 \\
2 \cdot 00 \\
2 \cdot 10 \\
2 \cdot 22 \\
2 \cdot 38 \\
2 \cdot 62 \\
2 \cdot 80 \\
3 \cdot 05 \\
3 \cdot 37 \\
3 \cdot 82 \\
4 \cdot 50 \\
5 \cdot 38 \\
6 \cdot 39 \\
7 \cdot 05 \\
7 \cdot 22 \\
7 \cdot 27 \\
7 \cdot 23 \\
7 \cdot 08 \\
6 \cdot 28 \\
5 \cdot 28 \\
4 \cdot 20 \\
3 \cdot 40 \\
2 \cdot 60 \\
1 \cdot 95 \\
1 \cdot 43 \\
1 \cdot 05 \\
0 \cdot 70\end{array}$ & $\begin{array}{l}2 \cdot 38 \\
2 \cdot 48 \\
2 \cdot 60 \\
2 \cdot 73 \\
2 \cdot 88 \\
3 \cdot 05 \\
3 \cdot 26 \\
3 \cdot 40 \\
3 \cdot 68 \\
4 \cdot 05 \\
4 \cdot 70 \\
5 \cdot 44 \\
6 \cdot 32 \\
7 \cdot 43 \\
8 \cdot 08 \\
8 \cdot 25 \\
8 \cdot 30 \\
8 \cdot 25 \\
8 \cdot 08 \\
7 \cdot 25 \\
6 \cdot 19 \\
5 \cdot 20 \\
4 \cdot 36 \\
3 \cdot 55 \\
2 \cdot 82 \\
2 \cdot 27 \\
1 \cdot 83 \\
1 \cdot 48 \\
1 \cdot 17 \\
0 \cdot 92\end{array}$ & $\begin{array}{l}3 \cdot 12 \\
3 \cdot 25 \\
3 \cdot 41 \\
3 \cdot 58 \\
3 \cdot 76 \\
3 \cdot 95 \\
4 \cdot 20 \\
4 \cdot 40 \\
4 \cdot 63 \\
5 \cdot 05 \\
5 \cdot 73 \\
6 \cdot 54 \\
7 \cdot 50 \\
8 \cdot 50 \\
9 \cdot 15 \\
9 \cdot 31 \\
9 \cdot 36 \\
9 \cdot 32 \\
9 \cdot 08 \\
8 \cdot 20 \\
7 \cdot 00 \\
6 \cdot 00 \\
5 \cdot 10 \\
4 \cdot 44 \\
3 \cdot 85 \\
3 \cdot 38 \\
2 \cdot 94 \\
2 \cdot 55 \\
2 \cdot 22 \\
1 \cdot 92\end{array}$ & $\begin{array}{l}3 \cdot 93 \\
4 \cdot 09 \\
4 \cdot 27 \\
4 \cdot 44 \\
4 \cdot 62 \\
4 \cdot 81 \\
5 \cdot 07 \\
5 \cdot 28 \\
5 \cdot 60 \\
6 \cdot 00 \\
6 \cdot 70 \\
7 \cdot 50 \\
8 \cdot 45 \\
9 \cdot 30 \\
9 \cdot 80 \\
9 \cdot 90 \\
9 \cdot 93 \\
9 \cdot 91 \\
9 \cdot 77 \\
9 \cdot 10 \\
8 \cdot 00 \\
6 \cdot 83 \\
5 \cdot 85 \\
5 \cdot 20 \\
4 \cdot 55 \\
4 \cdot 08 \\
3 \cdot 67 \\
3 \cdot 30 \\
2 \cdot 99 \\
2 \cdot 70\end{array}$ & $\begin{array}{r}4 \cdot 94 \\
5 \cdot 13 \\
5 \cdot 32 \\
5 \cdot 52 \\
5 \cdot 73 \\
5 \cdot 98 \\
6 \cdot 30 \\
6 \cdot 48 \\
6 \cdot 78 \\
7 \cdot 18 \\
7 \cdot 75 \\
8 \cdot 54 \\
9 \cdot 35 \\
10 \cdot 05 \\
10 \cdot 48 \\
10 \cdot 57 \\
10 \cdot 60 \\
10 \cdot 57 \\
10 \cdot 46 \\
9 \cdot 80 \\
8 \cdot 75 \\
7 \cdot 83 \\
6 \cdot 77 \\
6 \cdot 10 \\
5 \cdot 50 \\
5 \cdot 00 \\
4 \cdot 55 \\
4 \cdot 15 \\
3 \cdot 82 \\
3 \cdot 48\end{array}$ \\
\hline
\end{tabular}

For source of data and method of construction, see text.

\section{Appendix II}

\section{Use of Table of Decimals of Year}

(1) Record the date of examination as a five-figure number, the first two figures being the year (i.e. '66) and the next three the decimal of the year corresponding to the date (i.e. Jan. 1 is 000 , Feb. 1 is 085 etc.). These three figures are obtained from the Table. Thus an examination carried out on Jan. 7, 1952, is recorded as 52.016.

(2) Immediately underneath write the date of birth of the subject, using the same system. Thus a boy born on June 23,1939 , has the birth date 39.474 .

(3) Subtract date (2) from date (1) in a normal arithmetic manner. The answer is the age at examination in years in the decimal system, i.e. in the example given, 12.542 .

(4) Round off this figure to two decimal points for recording, i.e. $12 \cdot 54$. 
Height, Weight, Height Velocity, Weight Velocity: British Children, 1965

Table of Decimals of Year

\begin{tabular}{|c|c|c|c|c|c|c|c|c|c|c|c|c|}
\hline & $\underset{\text { Jan. }}{1}$ & $\stackrel{2}{\text { Feb. }}$ & $\stackrel{3}{\operatorname{Mar} .}$ & $\stackrel{4}{\text { Apr. }}$ & $\stackrel{5}{\text { May }}$ & $\begin{array}{c}6 \\
\text { June }\end{array}$ & $\begin{array}{c}7 \\
\text { July }\end{array}$ & $\begin{array}{c}8 \\
\text { Aug. }\end{array}$ & $\begin{array}{c}9 \\
\text { Sept. }\end{array}$ & $\begin{array}{c}10 \\
\text { Oct. }\end{array}$ & $\begin{array}{l}11 \\
\text { Nov. }\end{array}$ & $\begin{array}{c}12 \\
\text { Dec. }\end{array}$ \\
\hline $\begin{array}{r}1 \\
2 \\
3 \\
4 \\
5 \\
6 \\
7 \\
8 \\
9 \\
10\end{array}$ & $\begin{array}{l}000 \\
003 \\
005 \\
008 \\
011 \\
014 \\
016 \\
019 \\
022 \\
025\end{array}$ & $\begin{array}{l}085 \\
088 \\
090 \\
093 \\
096 \\
099 \\
101 \\
104 \\
107 \\
110\end{array}$ & $\begin{array}{l}162 \\
164 \\
167 \\
170 \\
173 \\
175 \\
178 \\
181 \\
184 \\
186\end{array}$ & $\begin{array}{l}247 \\
249 \\
252 \\
255 \\
258 \\
260 \\
263 \\
266 \\
268 \\
271\end{array}$ & $\begin{array}{l}329 \\
332 \\
334 \\
337 \\
340 \\
342 \\
345 \\
348 \\
351 \\
353\end{array}$ & $\begin{array}{l}414 \\
416 \\
419 \\
422 \\
425 \\
427 \\
430 \\
433 \\
436 \\
438\end{array}$ & $\begin{array}{l}496 \\
499 \\
501 \\
504 \\
507 \\
510 \\
512 \\
515 \\
518 \\
521\end{array}$ & $\begin{array}{l}581 \\
584 \\
586 \\
589 \\
592 \\
595 \\
597 \\
600 \\
603 \\
605\end{array}$ & $\begin{array}{l}666 \\
668 \\
671 \\
674 \\
677 \\
679 \\
682 \\
685 \\
688 \\
690\end{array}$ & $\begin{array}{l}748 \\
751 \\
753 \\
756 \\
759 \\
762 \\
764 \\
767 \\
770 \\
773\end{array}$ & $\begin{array}{l}833 \\
836 \\
838 \\
841 \\
844 \\
847 \\
849 \\
852 \\
855 \\
858\end{array}$ & $\begin{array}{l}915 \\
918 \\
921 \\
923 \\
926 \\
929 \\
932 \\
934 \\
937 \\
940\end{array}$ \\
\hline $\begin{array}{l}11 \\
12 \\
13 \\
14 \\
15 \\
16 \\
17 \\
18 \\
19 \\
20\end{array}$ & $\begin{array}{l}027 \\
030 \\
033 \\
036 \\
038 \\
041 \\
044 \\
047 \\
049 \\
052\end{array}$ & $\begin{array}{l}112 \\
115 \\
118 \\
121 \\
123 \\
126 \\
129 \\
132 \\
134 \\
137\end{array}$ & $\begin{array}{l}189 \\
192 \\
195 \\
197 \\
200 \\
203 \\
205 \\
208 \\
211 \\
214\end{array}$ & $\begin{array}{l}274 \\
277 \\
279 \\
282 \\
285 \\
288 \\
290 \\
293 \\
296 \\
299\end{array}$ & $\begin{array}{l}356 \\
359 \\
362 \\
364 \\
367 \\
370 \\
373 \\
375 \\
378 \\
381\end{array}$ & $\begin{array}{l}441 \\
444 \\
447 \\
449 \\
452 \\
455 \\
458 \\
460 \\
463 \\
466\end{array}$ & $\begin{array}{l}\mathbf{5 2 3} \\
526 \\
529 \\
532 \\
534 \\
537 \\
540 \\
542 \\
545 \\
548\end{array}$ & $\begin{array}{l}608 \\
611 \\
614 \\
616 \\
619 \\
622 \\
625 \\
627 \\
630 \\
633\end{array}$ & $\begin{array}{l}693 \\
696 \\
699 \\
701 \\
704 \\
707 \\
710 \\
712 \\
715 \\
718\end{array}$ & $\begin{array}{l}775 \\
778 \\
781 \\
784 \\
786 \\
789 \\
792 \\
795 \\
797 \\
800\end{array}$ & $\begin{array}{l}860 \\
863 \\
866 \\
868 \\
871 \\
874 \\
877 \\
879 \\
882 \\
885\end{array}$ & $\begin{array}{l}942 \\
945 \\
948 \\
951 \\
953 \\
956 \\
959 \\
962 \\
964 \\
967\end{array}$ \\
\hline $\begin{array}{l}21 \\
22 \\
23 \\
24 \\
25 \\
26 \\
27 \\
28 \\
29 \\
30 \\
31\end{array}$ & $\begin{array}{l}055 \\
058 \\
060 \\
063 \\
066 \\
068 \\
071 \\
074 \\
077 \\
079 \\
082\end{array}$ & $\begin{array}{l}140 \\
142 \\
145 \\
148 \\
151 \\
153 \\
156 \\
159\end{array}$ & $\begin{array}{l}216 \\
219 \\
222 \\
225 \\
227 \\
230 \\
233 \\
236 \\
238 \\
241 \\
244\end{array}$ & $\begin{array}{l}301 \\
304 \\
307 \\
310 \\
312 \\
315 \\
318 \\
321 \\
323 \\
326\end{array}$ & $\begin{array}{l}384 \\
386 \\
389 \\
392 \\
395 \\
397 \\
400 \\
403 \\
405 \\
408 \\
411\end{array}$ & $\begin{array}{l}468 \\
471 \\
474 \\
477 \\
479 \\
482 \\
485 \\
488 \\
490 \\
493\end{array}$ & $\begin{array}{l}\mathbf{5 5 1} \\
\mathbf{5 5 3} \\
\mathbf{5 5 6} \\
\mathbf{5 5 9} \\
\mathbf{5 6 2} \\
\mathbf{5 6 4} \\
\mathbf{5 6 7} \\
\mathbf{5 7 0} \\
\mathbf{5 7 3} \\
\mathbf{5 7 5} \\
\mathbf{5 7 8}\end{array}$ & $\begin{array}{l}636 \\
638 \\
641 \\
644 \\
647 \\
649 \\
652 \\
655 \\
658 \\
660 \\
663\end{array}$ & $\begin{array}{l}721 \\
723 \\
726 \\
729 \\
731 \\
734 \\
737 \\
740 \\
742 \\
745\end{array}$ & $\begin{array}{l}803 \\
805 \\
808 \\
811 \\
814 \\
816 \\
819 \\
822 \\
825 \\
827 \\
830\end{array}$ & $\begin{array}{l}888 \\
890 \\
893 \\
896 \\
899 \\
901 \\
904 \\
907 \\
910 \\
912\end{array}$ & $\begin{array}{l}970 \\
973 \\
975 \\
978 \\
981 \\
984 \\
986 \\
989 \\
992 \\
995 \\
997\end{array}$ \\
\hline • & $\underset{1}{\operatorname{Jan} .}$ & $\underset{2}{\text { Feb. }}$ & $\underset{3}{\text { Mar. }}$ & Apr. & $\underset{5}{\operatorname{May}}$ & $\underset{6}{\text { June }}$ & $\underset{7}{\text { July }}$ & Aug. & Sept. & Oct. & $\begin{array}{c}\text { Nov. } \\
11\end{array}$ & $\begin{array}{c}\text { Dec. } \\
12\end{array}$ \\
\hline
\end{tabular}

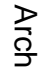

吕

을

$\overrightarrow{\vec{ज}}$

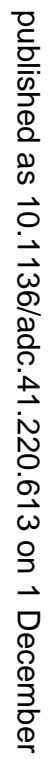

융

을

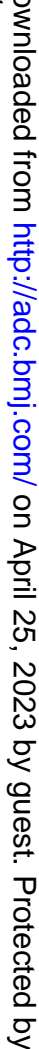

